Jorge Santos Lyra

\title{
ESTUDO DA INFLUÊNCIA DE POLICARBOXILATO COMERCIAL NA HIDRATAÇÃO, REOLOGIA E FÍSICO- QUIIMICA DE SUPERFÍCIE DO CIMENTO
}

Dissertação Apresentada à Escola Politécnica da Universidade de São Paulo para a obtenção do Título de Mestre

SÃO PAULO

2010 


\section{Jorge Santos Lyra}

\section{ESTUDO DA INFLUÊNCIA DE POLICARBOXILATO COMERCIAL NA HIDRATAÇÃO, REOLOGIA E FÍSICO- QUIIMICA DE SUPERFÍCIE DO CIMENTO}

Dissertação Apresentada à Escola Politécnica da Universidade de São Paulo para a obtenção do Título de Mestre

Programa de Pós-Graduação do Departamento de Engenharia Metalúrgica e de Materiais da Escola Politécnica da USP

Orientador: Prof. Dr. Douglas Gouvêa 
Este exemplar foi revisado e alterado em relação à versão original, sob responsabilidade única do autor e com a anuência de seu orientador.

São Paulo, de abril de 2010.

Assinatura do autor

Assinatura do orientador

FICHA CATALOGRÁFICA

Lyra, Jorge Santos

Estudo da influência de policarboxilato comercial na hidratacão, reologia e físico-química de superfície do cimento / J.S. Lyra. -- ed.rev. -- São Paulo, 2010.

$99 \mathrm{p}$.

Dissertação (Mestrado) - Escola Politécnica da Universidade de São Paulo. Departamento de Engenharia Metalúrgica e de Materiais.

1. Cimento 2. Reologia 3. Viscosidade 4. Hidratação l. Universidade de São Paulo. Escola Politécnica. Departamento de Engenharia Metalúrgica e de Materiais II. t. 
Dedico mais esta vitória à minha amada e estimada família, que sempre esteve ao meu lado, torcendo para que eu pudesse atingir os meus objetivos 


\section{Agradecimentos}

É importante enfatizar que ao término deste trabalho meus primeiros agradecimentos são ao Criador, que foi a minha força nas horas de desânimo e nos momentos difíceis a minha luz. A quem serei eternamente grato por vencer mais essa etapa tão importante da minha vida.

À minha maravilhosa família, que me acompanhou em todos os passos dados na trajetória da conquista.

Agradeço a todas as pessoas que contribuíram para esta vitória. Em especial agradeço ao meu orientador Douglas Gouvêa, pela confiança depositada em mim, pela sua dedicação e desempenho, pelos seus conselhos que contribuíram para a minha formação.

Aos amigos e colegas do Departamento de Engenharia Metalúrgica e de Materiais da EPUSP, que contribuíram direta ou indiretamente para a realização deste trabalho. Em especial, Fausto, Silvio, Gilberto, Ricardinho, Marcos, Antonio, Douglas, Márcio, Laércio, Carola, Flávia, Edilene, Marta e Roberta. Agradeço de coração por tudo quanto tem feito por mim e principalmente pela amizade.

Aos amigos, professores e funcionários do Departamento de Engenharia e Construção Civil (PCC) da EPUSP. Em especial, ao Prof. Dr. Rafael Pileggi, a Profá . Dr. aㅗ Maria Alba e ao químico César Romano pela realização dos ensaios de reologia e orientações, ao Brunoro, Daniel, Rui, Cleber, Fábio, Mário, Valeska, Andrea, Eliane, pela amizade e contribuição direta ou indireta para a realização deste trabalho.

Não poderia deixar de agradecer também a Prof ${ }^{a}$. Dr. ․ Sonia Hatsue Tatumi, que foi a raiz de meus estímulos à pesquisa.

A CAPES - Coordenação de Aperfeiçoamento de Pessoal de Nível Superior, pelo apoio financeiro dado ao desenvolvimento da presente pesquisa.

À Escola Politécnica da Universidade de São Paulo pela oportunidade e infraestrutura. 


\section{Resumo}

Os policarboxilatos são macromoléculas utilizadas como dispersantes de alta eficiência em composições cimentícias reduzindo a viscosidade das suspensões e minimizando a quantidade de água utilizada para o processamento. Estes aditivos são muito eficientes por promover estabilização eletroestérica devido a grupos funcionais que geram cargas e se adsorvem na superfície das partículas e suas cadeias poliméricas laterais apolares (side chains). Por isto, esses aditivos têm sido amplamente empregados em composições de concretos. No entanto, além de alterar as características reológicas dos materiais cimentícios, a utilização de policarboxilatos afeta também o potencial de superfície, as reações de hidratação dos cimentos, e as propriedades viscoelásticas dos materiais. Desta forma, neste trabalho foram avaliados os efeitos da variação do teor de policarboxilato éter Glenium 51 - em suspensões de cimento Portland (CPIIE) a partir de ensaios de reometria rotacional e oscilatória, calorimetria de condução isotérmica e medidas de potencial zeta por ESA. Os resultados demonstram que para teores de 0.05 a $1.50 \%$ de aditivo ocorre a diminuição da viscosidade e da tensão de escoamento e aumento do tempo de pega dos cimentos. Estes comportamentos foram atribuídos à adsorção do aditivo na superfície das partículas de cimento em que o desempenho varia em função do tempo. Nos primeiros momentos da adsorção o efeito espacial é majoritário e se tornando também eletrostático após $15 \mathrm{~h}$ devido à reação do cálcio iônico com as moléculas de policarboxilato. O consumo dos íons cálcio faz com que a velocidade da reação de hidratação seja reduzida retardando o início e o final de pega. Para teores de aditivo superiores a 3,00 \% o sistema passa a apresentar um comportamento viscoelástico que não é adequado para o uso em materiais cimentícios. 


\begin{abstract}
The polycarboxylates are macromolecules used as high efficiency dispersants in cement compositions reducing the suspension's viscosity and the volume of water used in the processing. These additives are very efficient in promoting electrosteric stabilization due to functional groups that create charges and are absorbed by the particles' surface and their side chains. That's the reason why these additives have been used in concrete compositions. However, besides the change polycarboxylates cause to the rheologic characteristics of cementitious materials, the use of polycarboxylates affects also the surface potential, the cement hydratation reactions, and the materials' viscoelastic proprieties. In this work, the effects of ester polycarboxylate - glenium 51 - levels of variation were rated in Portland cement suspension (CP II-E) using rotational rheometry and oscillatory, isothermal conduction calorimetry and zeta potential measurement by ESA. The results show that for 0,05 to $1,50 \%$ levels of additives there was a reduction in viscosity and yield stress and an increase in the cement's setting time. These behaviors were attributed to the adsorption of the additive by the surface of the cements' particles whose performance alters because of the time function. In the adsorption's first steps the spatial effects are the majority, while after 15 hours they also become electrostatic due to the reaction of the ionic calcium with the polycarboxylate molecules. The calcium ions waste leads to a reduction of the velocity of the hydratation reaction, slowing down the beginning and the end of setting time. For higher than 3,00\% additive content, the system shows a viscoelastic behavior that is not fit for the use of cementitious materials.
\end{abstract}




\section{Sumário}

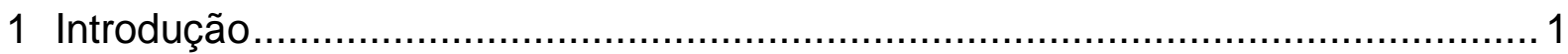

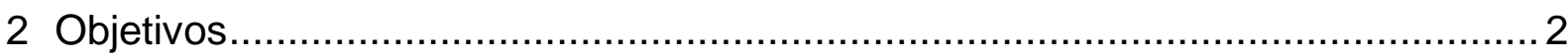

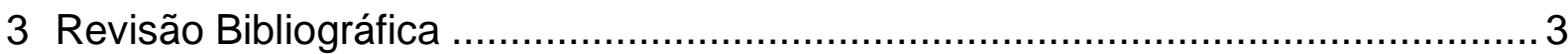

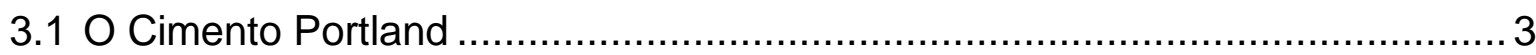

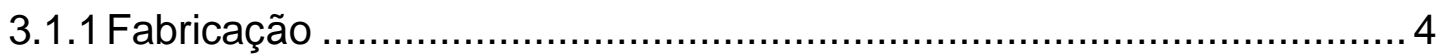

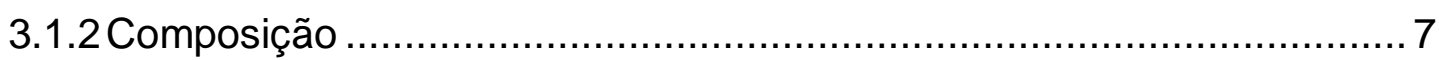

3.1.3 Mecanismos de hidratação.......................................................... 11

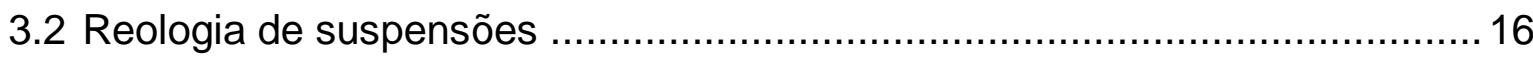

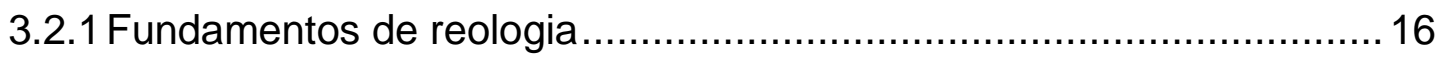

3.2.2 Comportamento reológico de suspensões .......................................21

3.2.3 Parâmetros que influenciam o comportamento reológico de uma

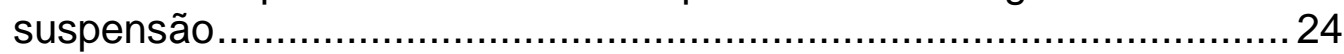

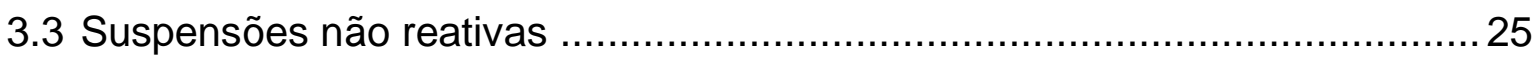

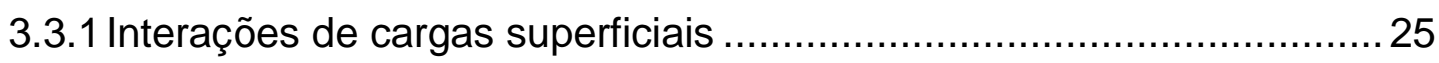

3.3.2 Mecanismos de estabilização de suspensões .................................... 31

3.3.3 Efeito da adsorção nas propriedades das suspensões......................... 34



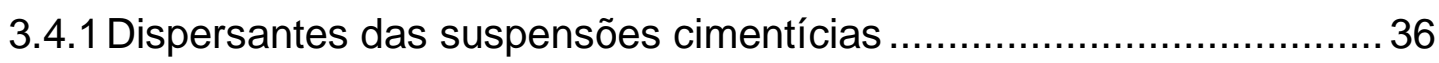



3.4.3 Ação de aditivos dispersantes na hidratação do cimento .................... 42

3.4.4 Interação das partículas de cimento com o aditivo dispersante ........... 44

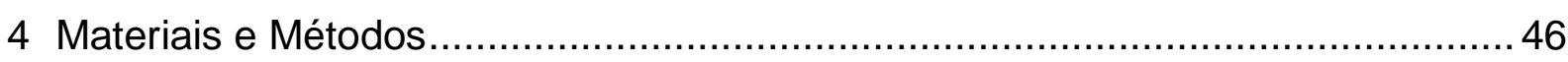



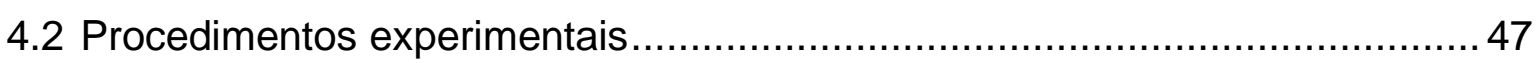

4.2.1 Caracterização do cimento Portland com adição de escória ............... 49

4.2.2 Preparação e Caracterização das Suspensões Cimentícias ................50

4.3 Princípios das técnicas de caracterização …………….............................. 54

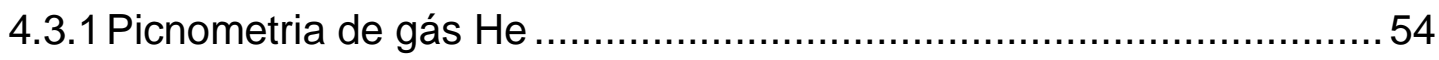





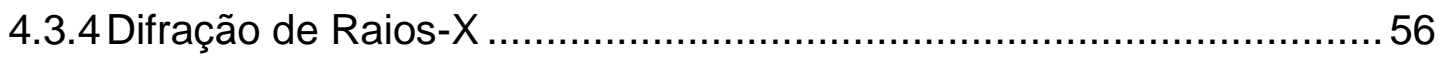

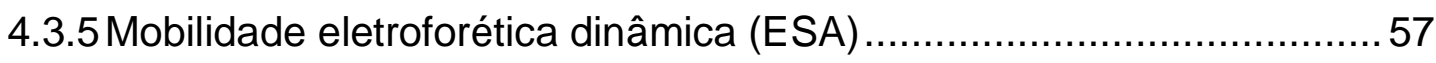








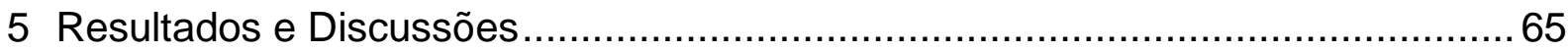

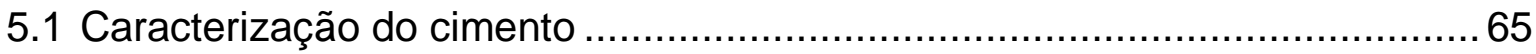

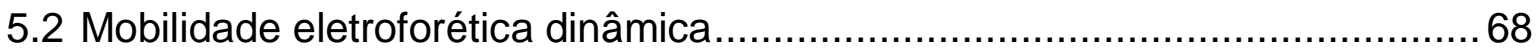

5.3 Avaliação da interação dos íons da suspensão cimentícia com o

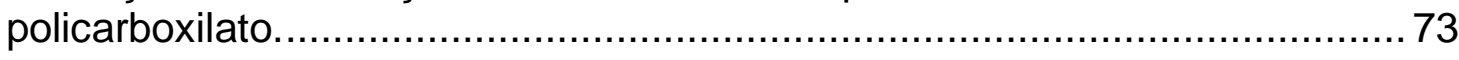

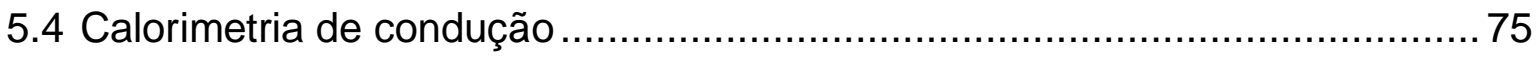

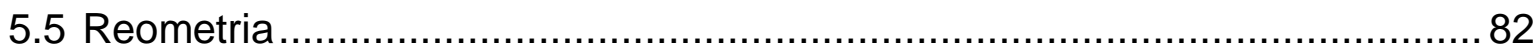

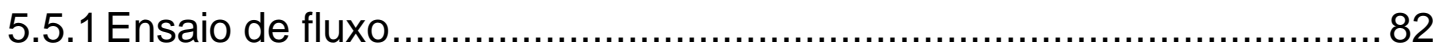

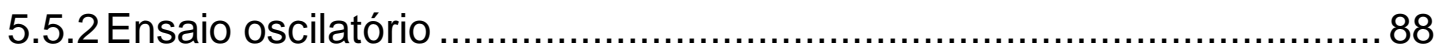

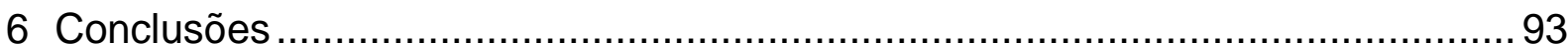

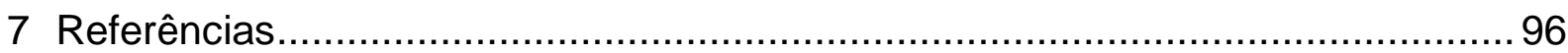




\section{Lista de Figuras}

FIGURA 1 - REAÇÕES DE FASE EM SISTEMA FORNO COM PRÉ-AQUECEDOR E PRÉ-CALCINADOR ([20], APUD [21])

Figura 2 - CRISTAIS IDIOMÓRFicos de ALITA (A), ARREdondados de BELITA (B) E FASE INTERSTICIAL (E). MiCROSCOPIA DE LUZ REFLETIDA (AMPLIAÇÃo 400X)

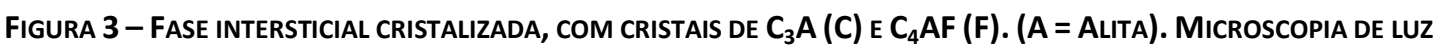
REFLETIDA (AMPLIAÇÃo 400x) ${ }^{[23]}$

Figura 4 - RepresentaÇÃo esquemática da liberaçÃo de CALOR (A) E A CONCENTRAÇÃo de CA ${ }^{2+}$ em SOluÇÃo (B)

DURANTE A HIDRATAÇÃo. ETAPAS dE REAÇÃo: (I) ESTÁGIO INICIAL; (II) PERÍOdO DE INDUÇÃO; (III) PERÍOdO dE ACELERAÇÃO; (IV) PERÍOdO DE DESACELERAÇÃO; E (V) ESTÁGIO FINAL ${ }^{[27]}$.

Figura 5 - Modelo de ISAAC NEWTON PARA DEFINIÇÃo do CONCEITO de VISCOSIDADE ${ }^{[3]}$. 19

FIGURA 6 - COMPORTAMENTO BÁSICO DE FLUIDOS ${ }^{[36]}$.

FIGURA 7 - QUEDA DO POTENCIAL ELÉTRICO DE SUPERFíCIE $\boldsymbol{\psi}_{0}$ EM FUNÇÃo DA DISTÂNCIA NO INTERIOR DAS CAMADAS DE STERN E DIFUSA QUE CIRCUNDAM A PARTÍCULA ${ }^{[3]}$.

FigURA 8 - ARRANJo ESPACIAL dos ÍONS QUE CONSTITUEM A DUPLA CAMADA ELÉTRICA DE UMA PARTícULA CARREGADA EM

UM MEIO LÍQUIDO ${ }^{[3]}$

FIGURA 9 - ENERGIAS POTENCIAIS DE INTERAÇÃo ATRATIVA, REPULSIVA E TOTAL EM FUNÇÃo DA DISTÂNCIA DE SEPARAÇÃo ENTRE AS PARTíCULAS, DE ACORDO COM A TEORIA DLVO PARA O MECANISMO DE ESTABILIZAÇÃo ELETROSTÁTICO ${ }^{[3]}$. 32

FigURA 10 - EFEITO do MECANISMO ESTÉRICO DE ESTABILIZAÇÃO, ONDE L É A ESPESSURA DA CAMADA DE MOLÉCULAS POLIMÉRICAS ADSORVIDAS NAS PARTÍCULAS, NESTE EXEMPLO, $2,5 \mathrm{NM}^{[3]}$

FIGURA 11 - EFEITO dO MECANISMO ELETROESTÉRICO, ONDE LÉ A ESPESSURA DA CAMADA DE MOLÉCULAS POLIMÉRICAS ADSORVIDAS NAS PARTÍCULAS, NESTE EXEMPLO, 2,5 NM ${ }^{[3]}$. 34

FigURA 12 - EFEITO dA ADSORÇÃo de MOLÉCULAS DETERMINANTES DE POTENCIAL NA SUPERFíCIE DA PARTíCULA SOBRE A QUEDA DE POTENCIAL NA DUPLA CAMADA ELÉTRICA EM DIFERENTES CONDIÇõES DE PH (ADAPTADO DA REFERÊNCIA [45], ONDE (1) = PLANO DE SUPERFícIE; (2) = PLANO DE CARGA; (3) = PLANO DE STERN; E $\Psi 0, \Psi$ pc, $\Psi \delta$ CORRESPONDEM AO POtenCial elétrico nOS PLANOS (1), (2) e (3), RESPECtivAMENTE).

FIGURA 13 - MONÔMERO DE UM LIGNOSSULFONATO ${ }^{[12]}$.

FIGURA 14 - MONÔMERO DE UM POLI-NAFTALENO SULFONATO DE SÓDIO LINEAR. 40

FIGURA 15 - MONÔMERO DE UM POLICARBOXILATO ${ }^{[54]}$.

FIGURA 16 - INFLUÊNCIA DA MELAMINA NA HIDRATAÇÃo DO $C_{3} A^{[12]}$ 
FIGURA 17 - INFLUÊNCIA DA MELAMINA NA HIDRATAÇÃo DO $C_{3} S^{[54]}$

Figura 18 - Calorímetro utilizado no trabalHo. Em (A) É APRESENTAdo o EQUiPAMENTo utilizado e EM (B) É ILUSTRADA A COLOCAÇÃO DE AMOSTRA NO COMPARTIMENTO.

FIGURA 19 - REÔMETRO UTILIZADO PARA CARACTERIZAÇÃo REOLÓGICA DAS PASTAS.

FIgURA 20 - EquiPAMENTOS UTILIZADOS NO PROCESSAMENTO DAS PASTAS. EM (A) ILUSTRA-SE O MISTURADOR DE BANCADA, COM BAIXA ENERGIA DE CISALHAMENTO E EM (B) O DISPERSOR DE ALTA ENERGIA DE CISALHAMENTO.

FiguRA 21 - PICNÔMETRO de GÁs HÉLIO, QUANTACHROME MVP 5DC. EM (A) É APRESENTADo o EQUIPAMENTO E EM (B) AS OPÇÕES DE PORTA-AMOSTRAS.

FIGURA 22 - REPRESENTAÇÃo ESQUEMÁTICA DE CURVA DE CALOR DE HIDRATAÇÃo E CRITÉRIOS PARA DETERMINAÇÃo DAS VARIÁVEIS ${ }^{[71,78]}$

FiguRA 23 - TIPOS DE GEOMETRIA UTILIZADOS PARA ENSAIOS REOLÓGICO DE PASTAS DE CIMENTO E ARGAMASSAS, 1-

“ESPINHA DE PEIXE”; 2 - CILINDRO CONCÊNTRICO LISO, 3 - CILINDRO CONCÊNTRICO RANHURADO, 4 - CILINDRO

CONCÊNTRICO ALETADO (VANE) E 5 - PLACAS PARALELAS RANHURADAS ${ }^{[78]}$

FIGURA 24 - DiSTRIBUIÇÃo GRANULOMÉTRICA DO CIMENTO CPII - E. .66

Figura 25 - DifRATOgRAMA do CIMENTO CP II-E.

Figura 26 - CURVAS de Potencial ZetA em função do tempo VARIANDO-SE O TEOR DE ADITIVO.

FIGURA 27 - CURVAS DE CONDUTIVIDADE IÔNICA EM FUNÇÃO DO TEMPO PARA DISPERSÕES DE CIMENTO CPII - E COM DIFERENTES TEORES DE ADITIVO.

FIGURA 28 - COMPARAÇÃo ENTRE OS VALORES INICIAIS DE CONDUTIVIDADE IÔNICA E POTENCIAL ZETA, PARA TEORES DE 0,0 -

$0,15-0,25-0,35$ E 1,50\%-P

FIGURA 29 - COMPARAÇÃo ENTRE OS VALORES FINAIS DE CONDUTIVIDADE IÔNICA E POTENCIAL ZETA, PARA TEORES DE 0,0 -

$0,15-0,25-0,35$ E 1,50\%-P 72

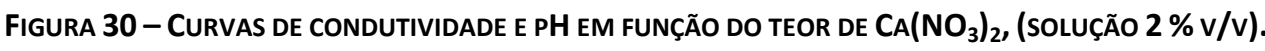

Figura 31- CuRVAS de CONDUtividAde E PH EM FUnÇÃo do teOR DE NITRATO de CÁlCIO - CA $\left(\mathrm{NO}_{3}\right)_{2}$. (SOLUÇÃo $20 \%$ $\mathrm{v} / \mathrm{v})$ .74

FiguRA 32 - CURVAS de FLUXo de CALOR (A) E CALOR ACUMULAdo (B) EM FUNÇão do TEMPO PARA PASTAS SEM ADITIVO E COM ADIÇÃO DE DIFERENTES TEORES DE ADITIVO.

FIGURA 33 - VARIAÇÃo do CALOR ACUMULAdO EM FUNÇÃo DO TEOR DE ADITIVO, PARA UM INTERVALO DE 16 HORAS. . 
FIGURA 35 - ILUSTRAÇÃo dO MÉTOdO GRÁFICO, COM BASE NAS TANGENTES NO MÁxIMO E MíNIMO dE CALOR LIBERADO NA

HIDRATAÇÃO DO CIMENTO.

FIGURA 36 - TEMPO ENTRE O INÍCIO E O FIM DE PEGA.

Figura 37 - VARIAÇÃo dA TENSÃo de CISALHAMENTO (A) PARA TEORES DE 0 A 0,45 \%P E (B) PARA TEORES DE 0,55 A 1,5

\%P.

FiguRA 38 - VARIAÇÃo dA VISCOSIDAde (A) PARA TEORES DE 0 A 0,45 \%P E (B) PARA TEORES DE 0,55 A 1,5\%P.

FIGURA 39 - CURVAS DE VISCOSIDADE NA TAXA DE CISALHAMENTO $\left(150 \mathrm{~s}^{-1}\right)$ E DE TENSÃo DE ESCOAMENTO PARA DIVERSOS TEORES DE ADITIVO.

FiguRA 40 - VARIAÇÃo do PERFIL DAS CURVAS DE VISCOSIDADE EM FUNÇÃO DA TAXA DE CISALHAMENTO; A) PARA TEORES NORMAIS E B) PARA ALTOS TEORES DE ADITIVO.

Figura 41 - Curvas de G' (A) E CURVAS de G” (B) EM FUnçÃo do teMPo, PARA Diversos teores de Aditivo. .89

FigurA 42 - CURVAS de G' EM FUnÇÃo do TEMPO, PARA ALTOS TEORES DE ADITIVO. 91

FiguRA 43 - CURVAS DE G' EM FUNÇÃo do CALOR ACUMULADO PARA SUSPENSÕES SEM ADITIVO E COM DIFERENTES TEORES DE POLICARBOXILATO ÉTER. 


\section{Lista de Tabelas}

TABELA 1 - PRINCIPAIS CONSTITUINTES DO CIMENTO EXPRESSO EM ÓXIDOS....................................................................

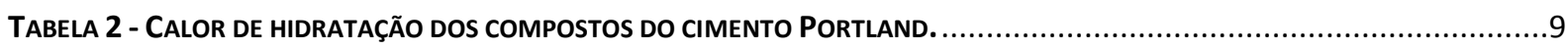

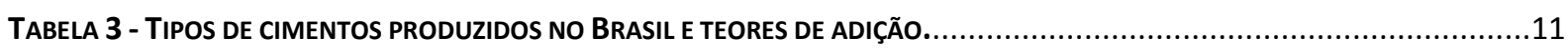

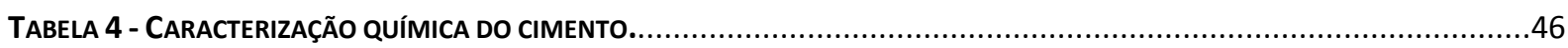

TABELA 5 - PRINCIPAIS PROPRIEDADES do POLICARBOXILATO ÉtER UTILIZADO COMO DISPERSANTE NA PREPARAÇÃo DAS SUSPENSÕES.

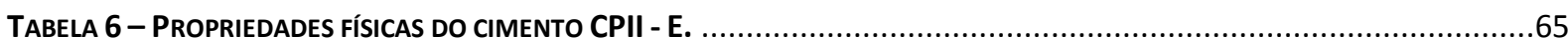

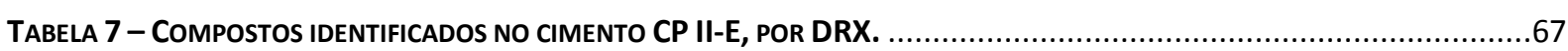

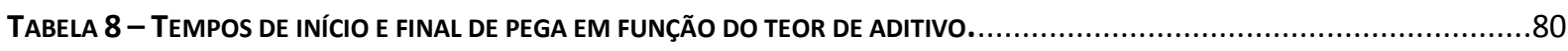

TABELA 9 - Área de hiSTERESE dAS CURVAS de CISALHAMENTO dAS SUSPENSÕes CIMENTíCIAS......................................8 


\section{Lista de Equações}

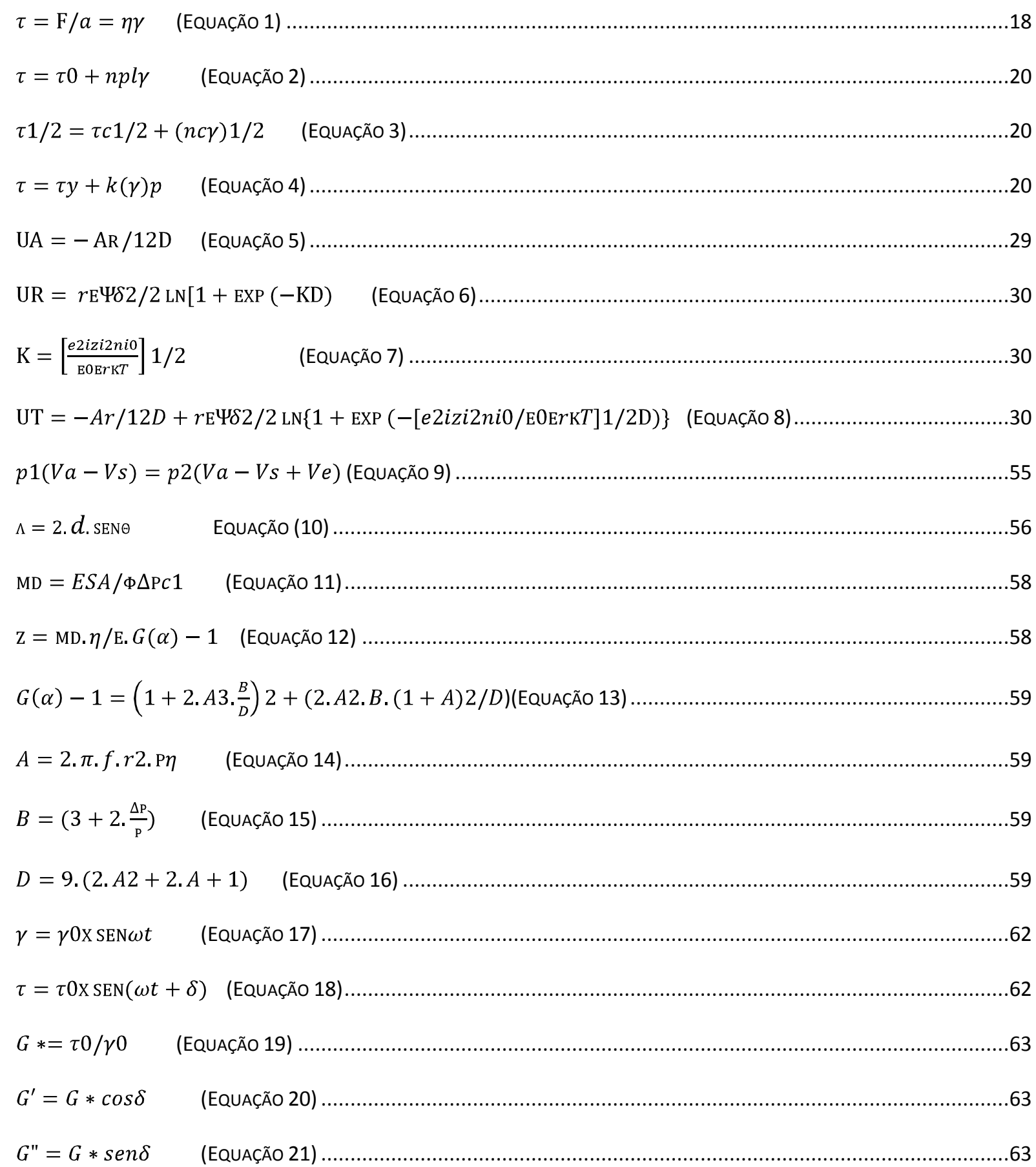




\section{Lista de Símbolos}

\begin{tabular}{|c|c|c|}
\hline C-S-H & $=$ & Silicato de cálcio hidratado \\
\hline AFt & $=$ & Etringita \\
\hline$(\tau)$ & $=$ & Tensão aplicada ou tensão de cisalhamento \\
\hline$(\dot{\gamma})$ & $=$ & Taxa de cisalhamento \\
\hline$\eta$ & $=$ & Viscosidade (Pa.s) \\
\hline $\mathrm{Pa}$ & $=$ & Pascal \\
\hline$\Psi_{0}$ & $=$ & Potencial elétrico de Superfície \\
\hline$\zeta$ & $=$ & Potencial Zeta \\
\hline$\psi_{\delta}$ & $=$ & Potencial de Stern \\
\hline$\varepsilon$ & $=$ & Permissividade do meio \\
\hline$\varepsilon_{0}$ & $=$ & Permissividade dielétrica do vácuo \\
\hline$\varepsilon_{\mathrm{r}}$ & $=$ & Constante dielétrica do material \\
\hline$Z_{i}$ & $=$ & Valência do íon i \\
\hline$e$ & $=$ & Carga do elétron $\left(1,6 \times 10^{-19} \mathrm{C}\right)$ \\
\hline K & $=$ & Constante de Boltzmann $\left(1,38 \times 10^{-23} \mathrm{~J} . \mathrm{K}^{-1}\right)$ \\
\hline $\mathrm{T}$ & $=$ & Temperatura absoluta \\
\hline $\mathrm{n}_{\mathrm{io}}$ & $=$ & Número de íons do tipo i por unidade de volume \\
\hline$\rho$ & $=$ & Densidade \\
\hline $\mathrm{C}_{1}$ & $=$ & Velocidade de propagação do som \\
\hline$a / c$ & $=$ & Relação água/cimento \\
\hline $\operatorname{tg} \alpha$ & $=$ & Inclinação da curva de aceleração de hidratação \\
\hline$(\sim)$ & $=$ & Aproximadamente \\
\hline$(\omega)$ & $=$ & Velocidade angular \\
\hline$\left(\gamma_{0}\right)$ & $=$ & Amplitude máxima de deformação \\
\hline (ठ) & $=$ & Ângulo de defasagem entre a tensão e a deformação \\
\hline $\mathrm{Al}_{2} \mathrm{O}_{3}$ & $=$ & Óxido de alumínio \\
\hline$\%$ & $=$ & Porcentagem \\
\hline${ }^{\circ} \mathrm{C}$ & $=$ & Grau Celsius \\
\hline $\mathrm{H}$ & $=$ & Hora \\
\hline $3 \mathrm{C}_{4} \mathrm{~A} \mathrm{~S} \mathrm{H} \mathrm{H}_{12}$ & $=$ & Monossulfoaluminato de cálcio ou fase AFm \\
\hline
\end{tabular}




\begin{tabular}{|c|c|c|}
\hline $\mathrm{AFm}$ & $=$ & Monossulfoaluminato de cálcio hidratado \\
\hline AFt & $=$ & Trissulfoaluminato de cálcio hidratado ou etringita \\
\hline $\mathrm{Al}(\mathrm{OH})_{4}^{-}$ & $=$ & Íon aluminato \\
\hline $\mathrm{C}_{2} \mathrm{~S}$ & $=$ & Silicato bicálcico ou belita \\
\hline $\mathrm{C}_{3} \mathrm{~A}$ & $=$ & Aluminato tricálcico \\
\hline $\mathrm{C}_{3} \mathrm{~S}$ & $=$ & Silicato tricálcico ou alita \\
\hline $\mathrm{C}_{3} \mathrm{~S}_{2} \mathrm{H}_{3}$ & $=$ & Silicato de cálcio hidratado \\
\hline $\mathrm{C}_{6} \mathrm{~A} S_{3} \mathrm{H}_{32}$ & $=$ & Etringita \\
\hline $\mathrm{Ca}(\mathrm{OH})_{2}$ & $=$ & Hidróxido de cálcio \\
\hline $\mathrm{Ca}^{2+}$ & $=$ & Íon cálcio \\
\hline $\mathrm{Ca}_{2} \mathrm{SiO}_{4} \mathrm{C}_{2} \mathrm{~S}$ & & silicato dicálcico ou belita \\
\hline $\mathrm{Ca}_{3} \mathrm{Al}_{2} \mathrm{O}_{6} \mathrm{C}_{3} \mathrm{~A}$ & & aluminato tricálcico \\
\hline $\mathrm{Ca}_{3} \mathrm{SiO}_{5} \mathrm{C}_{3} \mathrm{~S}$ & & silicato tricálcico ou alita \\
\hline $\mathrm{CaCO}_{3}$ & $=$ & Carbonato de cálcio \\
\hline $\mathrm{C}-\mathrm{A}-\mathrm{H}$ & $=$ & Aluminato de cálcio hidratado \\
\hline $\mathrm{CaMg}\left(\mathrm{CO}_{3}\right)_{2}$ & $=$ & Carbonato de cálcio e magnésio ou dolomita \\
\hline $\mathrm{CaO}$ & $=$ & Óxido de cálcio ou cal livre \\
\hline $\mathrm{CaSO}_{4}$ & $=$ & Sulfato de cálcio ou anidrita \\
\hline $\mathrm{CH}$ & $=$ & Hidróxido de cálcio ou $\mathrm{Ca}(\mathrm{OH})_{2}$ ou portlandita \\
\hline $\mathrm{CS} \mathrm{H}_{2}$ & $=$ & Gipsita \\
\hline $\mathrm{CO}_{2}$ & $=$ & Anidrido carbônico \\
\hline G & $=$ & Giga $\left(10^{9}\right)$ \\
\hline$G^{\prime}$ & $=$ & Componente elástica ou módulo de armazenamento \\
\hline G” & $=$ & Componente viscosa ou módulo de perda. \\
\hline
\end{tabular}




\section{Introdução}

Alguns aditivos são utilizados em pastas cimentícias com a finalidade de melhorar as propriedades reológicas e seu estado endurecido. Independentemente do tipo de mecanismo de estabilização (eletrostático, estérico e/ou eletroestérico ${ }^{[1-4]}$ ), a utilização de dispersantes torna possível a obtenção de pastas com menores teores de água, melhorando a homogeneidade e facilitando a mistura ${ }^{[3,5]}$.

Dentre as inúmeras aplicações, pode ser citado o uso em concretos autoadensáveis, onde se deve garantir elevada fluidez do sistema sem que ocorra separação de fases e/ou exsudação.

Para este fim, vários tipos de dispersantes podem ser utilizados, como os polímeros à base de éteres policarboxilatos, conhecidos no setor de construção civil como dispersantes de última geração.

Ao serem adicionados nas pastas cimentícias, os aditivos dispersantes são responsáveis pela estabilização eletroestérica das suspensões, já que a estrutura das moléculas de dispersante apresentam ramificações (responsáveis pela estabilização estérica) e cargas elétricas (responsáveis pela estabilização eletrostática). No entanto, o dispersante adsorvido à superfície das partículas afetará os primeiros minutos de hidratação do cimento, retardando a dissolução das fases e aumentando o tempo de início de pega.

Por mais que se tenha estudado e realizado ensaios para o entendimento mais profundo sobre a reação de hidratação de cimento Portland em presença de aditivos, algumas vezes focando os aspectos físicos ${ }^{[6,7]}$, em outras os aspectos químicos $^{[8,9]}$, e o efeito dos aditivos nas diferentes fases constituintes: $C_{3} S, C_{2} S$, 
$\mathrm{C}_{3} \mathrm{~A}$, e $\mathrm{C}_{4} \mathrm{AF}^{[10,11]}$, não existe ainda, uma teoria bem aceita explicando a ação dos aditivos sobre as partículas do cimento durante a mistura e hidratação inicial, e sobre os produtos intermediários na hidratação ${ }^{[12,13]}$.

Desta forma, é de fundamental importância a avaliação dos efeitos provocados no potencial de superfície das partículas e nas propriedades reológicas das pastas aditivadas com dispersantes, a fim de se conhecer as propriedades dos materiais cimentícios sob fluxo, e durante a consolidação. Assim, neste trabalho foram avaliados os efeitos da variação do teor de éter policarboxilato - Glenium 51 em suspensões de cimento Portland (CPIIE) a partir de ensaios de reometria rotacional e oscilatória, calorimetria de condução isotérmica e medidas de potencial zeta por eletroacústica.

\section{Objetivos}

Este trabalho teve como objetivo avaliar os efeitos provocados pelo aumento do teor de dispersante à base de policarboxilato éter, na viscosidade, tensão de escoamento e consolidação das suspensões de cimento Portland (CPII-E) a partir de ensaios de reometria rotacional e oscilatória, calorimetria de condução isotérmica e medidas de mobilidade eletrocinética dinâmica. 


\section{Revisão Bibliográfica}

\subsection{O Cimento Portland}

O clínquer é produzido através do aquecimento até $1450^{\circ} \mathrm{C}$ de uma mistura de calcário e argila, ou de outros materiais em proporções adequadas. Durante o aquecimento ocorre uma fusão parcial das diferentes fases constituintes do clínquer ${ }^{[14]}$.

A mistura entre o clínquer e uma determinada porcentagem de gipsita, quando moído finamente, dá origem ao cimento Portland. Este possui propriedades ligantes relacionadas às transformações das espécies químicas constituintes do material por reação com a água, e assim adquirindo consistência e dando origem a produtos que têm resistência mecânica adequada para aplicações em construção civil $^{[14-16]}$.

A norma ASTM C 150, define o cimento Portland (CP) como um aglomerante hidráulico produzido pela moagem de clínqueres constituídos essencialmente por silicatos de cálcio hidráulicos e uma pequena quantidade de uma ou mais formas de sulfato de cálcio ${ }^{[15]}$.

Para a norma brasileira NBR 5732/91, o cimento Portland comum é definido como o aglomerante hidráulico obtido pela moagem de clínquer Portland com adição de uma ou mais formas de sulfato de cálcio. Dentro dos limites da norma, é permitida a adição de materiais pozolânicos, escória de alto-forno e filer calcário, dando origem aos cimentos compostos ${ }^{[17]}$.

Atualmente são produzidos no Brasil diferentes tipos de cimentos Portland compostos por clínquer Portland e sulfato de cálcio, e os que contêm adições de filer 
calcário, escória granulada de alto-forno ou pozolana (cinza volante ou argila calcinada). Assim, é possível a fabricação de um determinado cimento com características e propriedades adequadas para uma aplicação específica.

\subsubsection{Fabricação}

O processo de fabricação do cimento Portland consiste basicamente na mineração e britagem das matérias primas, preparação adequada da mistura crua denominada "farinha", e aquecimento a $1450^{\circ} \mathrm{C}$ em forno rotativo, dando origem ao clínquer Portland. Quando este é devidamente moído e misturado em proporções adequadas com sulfato de cálcio e/ou outra adição, tem-se o aglomerante hidráulico denominado de cimento Portland ${ }^{[14-16]}$.

A matéria-prima utilizada na produção do CP deve conter proporções adequadas de cálcio e sílica, devido aos seus constituintes primários serem silicatos de cálcio. O cálcio pode ser obtido do calcário, calcário argiloso e conchas do mar, já que esses materiais são fontes industriais comuns de cálcio. A sílica é extraída preferencialmente de argilas e folhelhos, sendo adicionada na mistura da matériaprima para formar os silicatos de cálcio.

Os minerais argilosos também contêm alumina, óxido de ferro e álcalis. A presença de alumínio, ferro e magnésio, além dos ácalis na mistura da matériaprima, tem um efeito mineralizante na formação de silicatos de cálcio, isto é, facilitam a formação de silicato de cálcio a temperaturas consideravelmente mais baixas do que seria possível de outra forma. Portanto, quando é verificado que a quantidade desses minerais não é suficiente nas matérias-primas principais, são adicionados materiais secundários, como bauxita e minério de ferro. Assim, são obtidos os 
silicatos de cálcio a baixa temperatura e o clínquer Portland contendo aluminatos e ferroaluminatos de cálcio ${ }^{[15]}$.

A proporção adequada do calcário, argila e corretivos para a composição da farinha é definida de acordo com a composição química das matérias-primas, através de módulos que relacionam os óxidos dos quatro constituintes principais, $\mathrm{CaO}, \mathrm{SiO}_{2}, \mathrm{Al}_{2} \mathrm{O}_{3}$ e $\mathrm{Fe}_{2} \mathrm{O}_{3}$, conhecidos como: Fator de saturação de $\mathrm{Cal}$ (FSC), Módulo de Sílica (MS) e Módulo de Alumina (MA). Para tipos normais de clínquer de cimento Portland, MS está comumente na faixa de $2.0-3.0$, e MA $1.2-3.2$, mas estas faixas de valores não são aplicadas para tipos especiais, como os cimentos resistentes a sulfato ou clínquer de cimento branco ${ }^{[18]}$.

O MS controla a proporção das fases de silicato no clínquer. Aumentando o MS diminui a proporção de líquido em qualquer temperatura dada no forno, e torna o clínquer conseqüentemente mais difícil para formar-se. O MA governa a proporção entre as fases aluminato e ferrita no clínquer, os quais têm efeitos importantes nas propriedades do cimento, como também determina a quantidade de líquido formado nas faixas mais baixas do processo de clinquerização ${ }^{[19]}$.

A formação dos compostos do clínquer de cimento Portland é facilitada se o processo de produção for bem controlado, destacando-se a série de operações de britagem, moagem e mistura da matéria-prima, que resultará numa mistura homogênea antes do tratamento térmico.

O processo de fabricação preferido das fábricas modernas é o por via seca, devido ser mais eficiente energeticamente do que o processo por via úmida ${ }^{[15]}$.

O sistema dos fornos utilizados no processo por via seca passou por modificações objetivando economia de combustível. Surgindo assim fornos com 
pré-aquecedores e pré-calcinadores (Figura1), que resultam na diminuição do comprimento do forno de clinquerização, como também a redução do tempo entre as etapas de clinquerização. Outra conseqüência da diminuição no tempo em que a matéria-prima permanece no forno é o aumento no tempo útil do revestimento refratário, isto é, maior espaço de tempo entre os serviços de reparo e manutenção.

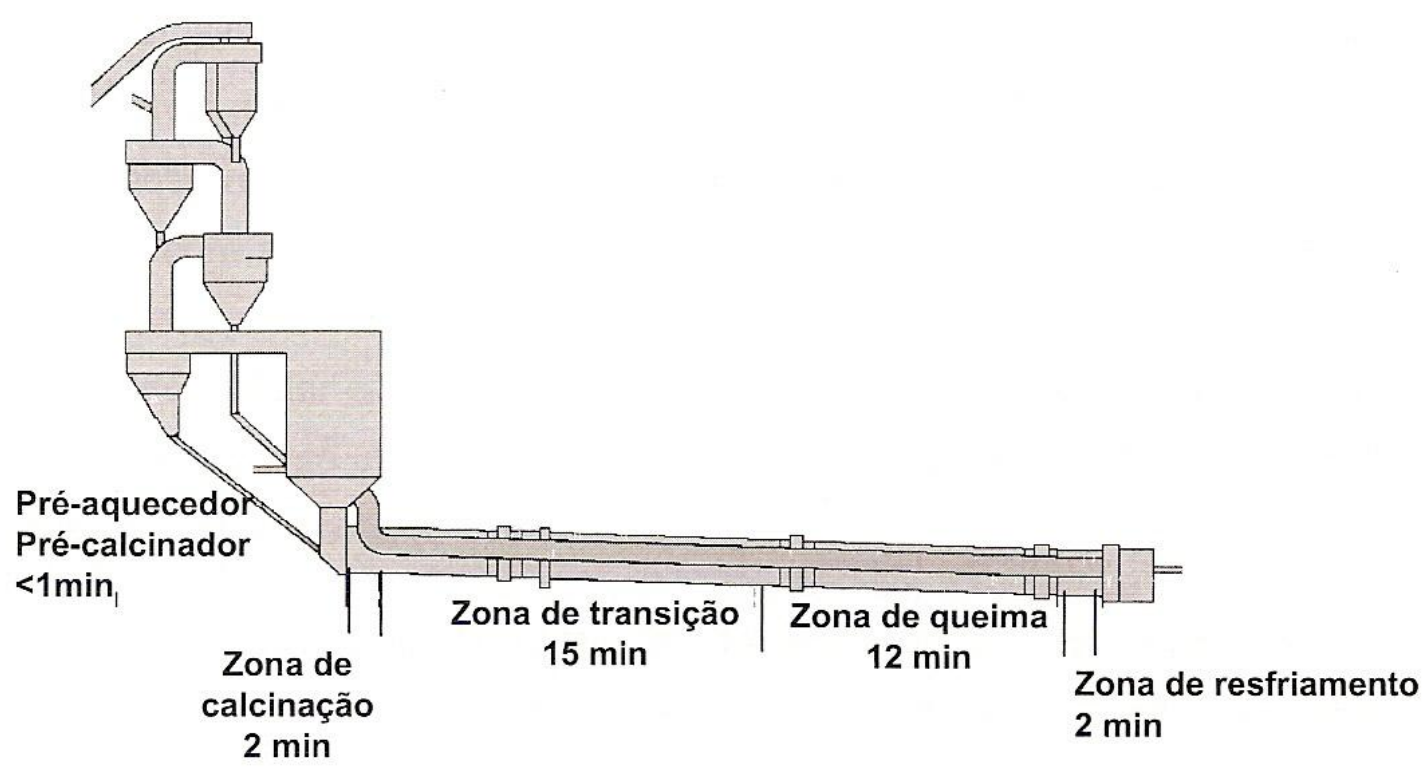

Figura 1- Reações de fase em sistema forno com pré-aquecedor e pré-calcinador ([20], apud [21]).

A etapa final do processo de fabricação do cimento Portland é realizada em moinhos de bolas, com partículas de clínquer entre 10 e $15 \mu \mathrm{m}$ em média e aproximadamente $5 \%$ de gipsita ou sulfato de cálcio, tendo estes como função o controle das reações iniciais da hidratação que resultam no fenômeno da pega do cimento.

A finura e a distribuição granulométrica do cimento é um fator muito importante para o seu comportamento reológico e desempenho mecânico. Sabe-se que, a hidratação inicia-se pela superfície das partículas, assim, a área superficial 
específica é um parâmetro importantíssimo. Quanto mais fino estiver o cimento, maior será a taxa de hidratação. Logo, para o desenvolvimento rápido da resistência mecânica é necessário um elevado grau de finura ${ }^{[22]}$.

\subsubsection{Composição}

Os principais constituintes do cimento Portland podem ser identificados a partir de uma análise química, expressa em óxidos, conforme a Tabela 1 que apresenta uma notação própria da química do cimento.

Tabela 1 - Principais constituintes do cimento expresso em óxidos.

\begin{tabular}{c|c||c|c}
\hline Óxido & Abreviação & Composto & Abreviação \\
\cline { 2 - 3 } $\mathrm{CaO}$ & $\mathrm{C}$ & $3 \mathrm{CaO} . \mathrm{SiO}_{2}$ & $\mathrm{C}_{3} \mathrm{~S}$ \\
$\mathrm{SiO}_{2}$ & $\mathrm{~S}$ & $2 \mathrm{CaO} . \mathrm{SiO}_{2}$ & $\mathrm{C}_{2} \mathrm{~S}$ \\
$\mathrm{Al}_{2} \mathrm{O}_{3}$ & $\mathrm{~A}$ & $3 \mathrm{CaO} \cdot \mathrm{Al}_{2} \mathrm{O}_{3}$ & $\mathrm{C}_{3} \mathrm{~A}$ \\
$\mathrm{Fe}_{2} \mathrm{O}_{3}$ & $\mathrm{~F}$ & $4 \mathrm{CaO} \cdot \mathrm{Al}_{2} \mathrm{O}_{3} \cdot \mathrm{Fe}_{2} \mathrm{O}_{3}$ & $\mathrm{C}_{4} \mathrm{AF}$ \\
$\mathrm{MgO}$ & $\mathrm{M}$ & $4 \mathrm{CaO} \cdot 3 \mathrm{Al}_{2} \mathrm{O}_{3} \cdot \mathrm{SO}_{3}$ & $\mathrm{C}_{4} \mathrm{~A}_{3} \overline{\mathrm{S}}$ \\
$\mathrm{H}_{2} \mathrm{O}$ & $\mathrm{H}$ & $\mathrm{CaSO}_{4} \cdot 2 \mathrm{H}_{2} \mathrm{O}$ & $\mathrm{C} \overline{\mathrm{S}} \mathrm{H}_{2}$ \\
\hline
\end{tabular}

Durante as reações de clinquerização são formados os minerais: silicatos de cálcio $\mathrm{Ca}_{3} \mathrm{SiO}_{5}$ (alita ou $\mathrm{C}_{3} \mathrm{~S}$ ) e $\mathrm{Ca}_{2} \mathrm{SiO}_{4}$ (belita ou $\mathrm{C}_{2} \mathrm{~S}$ ) e o aluminato e ferroaluminato de cálcio $\mathrm{Ca}_{3} \mathrm{Al}_{2} \mathrm{O}_{6}\left(\mathrm{C}_{3} \mathrm{~A}\right)$ e $\mathrm{Ca}_{4} \mathrm{Al}_{2} \mathrm{Fe}_{2} \mathrm{O}_{10} \quad\left(\mathrm{C}_{4} \mathrm{AF}\right)$. Vale a pena ressaltar que essas fases não são puras, podendo incorporar elementos menores oriundos das matérias-primas ou da interação com os combustíveis utilizados na clinquerização $0^{[14-16]}$. Estas fases podem ser observadas a partir do microscópio 
óptico de luz refletida, como são apresentados na Figura 2 os silicatos de cálcio $\left(\mathrm{C}_{3} \mathrm{~S}\right.$ e $C_{2} S$ ) e na Figura 3 o aluminato e o ferroaluminato de cálcio $\left(C_{3} A\right.$ e $\left.C_{4} A F\right)$.

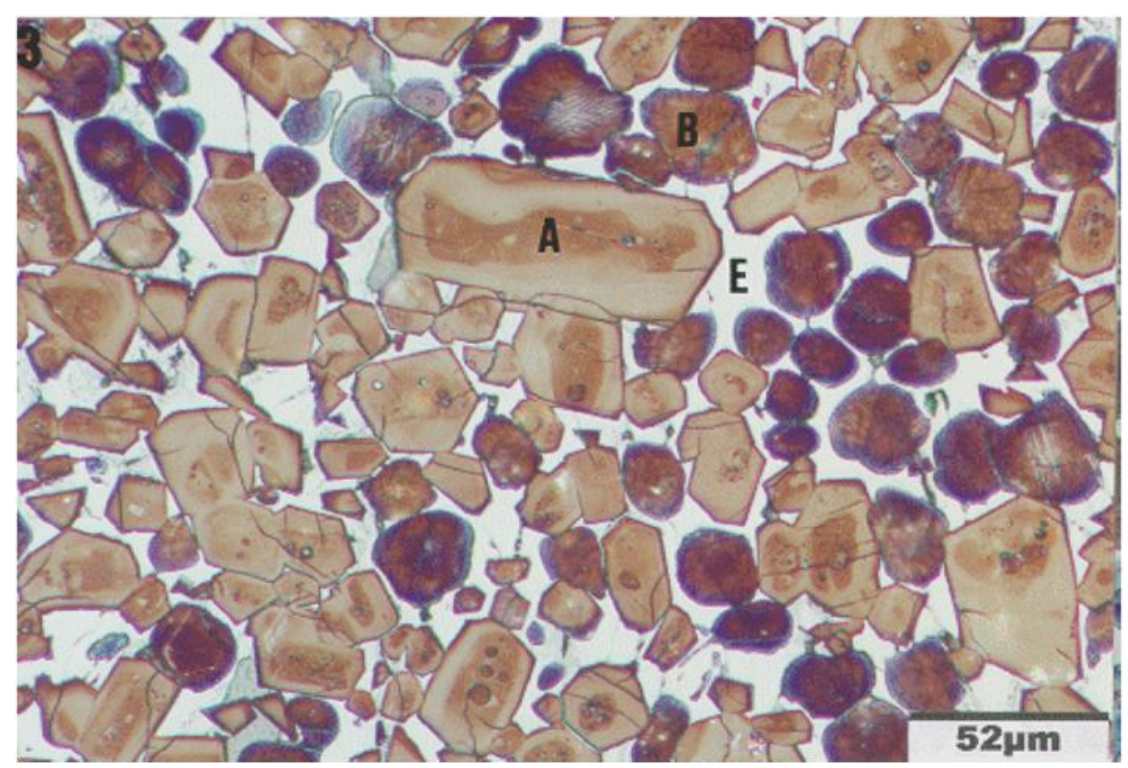

Figura 2 - Cristais idiomórficos de alita (A), arredondados de belita (B) e fase intersticial (E). Microscopia de luz refletida (Ampliação 400x) ${ }^{[23]}$.

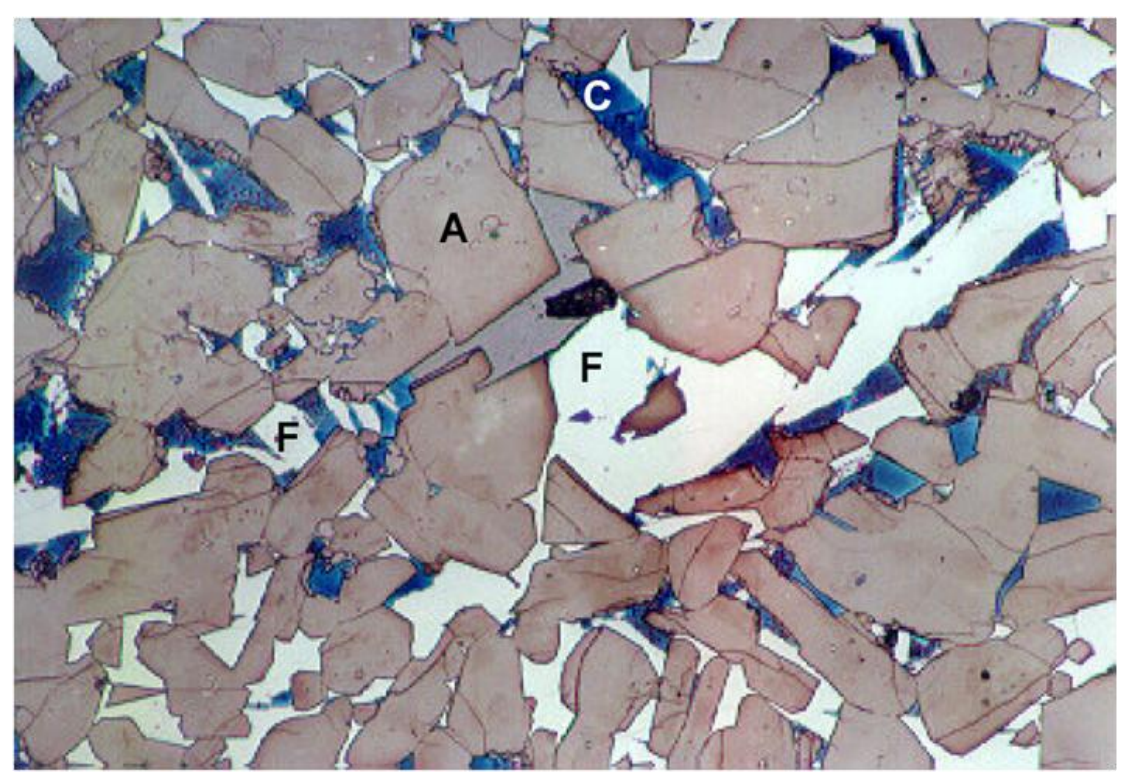

Figura 3 - Fase intersticial cristalizada, com cristais de $C_{3} A(C)$ e $C_{4} A F(F)$. (A = Alita). Microscopia de luz refletida (Ampliação 400x) ${ }^{[23]}$. 
As fases cal livre, periclásio e as fases sulfáticas arcanita - $\mathrm{K}_{2} \mathrm{SO}_{4}$; langbeinita - $\mathrm{K}_{2} \mathrm{Ca}_{2}\left(\mathrm{SO}_{4}\right)_{3}$; aftitalita $-\mathrm{K}_{3} \mathrm{Na}\left(\mathrm{SO}_{4}\right)_{2}$ também compõem o clínquer Portland. Os sulfatos são oriundos dos combustíveis e os álcalis da matéria-prima ${ }^{[14]}$.

As fases do clínquer Portland apresentam-se em teores variados e reatividades diferentes, sendo que a fase mais reativa é o $C_{3} A$. Este proporciona o maior calor de hidratação por unidade de massa, como também influencia na taxa de hidratação do cimento ${ }^{[15,24]}$. A Tabela 2 mostra o calor de hidratação dos principais compostos do cimento Portland ${ }^{[15]}$.

Tabela 2 - Calor de hidratação dos compostos do cimento Portland.

\begin{tabular}{c|c|c|c}
\hline & \multicolumn{3}{|c}{ Calor de hidratação a uma dada idade (cal/g) } \\
\hline Composto & $\mathbf{3}$ dias & $\mathbf{9}$ dias & $\mathbf{1 3}$ dias \\
\hline $\mathrm{C}_{3} \mathrm{~S}$ & 58 & 104 & 122 \\
$\mathrm{C}_{2} \mathrm{~S}$ & 12 & 42 & 59 \\
$\mathrm{C}_{3} \mathrm{~A}$ & 212 & 311 & 324 \\
$\mathrm{C}_{4} \mathrm{AF}$ & 69 & 98 & 102 \\
\hline
\end{tabular}

Outros constituintes importantes do cimento Portland são os sulfatos de cálcio, adicionados ao clínquer durante a moagem. Esta adição tem como objetivo retardar a tendência de pega rápida do clínquer Portland moído, devido à alta reatividade do $\mathrm{C}_{3} \mathrm{~A}$. Durante a reação de hidratação o $\mathrm{C}_{3} \mathrm{~A}$ reage com os sulfatos de cálcio formando inicialmente trissulfoaluminato de cálcio (etringita) e posteriormente monossulfoaluminato de cálcio, que impede a rápida formação do aluminato hidratado $\left(\mathrm{C}_{4} \mathrm{AH}_{13}\right)^{[14,15]}$. 
Os sulfatos de cálcio utilizados pela indústria brasileira são normalmente: gipsita $\left(\mathrm{CaSO}_{4} \cdot 2 \mathrm{H}_{2} \mathrm{O}\right)$ e anidrita $\left(\mathrm{CaSO}_{4}\right)$, subprodutos da produção de ácido fluorídrico.

As propriedades do cimento Portland são modificadas, alterando-se a sua composição através de adições de materiais como:

- fíler calcário - reduz os custos de produção, preserva as jazidas minerais e diminui as taxas de emissão de $\mathrm{CO}_{2}$. Os efeitos da adição dependem da relação água/cimento $(\mathrm{a} / \mathrm{c})$ e das propriedades do fíler, podendo reduzir os espaços vazios, melhorar o empacotamento, e modificar a cinética de reações de hidratação, como também, a morfologia dos produtos hidratados ${ }^{[25]}$.

- escória de alto-forno - são subprodutos da fabricação do ferro gusa, só podem ser adicionadas ao cimento Portland se forem vitrificadas por resfriamento brusco e possuírem composição adequada de caráter básico. Sua adição proporciona ao cimento melhores propriedades como: baixo calor de hidratação, baixa permeabilidade, e aumento da resistência mecânica e da durabilidade. A adição também contribui na redução de $\mathrm{CO}_{2}$ e preservação das matérias-primas (calcário e argila) ${ }^{[15]}$.

- materiais pozolânicos - materiais silicosos ou sílico-aluminosos que possuem pouca ou nenhuma atividade aglomerante, mas, quando finamente moído e na presença de água, reage com hidróxido de cálcio à temperatura ambiente, formando compostos com propriedades hidráulicas. As principais pozolanas adicionadas aos cimentos brasileiros são a cinza volante, subproduto da queima do carvão mineral, e as argilas calcinadas, ativadas à temperatura próximas a $800^{\circ} \mathcal{C}^{[15]}$. 
A Tabela 3 mostra os tipos de cimentos produzidos pela indústria brasileira de cimento bem como os teores de adição permitidos por norma ${ }^{[15]}$.

Tabela 3 - Tipos de cimentos produzidos no Brasil e teores de adição.

\begin{tabular}{c|c|c|c|c}
\hline & $\begin{array}{c}\text { Clínquer + sulfato de } \\
\text { cálcio }\end{array}$ & Fíler & Pozolana & Escória \\
\hline CP I-S & $99-95$ & $1-5$ & $1-5$ & $1-5$ \\
CP II-E & $94-56$ & $0-10$ & $6-34$ \\
CP II-F & $94-90$ & $6-10$ & $6-14$ & \\
CP II-Z & $94-86$ & $0-10$ & & $35-70$ \\
CP III & $65-25$ & $0-5$ & $15-50$ & \\
CP IV & $85-45$ & $0-5$ & $0-5$ & \\
CP V ARI & $100-95$ & & \\
\hline
\end{tabular}

\subsubsection{Mecanismos de hidratação}

A reação química do cimento com a água é denominada de hidratação, tendo como resultado produtos que possuem características de pega e endurecimento. As reações químicas que ocorrem são geralmente mais complexas do que simples conversões entre compostos anidros e hidratos ${ }^{[14,15]}$.

A água não tem como objetivo somente propiciar a suspensão do sólido. Ela dissolve as espécies químicas constituintes do cimento, até a saturação, proporcionando consistência à suspensão (início de pega), que evolui até o enrijecimento (fim de pega), chegando ao endurecimento (ganho de resistência) de forma acentuada. O endurecimento é o resultado das transformações do cimento anidro, através de reações químicas associadas a um mecanismo de reação, a uma 
cinética de reação, e esta vinculada à reatividade do produto e a condições de pressão e de temperatura.

Brunauer e Copeland ${ }^{[26]}$ descrevem que a química do concreto é essencialmente a química da reação entre o cimento Portland e a água, destacando a importância do conhecimento sobre as espécies químicas formadas quando o cimento Portland reage.

A velocidade da reação é outro parâmetro importante, pois determina o tempo de pega e endurecimento. Salienta-se que a reação inicial deve ser suficientemente lenta para permitir que o concreto seja lançado e após o lançamento é desejável um rápido endurecimento ${ }^{[26]}$.

A hidratação do cimento Portland se dá através de dois mecanismo ${ }^{[15]}$ :

a) Dissolução-precipitação: resume-se em dissolução de compostos anidros em seus constituintes iônicos, a formação de hidratos em solução seguida de precipitação de hidratos resultantes da solução supersaturada.

b) Topoquímico: as reações acontecem diretamente na superfície dos compostos do cimento anidro sem que os compostos entrem em solução, e se completa com o tempo, desde que haja contato do cimento com a água. Vale ressaltar que para o concreto a difusão da umidade ambiente governará as reações, sendo dependente da porosidade da pasta.

Logo após o cimento ser misturado com água ocorre uma troca de espécies iônicas entre os sólidos e a fase líquida, seguida pelo aumento da concentração de aluminatos, sulfatos e álcalis (sódio, potássio e cálcio) na fase líquida, este aumento é resultado da solubilidade dos constituintes do clínquer, como ${ }^{[27]}$ :

- Silicato de cálcio; 
- Aluminatos de cálcio;

- Sulfato de cálcio;

- Sulfatos alcalinos.

A solubilidade é diferenciada e, em conseqüência, as fases do clínquer hidratam-se em momentos diferentes, sendo, por isso mesmo, um sistema complexo.

O grau de hidratação do cimento pode ser acompanhado por meio da determinação dos teores das fases anidras e hidratadas, pela determinação do teor de água quimicamente combinada, pela determinação da concentração iônica na fase aquosa e pela evolução do calor liberado pelas reações de hidratação ${ }^{[14]}$.

Por isso a cinética de hidratação pode ser acompanhada por meio da determinação da taxa de liberação de calor gerado pelas reações químicas, conforme ilustrado na Figura 4, a partir do perfil da curva de evolução de calor do cimento Portland.

O mecanismo de hidratação pode ser dividido em cinco etapas: estágio inicial (I), período de indução (II), período de aceleração (III), período de desaceleração (IV) e estágio final $(\mathrm{V})^{[14,27]}$. A Figura 4 mostra as etapas da hidratação associadas à variação da concentração de íons cálcio em solução com o tempo de hidratação. 


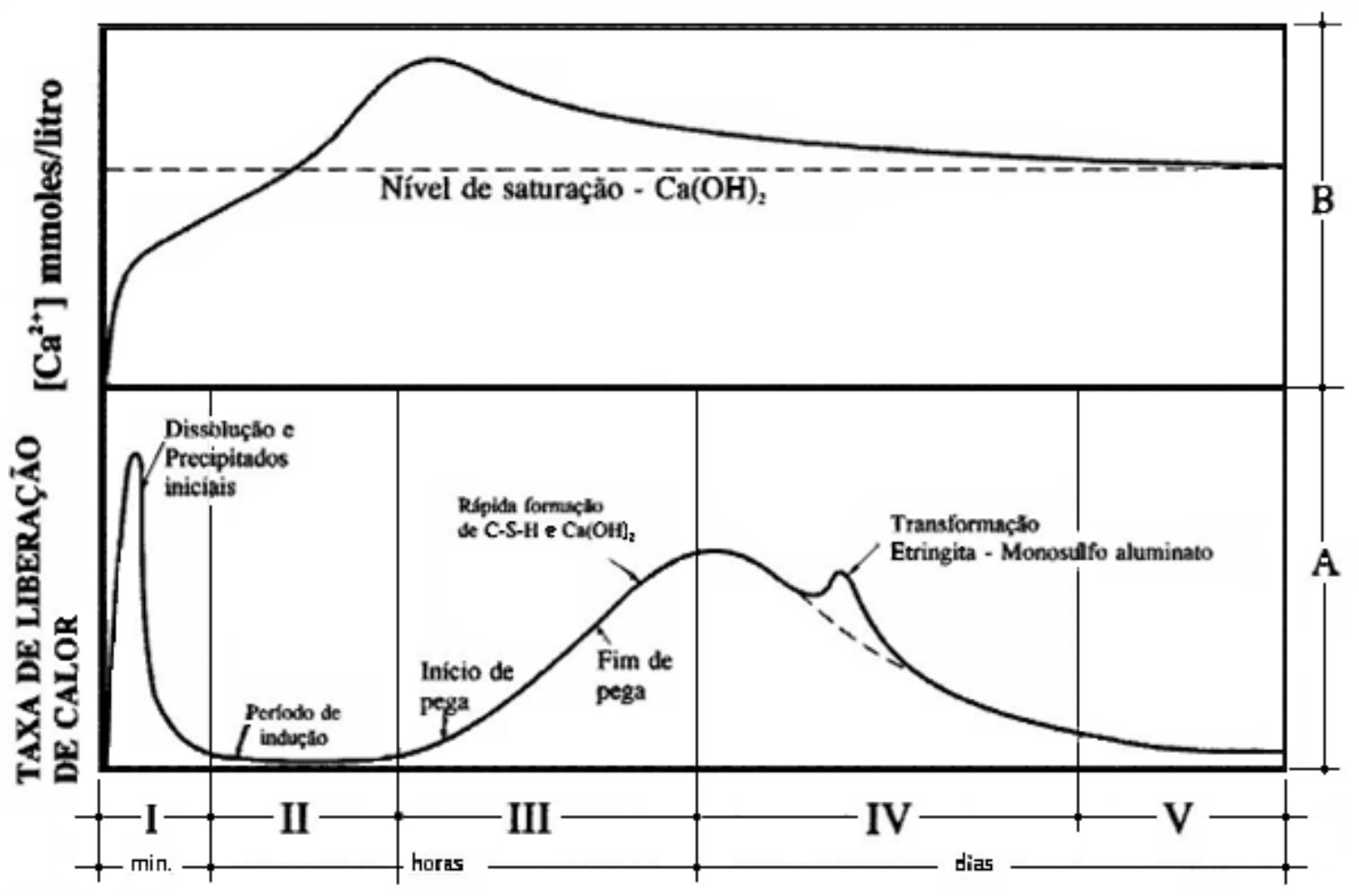

TEMPO DE HIDRATAÇÃo

Figura 4 - Representação esquemática da liberação de calor (A) e a concentração de $\mathrm{Ca}^{2+}$ em solução (B) durante a hidratação. Etapas de reação:

(I) estágio inicial; (II) período de indução; (III) período de aceleração; (IV) período de desaceleração; e (V) estágio final ${ }^{[27]}$.

Estágio inicial (I): imediatamente após a mistura do cimento com a água ocorre em primeiro lugar a dissolução dos sulfatos alcalinos, que liberam íons $\mathrm{K}^{+}$, $\mathrm{Na}^{+}$e $\mathrm{SO}_{4}{ }^{2-}$. O sulfato de cálcio dissolve até a saturação liberando íons $\mathrm{Ca}^{2+}$ e $\mathrm{SO}_{4}{ }^{2-}$; em seguida, inicia-se a dissolução das fases anidras $\mathrm{C}_{3} \mathrm{~S}, \mathrm{C}_{3} \mathrm{~A}$ e $\mathrm{C}_{4} \mathrm{AF}$. Estas reações, como também a eventual conversão do sulfato de cálcio hemihidratado em dihidratado e o efeito de molhamento das partículas são responsáveis pela formação do primeiro pico de liberação de calor.

Neste estágio é formada uma camada de silicato de cálcio hidratado (C-S-H) sobre as partículas de cimento, com liberação de íons $\mathrm{Ca}^{2+} \mathrm{e} \mathrm{OH}^{-}$em solução. Neste momento ocorrem reações do $\mathrm{C}_{3} \mathrm{~A}$ e $\mathrm{C}_{4} \mathrm{AF}$ dissolvidos com os íons $\mathrm{Ca}^{2+}$ e $\mathrm{SO}_{4}{ }^{2-}$ 
presentes na solução. Um gel amorfo, rico em aluminato é formado sobre a superfície dos grãos de cimento com o aparecimento de espessas agulhas da fase etringita (AFt) sobre o gel e na solução ${ }^{[14,28]}$.

Período de indução (II): neste período ocorre a hidratação da cal livre (CaO) e uma reação de pequena intensidade com a alita. Estas reações ocorrem com certa velocidade, mas são desaceleradas devido à deposição do gel hidratado sobre os grãos; que faz com que surja uma barreira entre as fases anidras e a fase aquosa, dando origem a um período dormente. Este período geralmente dura de 30 minutos a 3 horas e termina quando a camada formada sobre o grão de cimento se rompe ou quando se torna permeável, devido à transformação de fase, coincidindo com a nucleação e o crescimento de C-S-H e $\mathrm{Ca}(\mathrm{OH})_{2}{ }^{[14,29]}$.

Período de aceleração (III): a hidratação segue com uma intensa liberação de calor e rápida formação de C-S-H e hidróxido de cálcio, com decaimento da concentração de íons $\mathrm{Ca}^{2+}$ na solução. Este período dura de 3 a 12 horas após a mistura do cimento com a água. Ocorre também a dissolução por completo do sulfato de cálcio e redução na concentração dos íons $\mathrm{SO}_{4}{ }^{2+}$ em solução, devido à adsorção dos íons na superfície das partículas de C-S-H e de formação da fase $\mathrm{AFt}^{[29]}$. Neste período a cinética de hidratação é controlada pela velocidade de nucleação e crescimento do C-S-H ${ }^{[14]}$.

O fenômeno da pega é observado no decorrer do período de aceleração, em que os silicatos, sobretudo a alita, passam a se hidratar rapidamente até alcançar a taxa máxima de hidratação, que corresponde ao pico máximo de calor liberado ${ }^{[27]}$.

Período de desaceleração (IV): a taxa de reação diminui progressivamente. Posterior ao decaimento do período de aceleração a hidratação passa a ser controlada pelo mecanismo de difusão iônica ou por reação topoquímica. Neste 
estágio a hidratação da belita torna-se mais importante e a formação do C-S-H e do hidróxido de cálcio ocorre de forma mais lenta. A fase aquosa sofre uma redução dos íons $\mathrm{SO}_{4}{ }^{2-}$, e alguns cimentos que contêm teores de $\mathrm{C}_{3} \mathrm{~A}$ acima de $12 \%$, podem apresentar uma formação diferente da fase AFt, com acentuada diminuição da concentração de íons $\mathrm{SO}_{4}{ }^{2-}$ e $\mathrm{Ca}^{2+}$ na solução, causando um aumento na liberação de calor de hidratação.

Estágio final: no estágio final ocorre a conversão das fases AFt em monossulfoaluminato de cálcio (AFm). A formação de placas hexagonais delgadas de $A F m$, a partir da reação da fase $A F t$ com $\circ C_{3} A$ e $\circ C_{4} A F$, ocorre devido à indisponibilidade de sulfato de cálcio no sistema e o prosseguimento da hidratação do $C_{4} A F$, mais lento do que a hidratação do $C_{3} A^{[14,30]}$.

A reação se completa com o tempo, desde que haja contato com a água, e fim da hidratação é atingido quando os grãos de cimento se hidratarem por completo ou quando não existir mais água para ocorrer reações de hidratação.

A cinética de hidratação sofre influência da composição do clínquer, devido à reatividade diferenciada das fases e a proporção relativa, uma vez que as fases interagem na hidratação inicial do cimento. No entanto, sendo $\mathrm{C}_{3} \mathrm{~A}$ e $\circ \mathrm{C}_{3} \mathrm{~S}$ as fases mais reativas, tem merecido uma atenção maior nos estudos sobre a cinética de hidratação ${ }^{[14,15]}$.

\subsection{Reologia de suspensões}

\subsubsection{Fundamentos de reologia}

A ciência que estuda o fluxo e a deformação dos materiais quando submetidos a uma determinada tensão ou solicitação mecânica externa é chamada 
de Reologia ${ }^{[31]}$. A palavra reologia vem da união dos radicais rheos (fluir) e logos (estudo). Sua aplicação em muitos estudos tem contribuído para o entendimento do comportamento de materiais sobre fluxo, sendo muito utilizada em sistemas coloidais e poliméricos. Segundo Banfill ${ }^{[32]}$, os principais parâmetros para estudo da reologia são: tensão, taxa de cisalhamento e tempo.

O controle reológico e o controle das propriedades que influenciam a natureza reológica do sistema são ferramentas indispensáveis na grande maioria dos processamentos de materiais.

O comportamento reológico dos materiais cimentícios é determinado basicamente por duas grandezas, que são: viscosidade e a tensão de escoamento. Viscosidade é a constante de proporcionalidade que relaciona a tensão de cisalhamento com a taxa de cisalhamento aplicada ao material. Também pode ser considerada uma expressão da resistência de um fluido ao escoamento: logo, quanto maior a viscosidade, mais difícil é o seu escoamento. Por sua vez, a tensão de escoamento é definida como a tensão mínima que precisa ser aplicada a um sistema para que o mesmo possa fluir. Este fenômeno está intrinsecamente ligado às propriedades do material, como as ligações entre as partículas por forças de interação, que podem ser rompidas quando o material é submetido a um cisalhamento.

Deste modo, o comportamento reológico dos materiais é usualmente descrito através de relações matemáticas entre a tensão aplicada e a respectiva taxa de cisalhamento, além de suas variações em relação ao tempo. 


\subsubsection{O conceito de viscosidade}

Para um líquido ser considerado newtoniano ideal a sua deformação total precisa apresentar uma proporcionalidade tanto ao esforço mecânico (tensão) como também ao tempo durante o qual essa solicitação é aplicada.

Newton definiu a viscosidade de um fluido (n), como uma constante de proporcionalidade que relaciona a taxa de cisalhamento $(\dot{\gamma})$ com a tensão de cisalhamento $(\tau)$ aplicada no fluido, de acordo com a equação 1:

$$
\tau=\frac{\mathrm{F}}{a}=\eta \dot{\gamma}
$$

onde:

$\tau=$ tensão de cisalhamento $\left(\mathrm{N} / \mathrm{m}^{2}=\mathrm{Pa}\right)$

$\mathrm{F}=$ Força externa

$a=$ área entre placas

$\dot{\gamma}=$ taxa de cisalhamento $\left(\mathrm{s}^{-1}\right)$

$\eta=$ viscosidade $(P a . s)$

Isaac Newton propôs um modelo composto por duas lâminas paralelas de fluido de área igual a "a", separadas por uma distância infinitesimal "dx", e movidas na mesma direção com velocidades distintas " $V_{1}$ " e " $V_{2}$ ", sob ação de uma força externa "F", como mostrado na Figura 5. Em virtude dessa diferença de velocidade (dv), o volume de fluido entre as lâminas é submetido a um cisalhamento simples, onde a taxa de deformação equivale ao gradiente de velocidade, ao longo da distância "dx", que é conhecida como taxa de cisalhamento $(\dot{\gamma}=d v / d x)$. 
Portanto, os fluidos que obedecem à equação 1 são considerados fluidos newtonianos. Este é o caso de suspensões diluídas e de grande parte dos líquidos puros (água, acetona, álcool, etc.). No entanto, é importante destacar que dependem da temperatura e de forma menos significativa, da pressão ${ }^{[3]}$.

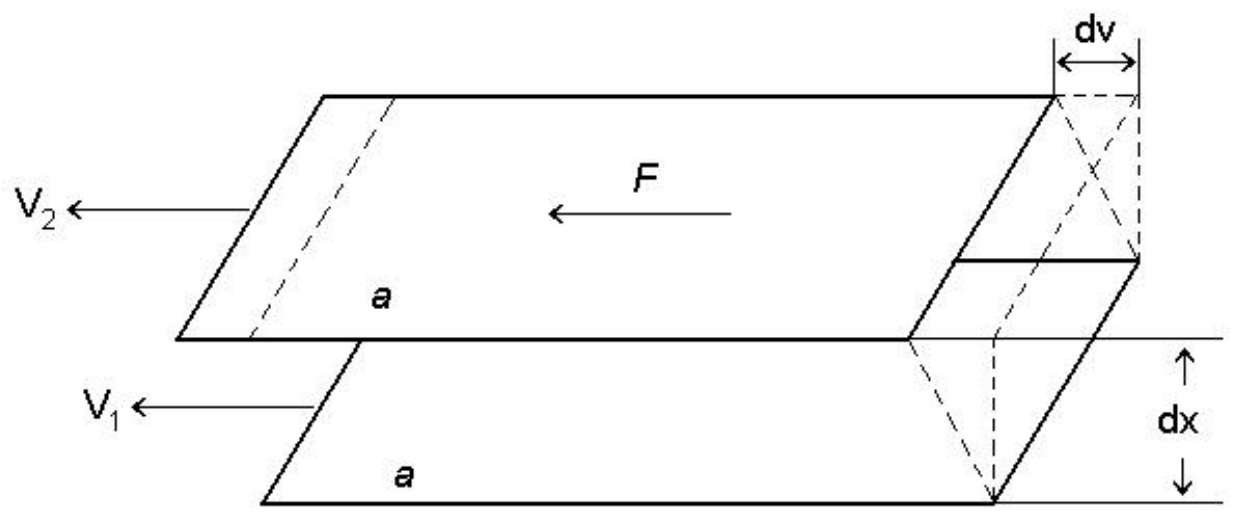

Figura 5 - Modelo de Isaac Newton para definição do conceito de viscosidade ${ }^{[3]}$.

Este modelo não pode ser aplicado em todos os fluidos, pois a grande maioria destes utilizados em processos tecnológicos, em específico as suspensões cerâmicas, não têm uma correlação linear entre a tensão e a taxa de cisalhamento.

\subsubsection{O conceito de tensão de escoamento}

O escoamento só ocorre para certos fluidos e suspensões quando os mesmos são submetidos a uma tensão mínima de cisalhamento. Quando solicitados abaixo desta tensão mínima, tais fluidos comportam-se como sólidos elásticos rígidos. Essa tensão mínima de cisalhamento, denominada tensão de escoamento é decorrente de forças de coesão nas partículas do fluido, formando em toda a suspensão partículas com estrutura espacial rígida ${ }^{[31]}$. A formação desta estrutura só ocorre se a suspensão apresentar uma concentração mínima de sólidos, capaz de aglomerar as partículas por todo o fluido. A tensão mínima para romper essa 
estrutura tridimensional de partículas é considerada a tensão de escoamento da suspensão em questão ${ }^{[33]}$.

Os fluidos com tensão de escoamento mais simples são denominados "fluidos de Bingham" e obedecem à seguinte equação de estado reológico:

$$
\tau=\tau_{0}+n_{p l} \dot{\gamma}
$$

onde:

$\tau_{0}=$ tensão de escoamento de um fluido de Bingham

$\eta_{\mathrm{pl}}=$ viscosidade plástica da suspensão

No entanto, a maioria dos fluidos que apresentam tensão de escoamento e utilizados em processos industriais, são caracterizados por comportamentos reológicos muito mais complexos do que o descrito pela equação de Bingham (equação 2). Por este motivo, outras equações de estado reológico têm sido propostas para descrever o comportamento desses fluidos. Dentre elas, destacamse a equação proposta por Casson ${ }^{[31]}$ :

$$
\tau^{1 / 2}=\tau_{c}{ }^{1 / 2}+\left(n_{c} \dot{\gamma}\right)^{1 / 2}
$$

onde $\tau_{c}$ é a tensão de escoamento de Casson e $\eta_{c}$ é a viscosidade de Casson; e a equação sugerida por Herschel e Bulkley ${ }^{[34]}$ :

$$
\tau=\tau_{y}+k(\dot{\gamma})^{p}
$$

onde $\tau_{y}$ é a tensão de escoamento de Herschel-Bulkley, $k$ uma constante, e p um índice de consistência do fluido obtido a partir do ajuste dos dados experimentais de $\tau$ e $\dot{\gamma}^{[3]}$. 
Uma pasta de cimento usual apresenta comportamento próximo a um fluido de Bingham, podendo também apresentar um comportamento desde um fluido newtoniano viscoso até um sólido pseudoplástico. Esse comportamento reológico depende da composição química, do procedimento de ensaio e das alterações promovidas pela incorporação de outros elementos à pasta de cimento ${ }^{[35]}$.

\subsubsection{Comportamento reológico de suspensões}

O modelo proposto por Newton expressa o comportamento de fluidos newtonianos. No entanto, para fluidos com adição de partículas formando uma suspensão, não se pode usar este modelo, pois as partículas sólidas e insolúveis se posicionarão entre os planos de escoamento do fluido, afetando a resistência que o fluido oferece ao escoamento, com alteração na viscosidade do sistema. Logo, podemos observar outros comportamentos, denominados de não-newtonianos, os quais apresentam uma viscosidade dependente da taxa de cisalhamento. Portanto, a viscosidade medida deixa de ser o coeficiente angular de uma relação linear entre tensão e taxa de cisalhamento, para se tornar uma propriedade dependente das condições a que o fluido é submetido, e é chamada de "viscosidade aparente" $\left(\eta_{\mathrm{ap}}=\tau / \dot{\gamma}\right)$. Estes comportamentos podem ser divididos em dois grupos principais:

a. Comportamentos que não dependem do tempo, e que além de destacar o comportamento Newtoniano, podem apresentar os comportamentos Pseudoplástico e Dilatante. Como mostrado na Figura 6;

b. Comportamentos que dependem do tempo destacando os comportamentos Tixotrópicos e Reopéxicos. 


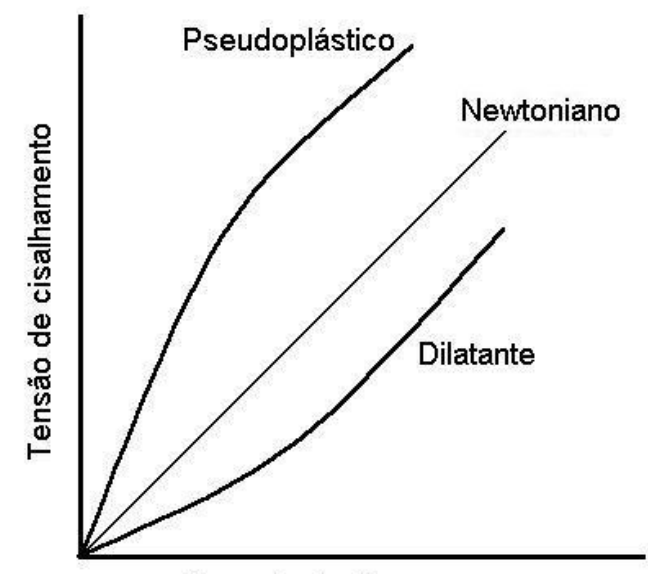

Taxa de cisalhamento

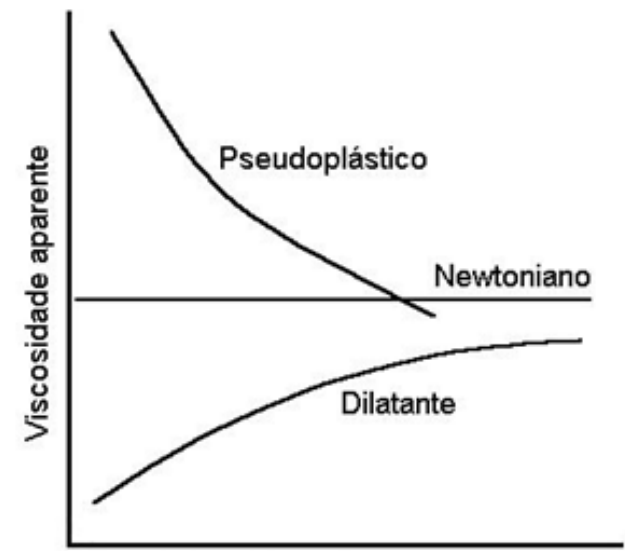

Taxa de cisalhamento

Figura 6 - Comportamento básico de fluidos ${ }^{[36]}$.

Um breve resumo das características dos comportamentos reológicos será descrito em seguida:

Pseudoplasticidade - Este comportamento exibirá um fluido com a viscosidade aparente decrescente com o aumento da taxa de cisalhamento. Dentre os fatores relevantes para a ocorrência deste comportamento estão: área superficial, formato e dimensão das partículas; tipo de interação entre as partículas (atração ou repulsão); massa molecular, concentração e conformação de moléculas de dispersante contidas no meio líquido. Os fluidos pseudoplásticos normalmente são considerados os fluidos não-newtonianos mais comuns, podendo ser citados as tintas, emulsões e diversos tipos de dispersões ${ }^{[3]}$.

Dilatância - Neste comportamento o fluido apresentará um aumento da viscosidade aparente à medida que se eleva a taxa de cisalhamento aplicada, e ocorre em fluidos contendo alta concentração de sólidos aglomerados, onde as partículas se encontram bem empacotadas e próximas entre si, em compostos cristalizados, 
misturas de areia e água e barbotinas de argilas. Neste último caso, há também uma forte dependência do $\mathrm{pH}$, sendo que as partículas de argila apresentam diferentes cargas elétricas nas diferentes faces para determinados $\mathrm{pH}$. O sistema como um todo tende a atingir o equilíbrio entre as cargas, ou seja, uma situação de mínima energia ${ }^{[3]}$.

Tixotropia - Este fenômeno consiste na diminuição da viscosidade aparente em função do tempo em suspensões submetidas a uma taxa ou tensão de cisalhamento constante, sendo observado em suspensões que apresentam aglomerados fracos de partículas. O comportamento tixotrópico tem origem quando tais suspensões são mantidas a baixas taxas de cisalhamento por um longo período e, em seguida, são submetidas a taxas superiores em intervalo relativamente curto de tempo. Quando uma taxa de cisalhamento fixa e superior é aplicada, a destruição dos aglomerados e a redução da viscosidade aparente são favorecidas. Porém, este processo acontece de forma lenta e necessita de certo intervalo de tempo para se proceder ${ }^{[3]}$.

Reopexia - Este fenômeno consiste no aumento da viscosidade aparente em função do tempo em suspensões submetidas a uma taxa ou tensão de cisalhamento constante. A reopexia pode ser considerada um fenômeno inverso da tixotropia, e, por isso, é geralmente observada em suspensões que apresentam partículas assimétricas ou aglomerados fracos. O fenômeno ocorre quando tais suspensões são primeiramente mantidas em elevada taxa de cisalhamento por um longo intervalo de tempo, e em seguida, submetida a baixas taxas por um intervalo de tempo relativamente curto. Podendo ser observado, que uma parcela das partículas da suspensão, submetida à baixa taxa de cisalhamento se une gradativamente, 
formando novos aglomerados, que aumentam a viscosidade aparente da suspensão em função do tempo ${ }^{[3]}$.

\subsubsection{Parâmetros que influenciam o comportamento reológico de uma suspensão}

O comportamento reológico das suspensões apresenta alta complexidade para interpretação e entendimento, quando estudada a atuação simultânea e sinérgica dos diversos parâmetros que podem influenciar o sistema como um todo. Estes fatores são descritos a seguir, cabendo ao pesquisador uma avaliação minuciosa da influência de cada um deles, para atingir às exigências requisitadas nos mais diversos tipos de processamento de materias.

Dentre os principais fatores que afetam o comportamento reológico das suspensões, podemos destacar ${ }^{[3]}$ :

- Características físicas do meio de dispersão (viscosidade, densidade, etc.);

- Concentração volumétrica de sólidos em suspensão;

- Características físicas das partículas (área superficial específica, distribuição granulométrica, densidade, forma, etc.);

- Peso molecular, conformação espacial e estrutura química da molécula de aditivos como dispersantes;

- Concentração de moléculas de dispersante no meio líquido;

- Magnitude de interação entre as partículas (indicativo da eficiência do mecanismo de estabilização empregado);

- Temperatura; 
- $\mathrm{pH}$ (em sistemas aquosos).

O comportamento reológico do fluido pode ser controlado por um ou mais destes fatores, dependendo das propriedades de cada suspensão e da amplitude da taxa de cisalhamento aplicada no sistema.

\subsection{Suspensões não reativas}

\subsubsection{Interações de cargas superficiais}

Geralmente os materiais com dimensões menores que $100 \mu \mathrm{m}$, apresentam um predomínio das forças de superfície em relação às forças mássicas, devido à sua elevada área superficial específica, a qual controla a forma de interação das partículas e, por consequência, seu comportamento reológico. Portanto, se as cargas atrativas forem superiores às repulsivas, a aglomeração poderá ocorrer de forma natural ${ }^{[3]}$.

As principais forças superficiais existentes entre as partículas são: a força de van der Waals e as forças eletrostáticas, além de outras forças, como capilaridade, solvatação e adsorção de água ${ }^{[37]}$.

A força de van der Waals é originada pela interação entre os dipolos elétricos, permanentes ou induzidos, situados no interior das partículas, sendo inversamente proporcional à distância ${ }^{[38]}$.

O surgimento das forças eletrostáticas é decorrente do desequilíbrio das cargas elétricas na superfície das partículas, devido às ligações insaturadas na estrutura que, em suspensão aquosa, podem atrair outras partículas ou íons de sinais opostos, ou repelirem as de mesmo sinal ${ }^{[37]}$. 
Para Callister ${ }^{[39]}$, a origem dessas cargas pode ser explicada a partir da definição de um cristal, sendo este um sólido com seus átomos arranjados de maneira organizada formando um reticulado periódico tridimensional. Um cristal ideal é aquele que possibilita a preservação da neutralidade elétrica, a minimização da repulsão existente entre os íons, além de permitir um agrupamento e um arranjo espacial mais compacto, ou seja, um arranjo atômico que minimize a energia livre por unidade de volume. No entanto, a superfície dos cristais é um defeito cristalino, responsável pelos distúrbios na estrutura, levando a um excesso de energia por unidade de área. Esta energia está relacionada diretamente à presença de ligações insaturadas. Portanto, quando partículas de óxidos entram em contato com a água, ocorre a hidroxilação ou hidratação superficial ${ }^{[3]}$.

No caso dos óxidos o mecanismo que dá origem a cargas na superfície é decorrente da reação de grupos $(-\mathrm{OH})$ superficiais com íons hidroxônio $\left(\mathrm{H}_{3} \mathrm{O}^{+}\right)$e hidroxila $\left(\mathrm{OH}^{-}\right)$. Sendo ele dependente do $\mathrm{pH}$ da suspensão, ou seja, em pH ácido do meio aquoso, predomina a reação com os íons hidroxônio e a carga da partícula é positiva; em pH básico do meio aquoso, há a preponderância da reação da superfície com os íons hidroxila, e a carga superficial da partícula ou o potencial elétrico é negativo. O surgimento de cargas elétricas na superfície das partículas gera um potencial elétrico $\left(\Psi_{0}\right)$, que atrai uma grande quantidade de íons de carga contrária (contra-íons) presentes na solução ao seu redor. A dimensão finita desses íons limita a quantidade dos mesmos que conseguem se aproximar por atração eletrostática. No caso de íons serem adsorvidos especificamente na superfície da partícula forma-se uma camada rígida de íons, denominada Camada de Stern ${ }^{[3,40]}$; apresenta potencial $\left(\Psi_{\delta}\right)$, e cargas próprias que podem ser de mesmo sinal ou de sinal contrário ao potencial de superfície e de magnitude também maior ou menor 
que o potencial de superfície, $\left(\psi_{0}\right)$. Entretanto, eles modificam linearmente 0 potencial elétrico de superfície $\left(\psi_{0}\right)$ para o denominado potencial de Stern $\left(\psi_{\delta}\right)$. Os contra-íons são limitados pela adsorção, não sendo capazes de neutralizar totalmente a carga da superfície da partícula como apresentado na Figura 7.

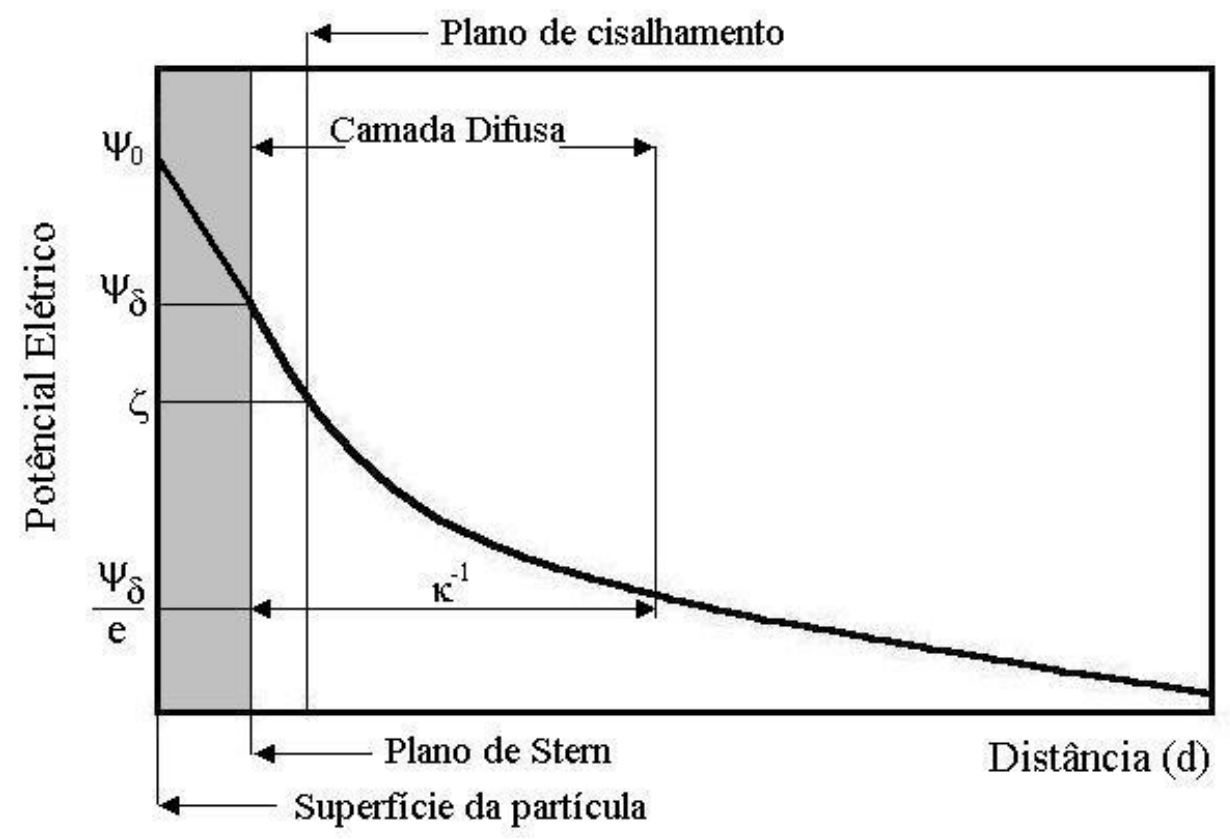

Figura 7 - Queda do potencial elétrico de superfície $\psi_{0}$ em função da distância no interior das camadas de Stern e difusa que circundam a partícula ${ }^{[3]}$.

Devido à limitação espacial, estas cargas de sinais opostos não conseguem neutralizar totalmente a carga da superfície da partícula. Assim, outros íons são atraídos, mas com menor intensidade, pois, como possuem a mesma carga que a camada Stern, sofrem repulsão, dando origem a uma nova camada (Figura 8) denominada Camada Difusa ${ }^{[3,40]}$, com espessura equivalente ao inverso do parâmetro $\kappa$ ou seja $\kappa^{-1}$ ( $\kappa$ é a constante de Boltzmann $\left(1,38 \times 10^{-23} \mathrm{~J}^{-1} \mathrm{~K}^{-1}\right)$ ). 


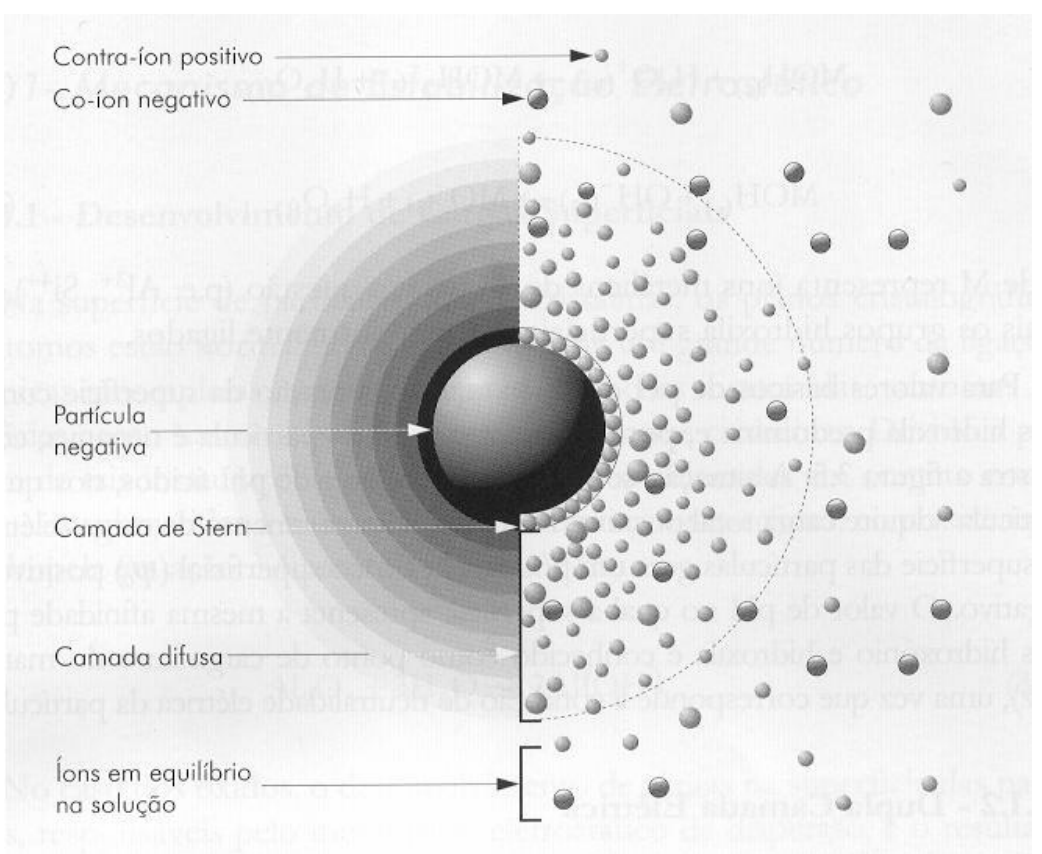

Figura 8 - Arranjo espacial dos íons que constituem a dupla camada elétrica de uma partícula carregada em um meio líquido ${ }^{[3]}$.

A concentração de contra-íons fracamente ligados às partículas, devido à influência repulsiva dos contra-íons já adsorvidos na camada de Stern diminui, enquanto que a concentração de co-íons (íons de mesma carga que a partícula) aumenta gradualmente com a distância, promovendo uma queda exponencial do potencial elétrico até a condição de neutralidade do meio líquido.

A região de desequilíbrio de cargas na interface partícula/líquido que engloba a camada superficial de cargas adsorvidas na superfície da partícula (1. aㅡ camada), na camada de Stern e a difusa (como 2. ${ }^{a}$ camada) é conhecida como Dupla Camada Elétrica. Assim, as partículas passam a se comportarem como unidades que se deslocam juntamente (partícula + nuvem iônica envolta) durante o fluxo da suspensão e, como unidades de fluxo de dimensões superiores, cujo raio é definido como o raio hidrodinâmico da partícula ${ }^{[3]}$.

O potencial elétrico na superfície das partículas não pode ser aferido precisamente, portanto a forma mais coerente de avaliar a energia de repulsão entre 
as partículas é a partir de experimentos baseados na mobilidade eletroforética das partículas (velocidade com que as partículas coloidais se movimentam sob aplicação de um potencial elétrico). Estes experimentos são capazes de medir o potencial próximo ao plano de Stern (no plano de cisalhamento - Figura 7 - onde ocorre o cisalhamento quando uma partícula se movimenta no líquido ${ }^{[1,2]}$, este potencial é denominado Potencial Zeta $(\zeta)^{[36]}$.

Através do potencial Zeta é possível determinar o estado de aglomeração da suspensão. Portanto, em um sistema onde todas as partículas apresentam cargas iguais, pode-se afirmar que, quanto maior o potencial Zeta, positivo ou negativo, maior a estabilidade da suspensão, superando a tendência natural de aglomeração $^{[37]}$.

Na década de 40, Derjaguin e Landau ${ }^{[41]}$, e Verwey e Overbeek ${ }^{[42]}$, estudaram a interação das forças atuantes entre as duplas camadas elétricas de partículas em suspensão. Nestes estudos eles denominaram o modelo como "Teoria da Estabilidade de Colóides Liofóbicos" também conhecida como teoria DLVO.

Basicamente, esta teoria indica o estado de dispersão de um sistema de partículas carregadas eletricamente em um líquido pela energia potencial total do sistema $\left(\cup_{T}\right)$, que é dada pela soma das energias potenciais de atração $\left(U_{A}\right)$ e de repulsão $\left(U_{R}\right)$.

A energia potencial de atração entre duas partículas esféricas de mesmo raio e material está associada à força de van der Waals e obedece à seguinte equação $^{[43]}$ :

$$
\mathrm{U}_{\mathrm{A}}=-\frac{\mathrm{Ar}}{12 \mathrm{D}}
$$


onde A é a constante de Hamaker (característica do material), r é o raio da partícula e D a distância de separação entre as superfícies das partículas.

Derjaguin $^{[44]}$, estimou a energia potencial de repulsão integrando em função da distância, a força de repulsão originada pela superposição das duplas camadas elétricas $\left(-\int F_{R} d D\right)$, que, para o caso de partículas esféricas e baixos valores do potencial de Stern, pode ser expressa como:

$$
\mathrm{U}_{\mathrm{R}}=\frac{r \varepsilon \Psi_{\delta}^{2}}{2} \ln [1+\exp (-\mathrm{KD})]
$$

onde $\varepsilon$ é a permissividade dielétrica do meio, $\Psi_{\bar{\delta}}$ é o potencial de Stern e K é denominado parâmetro de Debye-Hückel dado pela equação (7):

$$
\mathrm{K}=\left[\frac{e^{2} \sum_{i} z_{i}^{2} n_{i 0}}{\varepsilon_{0} \varepsilon_{r} \kappa T}\right]^{\frac{1}{2}}
$$

onde $\varepsilon_{0}$ é a permissividade dielétrica do vácuo, $\varepsilon_{\mathrm{r}}$ é a constante dielétrica do material, $\mathrm{z}_{\mathrm{i}}$ é a valência do íon i, e é a carga do elétron $\left(1,6 \times 10^{-19} \mathrm{C}\right), \kappa$ é a constante de Boltzmann $\left(1,38 \times 10^{-23} \mathrm{~J}^{-1}\right)$, T a temperatura absoluta e $n_{i 0}$ é o número de íons do tipo i por unidade de volume distante do plano de Stern. De acordo com a teoria Debye-Hückel, a espessura da camada difusa equivale ao inverso do parâmetro $\kappa$ ou seja $\kappa^{-1}[3,36]$.

Portanto, com a combinação das equações (5), (6) e (7), é possível determinar a energia potencial do sistema que é $U_{T}=U_{A}+U_{R}$ dada pela equação (8):

$$
\mathrm{U}_{\mathrm{T}}=-\frac{A r}{12 D}+\frac{r \varepsilon \Psi_{\delta}^{2}}{2} \ln \left\{1+\exp \left(-\left[\frac{e^{2} \sum_{i} z_{i}^{2} n_{i 0}}{\varepsilon_{0} \varepsilon_{r} \mathrm{~K} T}\right]^{\frac{1}{2}} \mathrm{D}\right)\right\} \quad \text { (Equação 8) }
$$

Para se obter uma suspensão dispersa, as forças repulsivas devem exceder as forças atrativas, considerando que essas forças dependem principalmente da 
formação de cargas na superfície. No caso de não haver forças de repulsão suficiente, o uso de dispersantes torna-se indispensável, pois os mesmos têm a função de promover a desaglomeração das partículas e uma boa dispersão da suspensão. Vale ressaltar que uma dispersão estável de partículas desaglomeradas pode ser obtida, onde a natureza e a quantidade ótimas de dispersante podem ser determinadas através de uma curva de adsorção ou em função da viscosidade, onde três mecanismos principais podem gerar forças de repulsão entre as partículas: efeito eletrostático, efeito estérico e efeito eletroestérico ${ }^{[3]}$.

\subsubsection{Mecanismos de estabilização de suspensões}

Os mecanismos normalmente utilizados para estabilização de suspensões são:

a) Eletrostático: a estabilização eletrostática ocorre devido à formação em um solvente polar, de uma dupla camada elétrica em torno de cada partícula. O controle da estabilização se dá pelo potencial de superfície das partículas e pela espessura da dupla camada formada pelos contra-íons (íons que apresentam cargas opostas àquela da superfície).

A Figura 9 ilustra uma situação em que a componente $U_{R}$ está presente, favorecendo o surgimento no sistema de uma energia de interação total que apresenta uma barreira energética repulsiva contra a aglomeração das partículas, mantendo as mesmas adequadamente dispersas. 


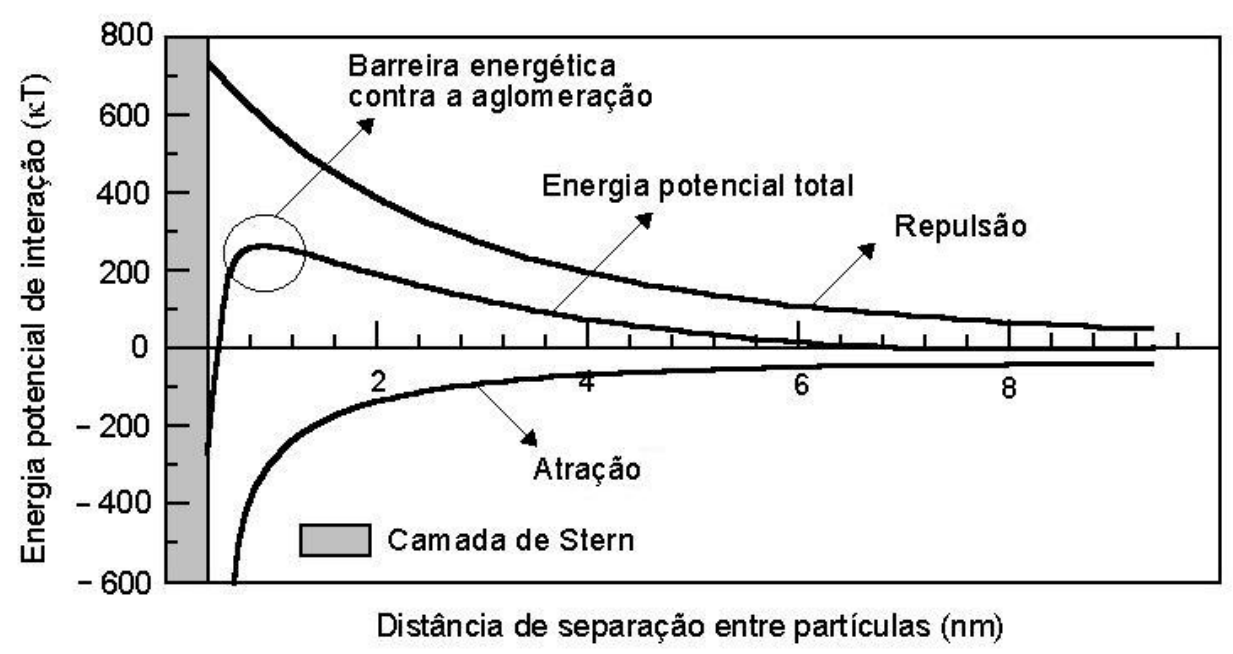

Figura 9 - Energias potenciais de interação atrativa, repulsiva e total em função da distância de separação entre as partículas, de acordo com a teoria DLVO para o mecanismo de estabilização eletrostático ${ }^{[3]}$.

b) Estérico: a estabilização estérica é obtida pela adsorção à superfície da partícula de um polímero neutro com cadeia molecular longa, o bastante para criar uma barreira física (Figura 10), impedindo que as partículas cheguem à distância de atuação das forças de van der Waals. Este polímero deve ter afinidade com a partícula, ou com algum de seus sítios, e também com o solvente, a fim de adsorver sobre toda superfície. A afinidade com o líquido contribui na conformação das cadeias poliméricas, tornando o mecanismo mais eficiente. Por esta razão, são utilizados co-polímeros onde segmentos insolúveis que apresentam afinidade com a partícula são combinados com unidades estabilizadoras solúveis no fluido ${ }^{[3]}$. 


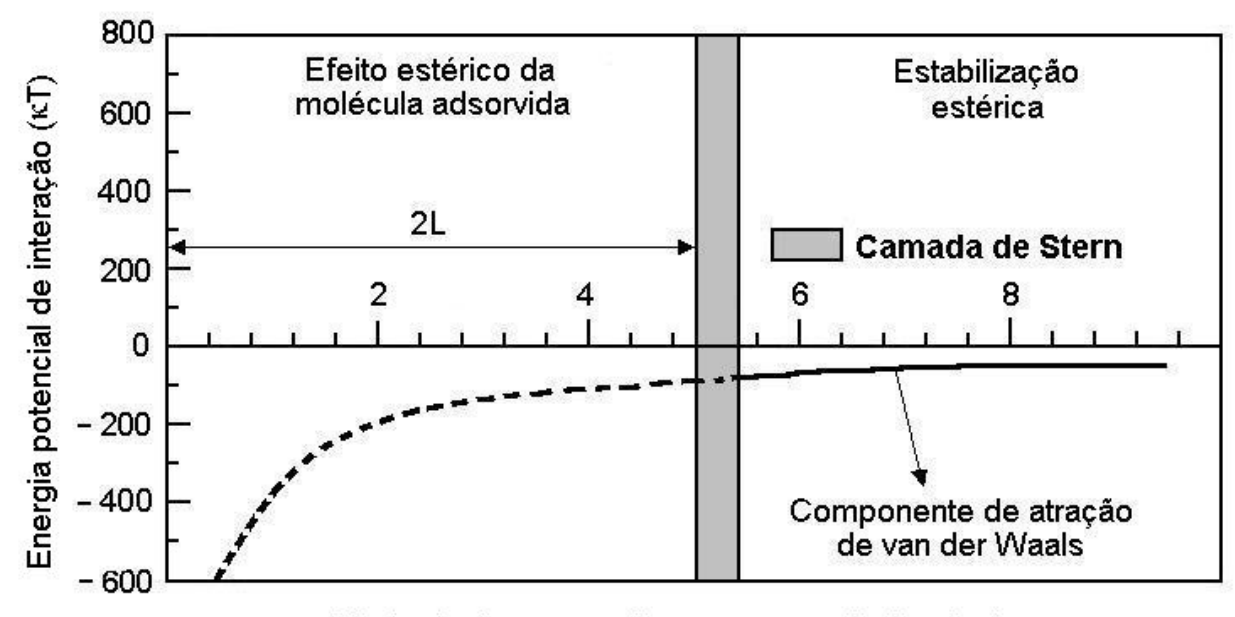

Distância de separação entre as partículas (nm)

Figura 10 - Efeito do mecanismo estérico de estabilização, onde L é a espessura da camada de moléculas poliméricas adsorvidas nas partículas, neste exemplo, $2,5 \mathrm{~nm}^{[3]}$.

c) Eletroestérico: este mecanismo ocorre na associação dos dois mecanismos citados acima (eletrostático e estérico). A estabilização eletroestérica é obtida pela adsorção de moléculas com grupos ionizáveis, como citratos, fosfatos, sulfatos ou moléculas poliméricas, como poliacrilatos e polimetacrilatos também conhecidos genericamente de polieletrólitos, à superfície das partículas. Os grupos ionizáveis se dissociam na solução e os íons somam à barreira física, o efeito eletrostático, resultando no aumento do potencial de repulsão devido aos grupos ionizáveis e ao potencial Zeta da barreira física, como mostrado na Figura 11.

Nestes casos o comportamento é influenciado, também, pela concentração de moléculas de dispersante no meio líquido, pela massa molecular e conformação espacial da molécula de dispersante, assim como a espessura da camada de moléculas adsorvidas na superfície das partículas. 


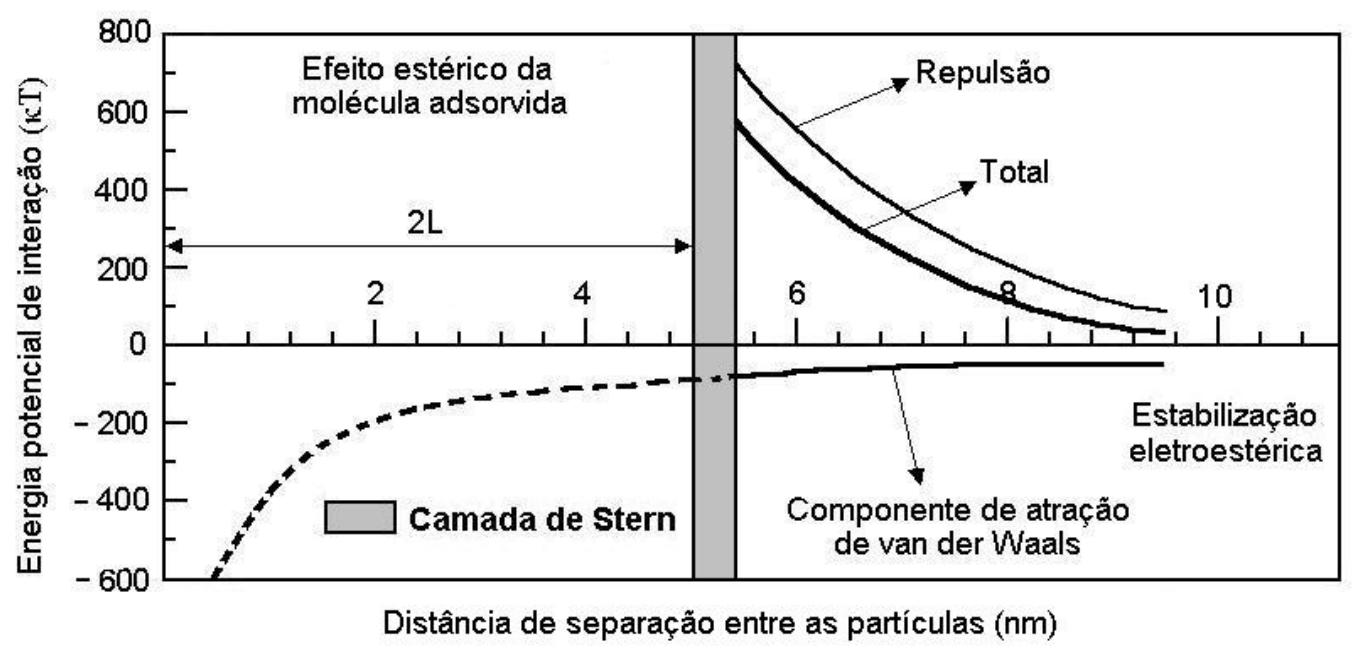

Figura 11 - Efeito do mecanismo eletroestérico, onde L é a espessura da camada de moléculas poliméricas adsorvidas nas partículas, neste exemplo, $2,5 \mathrm{~nm}^{[3]}$.

\subsubsection{Efeito da adsorção nas propriedades das suspensões}

A adsorção específica de uma espécie provoca uma mudança na distribuição de carga superficial originalmente presente na partícula, alterando o perfil de decaimento do potencial elétrico em função da distância relativa à superfície. Quando ocorre a adsorção de uma molécula eletricamente carregada sobre uma partícula, há uma alteração na sua distribuição superficial de cargas, devido à somatória das cargas gerada pela reação da superfície da partícula com o meio e a carga elétrica associada à molécula adsorvida. Podemos citar como exemplo os polieletrólitos, eficientes em suspensões cerâmicas, devido ao mecanismo de adsorção de uma camada polimérica sobre as partículas. A presença de uma camada polimérica com grupos ionizáveis revestindo as partículas faz com que os íons presentes em solução deixem de ser influenciados pelo potencial elétrico de superfície $\left(\psi_{0}\right)$ e passem a ser governados pelo potencial elétrico resultante do recobrimento superficial da partícula. Desse modo, verifica-se um deslocamento, na 
direção do meio líquido, do plano interno da camada de Stern (plano de carga), de uma distância equivalente à espessura da camada polimérica adsorvida ${ }^{[45]}$.

A adsorção específica de dispersantes contendo grupos carboxílicos na interface óxido/líquido é ocasionada pela substituição (reação de coordenação) de íons hidroxila $\left(-\mathrm{OH}^{-}\right)$ou grupos $-\mathrm{OH}_{2}{ }^{+}$presentes na superfície das partículas do óxido pelos íons carboxilato $\left(-\mathrm{COO}^{-}\right)$da molécula do dispersante. Assume-se que a substituição de grupos superficiais $-\mathrm{OH}_{2}{ }^{+}$se dê de forma preferencial e que a afinidade dos polieletrólitos aniônicos por partículas apresentando grupos superficiais carregados positivamente seja maior; porém não podemos dizer que esta afinidade seja nula para partículas apresentando grupos superficiais carregados negativamente. Assim, pode-se afirmar que o pH é um fator muito importante no mecanismo de estabilização eletroestérica, pois o mesmo afeta a distribuição de cargas superficiais e a dissociação dos polieletrólitos ${ }^{[3,36]}$.

Conforme ilustrado na Figura 12, a eficiência de adsorção do polieletrólito varia em função do pH do meio. Quando as cargas da cadeia polimérica neutralizam as cargas superficiais, surge um potencial nulo denominado de ponto isoelétrico (pie) do sistema partícula/adsorvente num determinado $\mathrm{pH}(\mathrm{pH}=$ pie). Para um pH > pie, ocorre geração de potencial negativo devido a cargas da molécula adsorvida, porém devido às interações eletrostáticas entre as cargas elétricas da superfície da partícula e da molécula determinante de potencial, a adsorção não ocorre com a mesma afinidade para toda a extensão de $\mathrm{pH}$. Para o caso de moléculas carregadas negativamente, a adsorção é de alta afinidade em pH inferiores ao ponto de carga zero $(\mathrm{pcz}=\mathrm{pie})$, do material $(\mathrm{pH}<\mathrm{pcz})^{[3]}$. 


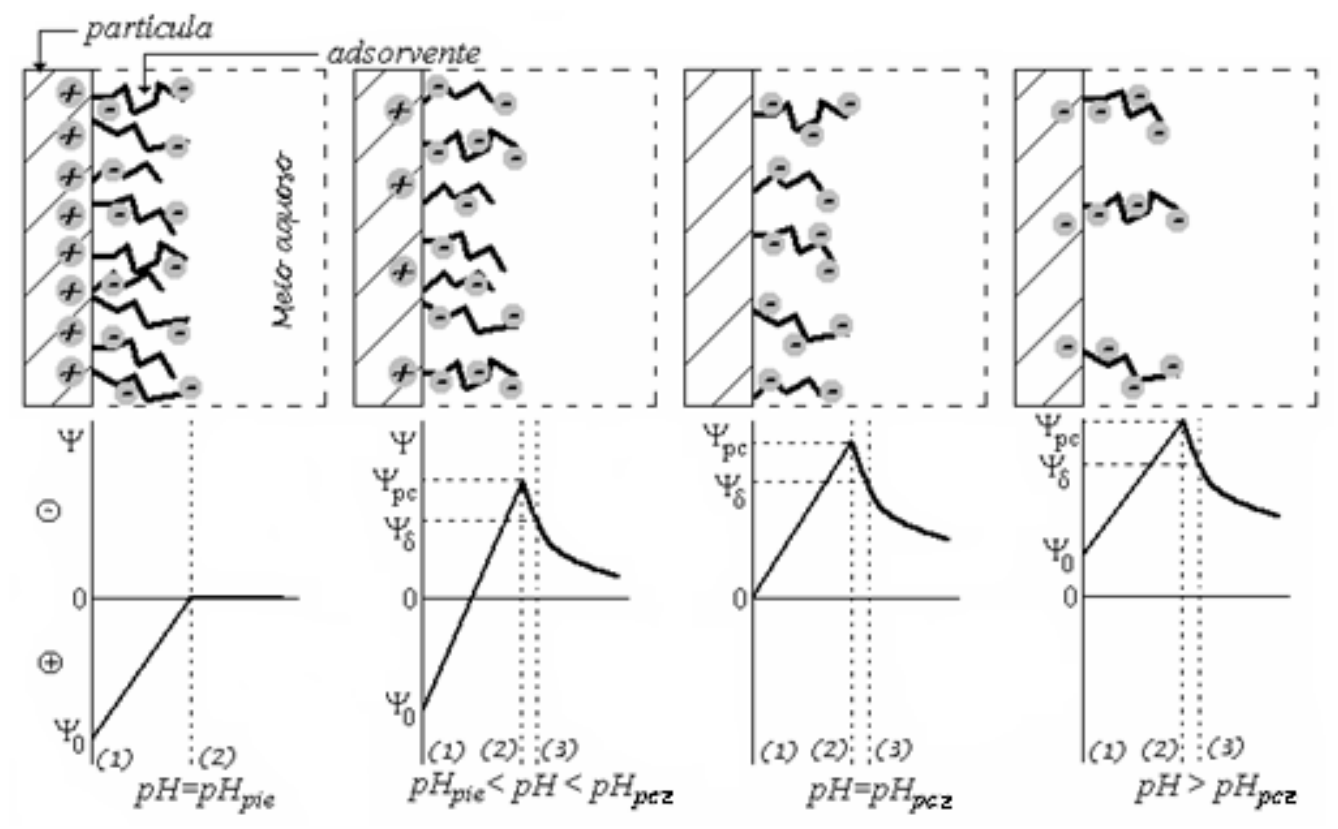

Figura 12 - Efeito da adsorção de moléculas determinantes de potencial na superfície da partícula sobre a queda de potencial na dupla camada elétrica em diferentes condições de pH (adaptado da referência [45], onde (1) = plano de superfície; (2) = plano de carga; (3) = plano de Stern; e $\Psi_{0}, \Psi_{\mathrm{pc}}, \Psi_{\delta}$ correspondem ao potencial elétrico nos planos (1), (2) e (3), respectivamente).

Vale ressaltar, que o fato da afinidade de adsorção ser baixa, não indica que as moléculas não adsorvem, promovendo um baixo grau de estabilidade da dispersão. Portanto outros fatores como o balanço entre contribuições estéricas e eletrostáticas devem sempre ser considerados.

\subsection{Dispersão de suspensões reativas}

\subsubsection{Dispersantes das suspensões cimentícias}

Os dispersantes, no caso deste trabalho o policarboxilato éter, são conhecidos como superplastificantes ou redutores de água de alta eficiência. Quando incorporados aos concretos em pequenas quantidades, durante o processo de mistura, modificam as propriedades no estado fresco ou endurecido ${ }^{[12,15]} \mathrm{Na}$ 
maioria das vezes a quantidade de aditivo é limitada a teores em torno de $0,5 \%$ da massa do cimento, podendo ser aumentado quando usado em certos tipos de concreto, como por exemplo, o concreto de alto desempenho ${ }^{[46]}$.

O uso de aditivos superplastificantes é considerado um dos mais importantes avanços na tecnologia de materiais cimentícios, proporcionando a estes durabilidade, alta resistência e adequada fluidez. Esta inovação veio através da indústria química, que tem desenvolvido novas aplicações específicas ou melhorando o proporcionamento de materiais para o concreto ${ }^{[47,48]}$.

Esses aditivos são comumente usados em todo o mundo com as seguintes finalidades:

- Reduzir o consumo de água para uma mesma consistência, aumentando assim a resistência e a durabilidade do concreto;

- Aumentar a fluidez da mistura sem alterar o consumo de água;

- Reduzir a quantidade de cimento da mistura, mantendo a consistência e a resistência à compressão com o objetivo de reduzir custos e ainda reduzir a retração, fluência e tensões térmicas ${ }^{[12,14,15]}$.

Rixom ${ }^{[48]}$, apresenta casos típicos de utilização de aditivos que causaram impactos na indústria do concreto, podendo ser citado a redução do esforço humano, com melhor manuseio, lançamento e acabamento dos concretos utilizados, resultando em economia. Outras descrições de aplicações de superplastificantes podem ser encontradas em Malhotra ${ }^{[49]}$.

\subsubsection{Tipos de aditivos dispersantes}

Os superplastificantes são polímeros solúveis em água, obtidos como subprodutos da indústria ou sinteticamente, por polimerização ${ }^{[12,50]}$. Na grande 
maioria são aniônicos com elevado número de grupos funcionais na cadeia de hidrocarboneto, formando longas moléculas que se adsorvem sobre as partículas de cimento e que, devido a fenômenos físico-químicos, como as forças de van der Waals, promovem a dispersão ${ }^{[51]}$. Assim, partículas de cimento com cargas opostas, que tendem a atrair-se, podem se repelir resultando numa hidratação mais rápida ou mais lenta do cimento e alterando tempos de pega iniciais e finais.

Os aditivos superplastificantes podem ser divididos em três grandes grupos de aditivos e descritos segundo três gerações: os condensados de lignossulfonados modificados, ácidos hidroxi-carboxílicos e polímeros hidroxilatos, ou aditivos de primeira geração, os condensados sulfonados de melamina-formaldeídos, condensados sulfonados de naftaleno-formaldeídos e os poliacrilatos, ou aditivos de segunda geração e os éteres, base policarboxilato, aditivos de terceira geração ${ }^{[13]}$.

1) Lignossulfonato ou aditivo de primeira geração

Os aditivos base lignossulfonato são utilizados como redutores de água e em alguns casos também como superplastificantes. São obtidos a partir do rejeito líquido do processo de extração da celulose da madeira, um subproduto que contém uma mistura complexa de produtos da lignina entre $20 \%$ a $30 \%$, produtos da decomposição da celulose, carboidratos e ácidos sulfurosos livres ou sulfatos ${ }^{[12]}$.

A obtenção desses aditivos é relativamente simples, sendo algumas vezes processados por fracionamento, para aumentar a massa molecular média. Suas composições podem variar em função do processo de fabricação, caso ocorra neutralização, precipitação ou fermentação ${ }^{[12]}$. Um parâmetro importante é a massa molecular do aditivo, está é como um índice da eficiência do aditivo na dispersão das partículas de cimento, sendo atualmente produzidos aditivos com cadeias mais 
longas e de maior massa molecular ${ }^{[6]}$. A estrutura molecular de um lignossulfonato é apresentada na Figura 13.

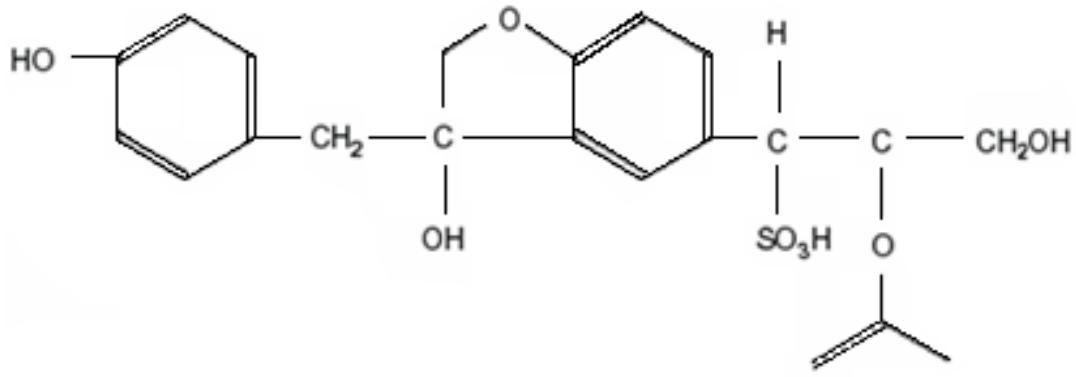

Figura 13 - Monômero de um lignossulfonato ${ }^{[12]}$.

O uso destes aditivos promove o retardo de pega, causado pelos altos teores de açúcares na sua composição - a lignina, o que pode gerar problemas como atrasos no endurecimento do concreto, além de incorporação indesejável de ar à mistura. Alguns fabricantes, submetem estes subprodutos industriais a processos de purificação mais refinados para remoção dos açúcares, por meio de ultra filtragens, tratamentos térmicos com $\mathrm{pH}$ controlado e fermentação, reduzindo os efeitos secundários e obtendo aditivos que não influenciam o tempo de pega e nem provocam incorporação de ar, porém torna-se um produto mais caro ${ }^{[13]}$. $\mathrm{O}$ uso deste aditivo permite uma redução da água da mistura entre 8 e 12\%, podendo alcançar uma eficiência de 15\%, segundo alguns fabricantes. Quando utilizados em altas dosagens, no extremo destes intervalos, podem causar excessivo retardo da pega e incorporação de grande quantidade de ar no concreto fresco, sendo por isso não indicado o seu uso sem certificação experimental da dosagem ${ }^{[12]}$.

2) Naftaleno Sulfonato ou aditivo de segunda geração

O naftaleno sulfonato foi uma das primeiras substâncias químicas a serem referenciadas na literatura técnica como um agente de redução de água nas 
misturas de concreto. No entanto, somente na década de 1970 ela foi empregada com exclusividade para a produção de aditivos superplastificantes ${ }^{[52]}$.

Estes aditivos à base de naftaleno são produzidos a partir da sulfonação e conseqüente polimerização dos semi-produtos. A descrição do processo genérico de produção dos aditivos à base de naftaleno pode ser encontrada em Rixom e Mailvaganam ${ }^{[12]}$, e algumas etapas também podem ser encontradas em Aïtcin ${ }^{[13]}$. Os mecanismos de ação foram descritos por Dezhen et al. ${ }^{[53]}$. A Figura 14 apresenta a estrutura molecular do aditivo base naftaleno ${ }^{[12,47,54]}$.

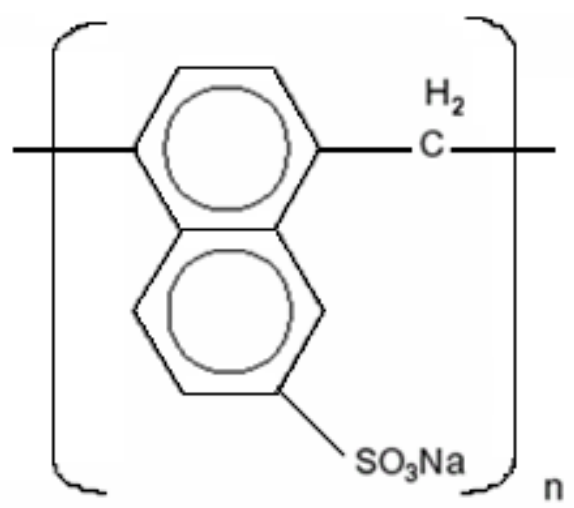

Figura 14 - Monômero de um poli-naftaleno sulfonato de sódio linear.

Esse aditivo, assim como os aditivos base melamina sulfonato e os poliacrilatos, são conhecidos comercialmente como aditivos de segunda geração e permitem a redução em até $25 \%$ da quantidade de água da mistura, se usados como redutores de água ${ }^{[13,55]}$.

3) Policarboxilatos ou aditivo de terceira geração

Os aditivos superplastificantes à base de policarboxilatos foram introduzidos recentemente no mercado nacional, disponíveis no mercado desde a década de 1990. Eles são também conhecidos como aditivos superplastificantes de alta eficiência ou ainda, como aditivos hiperplastificantes, pois promovem uma redução de água das misturas de aproximadamente $40 \%{ }^{[13,15]}$. 
Os policarboxilatos conferem considerável aumento na fluidez dos concretos, o que permite a utilização em concretos auto-adensáveis e redução da quantidade de água, resultando em concretos de elevada resistência, trabalhabilidade e durabilidade ${ }^{[13,56]}$. Esses aditivos poliméricos apresentam larga distribuição de massa molecular e sua caracterização química é muito complexa, assim como seu processo de produção. As propriedades desses aditivos são influenciadas, principalmente pelo comprimento de sua cadeia e pela quantidade de repetições dos meros, representados por a, b, c e d. Como pode ser observado na Figura 15.

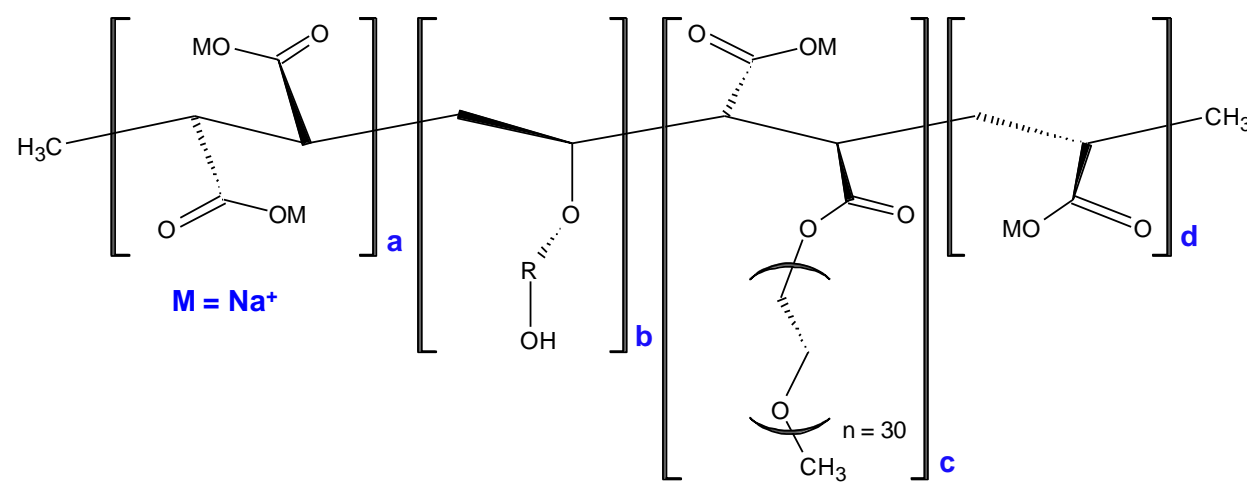

Figura 15 - Policarboxilato éter de sódio ${ }^{[54]}$.

Basicamente os policarboxilatos são formados por grupos carboxílicos e apresentam cadeias laterais de diferentes comprimentos, sendo este um parâmetro importante para o controle da eficiência do aditivo. Sabe-se que a dispersão das partículas de cimento e a estabilização da suspensão, podem ser controladas por meio da mudança do comprimento dessas cadeias e, ainda, pela mudança da cadeia central ${ }^{[57]}$. Em estudos sobre os efeitos da estrutura molecular dos superplastificantes à base de policarboxilato na fluidez das pastas de cimento foi constatado que, para uma mesma dosagem de aditivo, quanto maior o tamanho da cadeia desse aditivo, mais fluida é a mistura e maior é o seu tempo de pega; e 
também, quanto maior a quantidade de grupos sulfônicos e carboxílicos presentes nos polímeros, maior a fluidez do sistema, para uma mesma dosagem de aditivo.

\subsubsection{Ação de aditivos dispersantes na hidratação do cimento}

A utilização de diferentes superplastificantes pode dificultar significativamente o entendimento da hidratação do cimento, pois os diferentes modos de interação com o cimento podem alterar a cinética da reação de hidratação, e em alguns casos a morfologia dos produtos formados ${ }^{[61]}$. Segundo Jolicoeur e Simard ${ }^{[62]}$, as diferentes atuações de cada tipo de aditivo são causadas por vários efeitos, dentre eles, a adsorção diferenciada, que dificulta a difusão da água e dos íons de cálcio na interface cimento/solução; a ação dos íons $\mathrm{Ca}^{2+}$ dos aditivos, que alteram a nucleação/precipitação dos hidratos; e a forte ação dispersante, que altera a cinética de crescimento e morfologia dos produtos hidratados.

Nos primeiros instantes da adição do superplastificante na mistura, o aditivo pode estar livre na água (formando a solução) ou adsorvido nas partículas de cimento. $A$ adsorção no $C_{3} A$ ocorre rapidamente, em poucos segundos, retardando o prosseguimento da hidratação ${ }^{[63]}$. Os aditivos também podem retardar a hidratação nas fases silicato $\left(\mathrm{C}_{2} \mathrm{~S}\right.$ e $\left.\mathrm{C}_{3} \mathrm{~S}\right)$. No entanto, este efeito é mais fraco do que no $\mathrm{C}_{3} A$. Ramachandran e colaboradores ${ }^{[64]}$, observam que os aditivos à base de naftaleno e melamina retardam a hidratação do $\mathrm{C}_{3} \mathrm{~A}$. Na Figura 16, são comparadas as curvas de calor de hidratação isotermica do $\mathrm{C}_{3} \mathrm{~A}$ na presença de aditivo melamina com as correspondentes pasta de cimento sem aditivo.

Como observado na Figura 16, uma taxa de calor se desenvolve rapidamente, com pico em cerca de 9 minutos, para a amostra sem aditivo superplastificante, e em 7 minutos para a amostra com aditivo. A quantidade total de calor (até 30 min.) e 
o pico são menores na amostra contendo aditivo que no caso da amostra sem aditivo, fato que comprova a diminuição da taxa de reação.

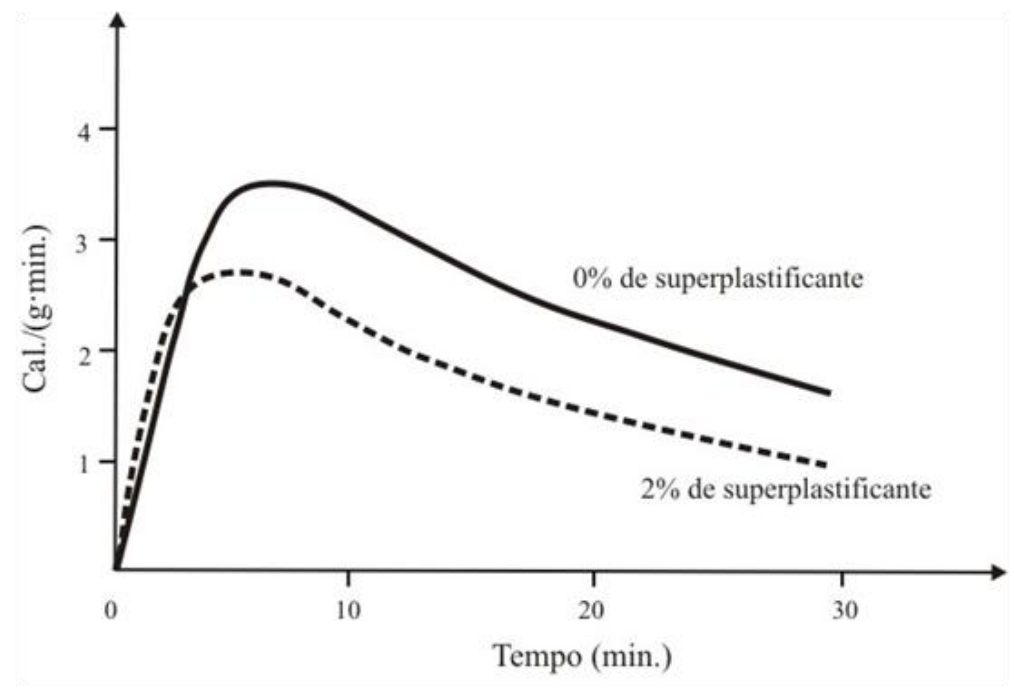

Figura 16 - Influência da melamina na hidratação do $C_{3} A^{[12]}$.

A Figura 17, ilustra o retardo da hidratação da fase $\mathrm{C}_{3} \mathrm{~S}$, mostrando a taxa de calor desenvolvida com $1 \%$ e $2 \%$ de aditivo. A taxa é um pouco maior para a adição de $1 \%$ se comparada aos demais teores. No entanto, para o traço de referência ( $0 \%$ de aditivo) a taxa de calor é bem maior, comprovando assim o retardo na hidratação da fase silicato tricálcico. Nos casos em que foram empregados aditivos superplastificantes também se observa um deslocamento do período de indução e do pico ${ }^{[54]}$.

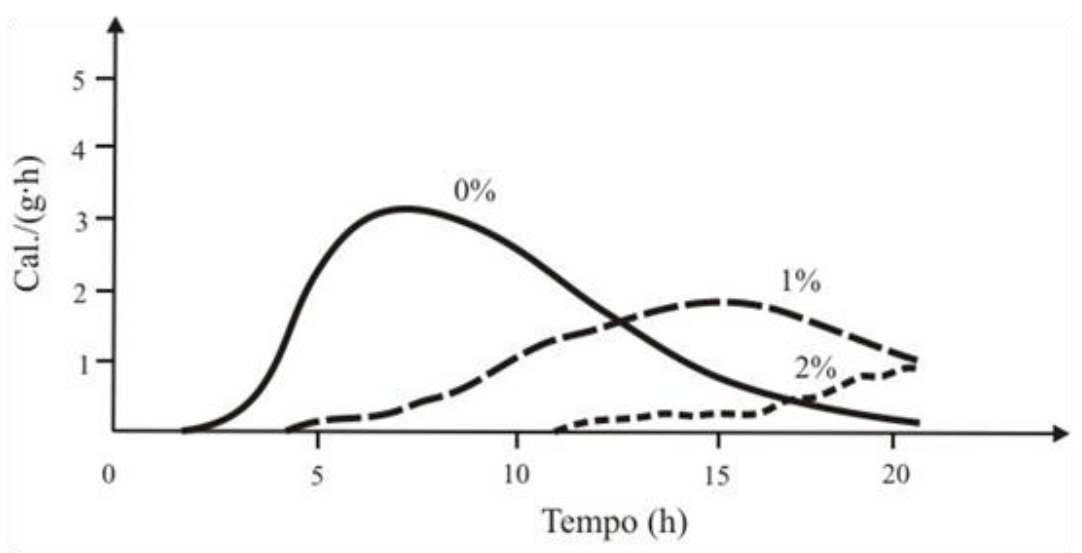

Figura 17 - Influência da melamina na hidratação do $C_{3} S^{[54]}$. 
Este estudo foi realizado para a hidratação das fases separadas. Admite-se que na hidratação do cimento, que é polifásico, o mecanismo é semelhante: os aditivos são adsorvidos pela fase $\mathrm{C}_{3} \mathrm{~A}$, resultando menor quantidade de aditivo para combinar com as demais fases, reduzindo o possível atraso na hidratação ${ }^{[63]}$.

O processo de hidratação do cimento pode ser alterado pela presença de aditivos de diversas formas, isoladamente ou em conjunto ${ }^{[12]}$, esta alteração pode-ser observada a partir de diversos efeitos e variações como: a alteração do grau de hidratação do cimento ou da composição e morfologia dos produtos hidratados; a precipitação de produtos insolúveis que agem como barreiras para a evolução da hidratação; e a alteração do pH da solução, alterando a solubilidade ou a estabilidade do sistema, quando o aditivo entra em contato com o cimento ${ }^{[12]}$.

\subsubsection{Interação das partículas de cimento com o aditivo dispersante}

Por mais que já se tenha estudado e realizado pesquisas, procurando um entendimento mais profundo sobre a reação de hidratação de cimento Portland na presença de aditivos, algumas vezes focando os aspectos físicos ${ }^{[6,7]}$, em outras os aspectos químicos ${ }^{[8,9]}$, e o efeito dos aditivos nas diferentes fases constituintes: $C_{3} S$, $\mathrm{C}_{2} \mathrm{~S}, \mathrm{C}_{3} \mathrm{~A}$, e $\mathrm{C}_{4} \mathrm{AF}^{[10,11]}$, não existe ainda uma teoria bem aceita explicando a ação dos aditivos sobre as partículas do cimento durante a mistura e hidratação inicial, e sobre os produtos intermediários da hidratação do cimento ${ }^{[12,13]}$.

Acredita-se que quando os aditivos entram em contato com o cimento, ocorre a adsorção das macromoléculas na superfície das partículas, provocando repulsão que resulta na desaglomeração, com grande redução da viscosidade do sistema cimento-água-aditivo. Estes aditivos, principalmente os aditivos base lignossulfonato, 
também podem reduzir a tensão superficial da água, aumentando o efeito de "lubrificação" das partículas de cimento ${ }^{[64]}$.

O fenômeno de aglomeração das partículas é ocasionado, quando as mesmas entram em contato com a água, devido aos diversos tipos de interação, tais como a ação das forças de van der Waals. Certa quantidade de água, fica aprisionada entre os grãos de cimento, reduzindo a água para a mistura e para lubrificação, resultando no aumento da viscosidade e redução da área de superfície específica dos grãos disponíveis para a hidratação ${ }^{[6,65]}$.

O uso de aditivos pode minimizar a tendência de aglomeração, presente nos diversos tipos de cimento Portland ${ }^{[13]}$. Esta redução está relacionada com as interações físico-químicas que ocorrem entre partícula/aditivo. 


\section{Materiais e Métodos}

\subsection{Materiais utilizados}

A caracterização química do cimento é apresentada na Tabela 4 e as características do aditivo são ilustradas na Tabela 5:

Tabela 4 - Caracterização química do cimento.

\begin{tabular}{|c|c|}
\hline Constituintes & Resultados \\
\hline \multicolumn{2}{|l|}{ a) Constituintes maiores } \\
\hline Perda ao fogo, \% & 5,90 \\
\hline Dióxido de silício $\left(\mathrm{SiO}_{2}\right), \%$ & 20,5 \\
\hline Óxido de alumínio $\left(\mathrm{Al}_{2} \mathrm{O}_{3}\right), \%$ & 6,04 \\
\hline Óxido de ferro $\left(\mathrm{Fe}_{2} \mathrm{O}_{3}\right), \%$ & 2,30 \\
\hline Óxido de cálcio (CaO), \% & 57,2 \\
\hline Óxido de magnésio (MgO), \% & 4,42 \\
\hline Trióxido de enxofre $\left(\mathrm{SO}_{3}\right), \%$ & 2,82 \\
\hline \multicolumn{2}{|l|}{ b) Constituintes menores } \\
\hline Óxido de sódio $\left(\mathrm{Na}_{2} \mathrm{O}\right), \%$ & 0,09 \\
\hline Óxido de potássio $\left(\mathrm{K}_{2} \mathrm{O}\right)$, \% & 0,69 \\
\hline Sulfeto $\left(S^{2-}\right), \%$ & 0,16 \\
\hline Equivalente alcalino $\left(\mathrm{em} \mathrm{Na} \mathrm{Na}_{2} \mathrm{O}\right), \%$ & 0,54 \\
\hline \multicolumn{2}{|l|}{ c) Determinação em separado } \\
\hline Óxido de cálcio livre (CaO), \% & 1,54 \\
\hline Resíduo insolúvel (RI), \% & 0,70 \\
\hline Anidrido carbônico $\left(\mathrm{CO}_{2}\right), \%$ & 4,33 \\
\hline \multicolumn{2}{|c|}{ d) Teor de material carbonático, a partir do anidro carbônico $\left(\mathrm{CO}_{2}\right)$} \\
\hline Material carbonático $\left(\mathrm{em} \mathrm{CaCO}_{3}\right), \%$ & 9,83 \\
\hline
\end{tabular}


Para a realização do trabalho foram utilizados cimento Portland (CPII-E) da marca Votoran e um aditivo dispersante de última geração à base de policarboxilato éter cujo nome comercial é Glenium 51.

Tabela 5 - Principais propriedades do policarboxilato éter utilizado como dispersante na preparação das suspensões.

\begin{tabular}{c|c}
\hline Propriedades & Definição \\
\hline Base química & Policarboxilatos \\
Aspecto & Líquido viscoso \\
Cor & Bege \\
Densidade & 1,067 a $1,107 \mathrm{~g} / \mathrm{cm}^{3}$ \\
pH & 5 a 7 \\
Teor de sólidos & 28,5 a $31,5 \%$ \\
\hline
\end{tabular}

A relação água/cimento foi fixada em 0,38 (em massa), com intuito de possibilitar a mistura e uma boa homogeneidade das pastas modificadas com policarboxilato éter.

Foi utilizada água deionizada como solvente na preparação das suspensões e nas análises realizadas apresentando como característica iniciais $\mathrm{pH}$ de 5,7 e condutividade iônica de $2 \mu \mathrm{S} / \mathrm{cm}$. Como fonte de íons cálcio foi utilizado nas análises Nitrato de cálcio $\mathrm{Ca}\left(\mathrm{NO}_{3}\right)_{2}$.

\subsection{Procedimentos experimentais}

O ponto de partida do presente trabalho foi a caracterização do cimento, com o objetivo de conhecer as especificações do material, e além disto, obter 
informações que proporcionassem um melhor entendimento das propriedades reológicas do material em suspensão.

O cimento Portland utilizado neste trabalho foi caracterizado através das seguintes técnicas:

- Picnometria de gás He;

- Granulometria a Laser;

- Área de Superfície Específica (BET);

- Difração de Raios X (DRX);

Terminada a etapa de caracterização do cimento foi realizada a preparação e caracterização das suspensões cimentícias, com o auxílio das seguintes técnicas:

- Mobilidade Eletrocinética Dinâmica;

- Calorimetria de condução isotérmica;

- Reometria (rotacional e oscilatória);

Os resultados obtidos por estas técnicas podem determinar as condições ideais de trabalho, como concentração de sólido e quantidade mínima de dispersante necessária para manter uma suspensão fluida, homogênea e estável. Permitem também elucidar de forma integrada a influência do aditivo nas características do cimento.

A preparação das amostras e os detalhes sobre as técnicas de caracterização serão discutidas nos itens 4.2.1 e 4.3. 


\subsubsection{Caracterização do cimento Portland com adição de escória}

\subsubsection{Picnometria de gás He}

Foi utilizado o equipamento Multipicnometer, da marca Quantachrome MVP 5DC, para determinar a densidade real do cimento, obtida a partir de uma média de 5 determinações da amostra.

\subsubsection{Granulometria a laser}

Para a análise granulométrica foi utilizado o granulômetro a laser da marca Malvern, modelo Mastersizer S long bed Ver 2.19, com intervalo de 0,05 a $555 \mu \mathrm{m}$. A amostra (CP II-E) foi desaglomerada com o auxilio de ultrassom por dois minutos e em seguida submetida ao ensaio (medido em água). $\mathrm{O}$ objetivo deste ensaio foi determinar a distribuição granulométrica do cimento estudado e usar esses dados para o detalhamento dos resultados reológicos das suspensões.

\subsubsection{3 Área de superfície específica}

O equipamento utilizado nesta análise foi um Gemini III 2375 Surface Area Analyser fabricado pela Micromeritics. As amostras foram submetidas a um tratamento no equipamento VacPrep 061 da empresa Micromeritics, para remover gases adsorvidos (principalmente vapor de água) que podem influenciar no resultado final da análise, realizado a uma temperatura de $70^{\circ} \mathrm{C}$ e pressão $(\sim 100 \mathrm{~m}$ torr).O objetivo desta análise foi conhecer a área de superfície específica da amostra, favorecendo o estudo da fisico-química de superfície do cimento em questão. 


\subsubsection{Difracão de Raios X}

Para a análise por difração de raios $X$, foi utilizado um difratômetro de raios $X$ da marca Panalytical, modelo X'Pert Pro, provido do detector X'Celerator, instalado no Laboratório de Caracterização Tecnológica da Escola Politécnica da USP.

Os dados foram obtidos na faixa de $2 \theta$ entre $3^{\circ}$ e $70^{\circ}$, com passo angular de 10 segundos, com 30 rpm de rotação da amostra, sendo empregado um tubo de Cu, $40 \mathrm{kV}, 40 \mathrm{~mA}$ e fenda divergente de $1 / 2$ grau.

\subsubsection{Preparação e Caracterização das Suspensões Cimentícias}

\subsubsection{Mobilidade eletrocinética dinâmica}

As análises eletrocinéticas foram realizadas com um equipamento ESA 9800 fabricado pela empresa Matec Applied Sciences (Hopkinton - U.S.A). Este equipamento funciona com um banho termostatizado, modelo TE-184 fabricado pela Tecnal (São Paulo - Brasil). Este dispositivo tem como objetivo proteger o ensaio de possíveis oscilações térmicas. O objetivo das análises eletrocinéticas foi avaliar o comportamento de cargas superficiais da suspensão cimentícia e também estudar a variação do $\mathrm{pH}$ e da condutividade em função do tempo. Para a realização destas análises foram preparadas suspensões aquosas com volume total de $230 \mathrm{~mL}$ e $5 \%$ em volume sólido. As suspensões foram preparadas primeiramente com a mistura da água deionizada (DI) e diferentes teores de dispersante, seguida da adição do cimento. Na preparação da solução, os teores variaram de 0,15 a $1,5 \%$. Cada análise teve duração de 15 horas. 


\subsubsection{Calorimetria de conducão isotérmica}

Os ensaios de calorimetria foram realizados no Laboratório de Microestrutura (LM) - Poli USP, utilizando um calorímetro isotérmico (TAM Air), por 48 horas. A Figura 18 ilustra o equipamento onde foi realizado o ensaio.

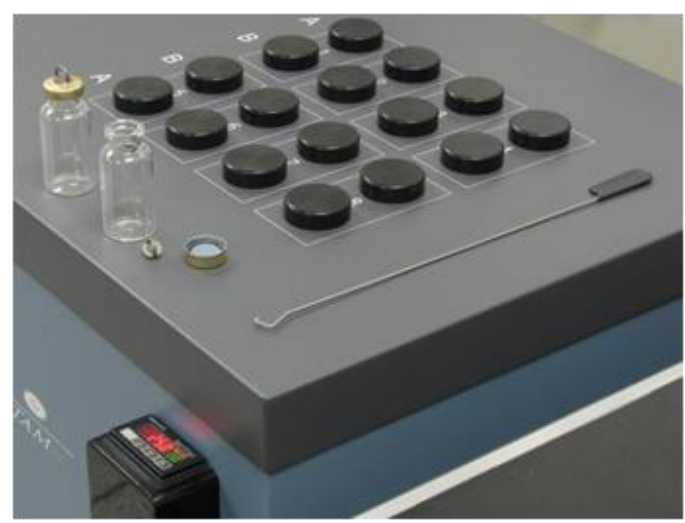

(a)

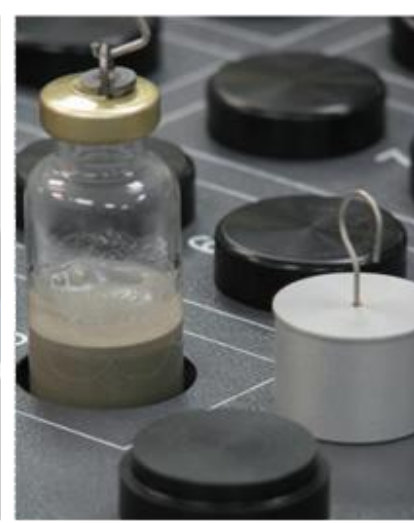

(b)

Figura 18 - Calorímetro utilizado no trabalho. Em (a) é apresentado o equipamento utilizado e em (b) é ilustrada a colocação de amostra no compartimento.

Esta técnica possibilitou a determinação da taxa de calor liberado durante a hidratação do cimento na pasta de referência e nas pastas modificadas com policarboxilato éter. Para tanto, o procedimento adotado consistiu na mistura manual de aproximadamente $50 \mathrm{~g}$ do cimento e o policarboxilato éter com a água, durante 3 minutos, em recipiente plástico. Imediatamente a seguir, esta mistura foi colocada em um porta-amostra, e levada ao calorímetro. A temperatura do sistema foi mantida constante em $25^{\circ} \mathrm{C}$ durante todo o período de aquisição dos dados. Os teores de aditivo adicionados nas pastas foram: $0,05-0,25-0,35-0,45-0,55-0,65-1,00$ e $1,50 \%$ em relação à massa do cimento e a relação água/cimento $(\mathrm{a} / \mathrm{c})$ permaneceu constante em 0,38. 


\subsubsection{Reometria}

Os ensaios de reologia foram realizados no Laboratório de Microestrutura (LM) - Poli USP, utilizando um reômetro para pastas AR 550 (TA Instruments), conforme ilustrado na Figura 19.
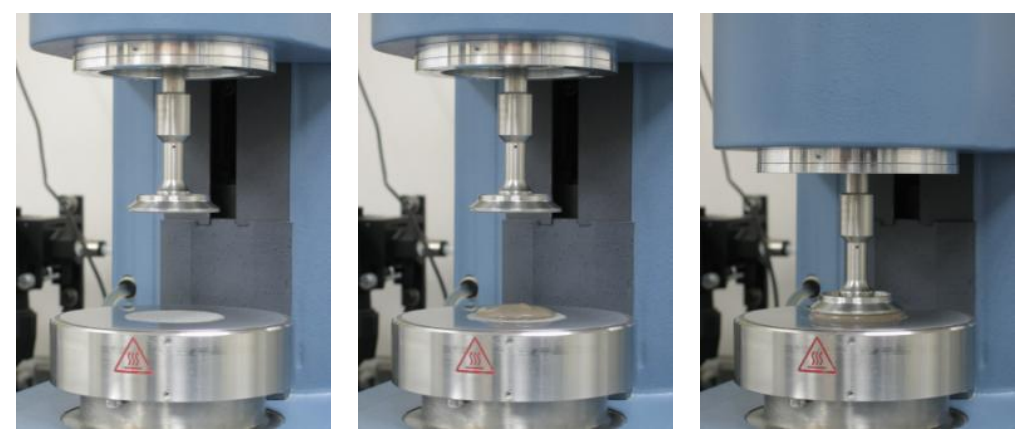

Figura 19 - Reômetro utilizado para caracterização reológica das pastas.

As amostras ( $2 \mathrm{~mL})$ foram colocadas no reômetro com placas paralelas de diâmetro 40 mm e gap de $1 \mathrm{~mm}$ e, 15 minutos após a adição do pó na água, iniciouse o ensaio. A temperatura foi mantida em $25^{\circ} \mathrm{C}$, controlada por uma placa Peltier e um sistema de circulação de água.

Os ensaios de fluxo foram realizados com a variação da taxa de cisalhamento de 0 a $150 \mathrm{~s}^{-1}$ (aceleração) e retorno a 0 (desaceleração). Já os ensaios oscilatórios foram realizados com controle de freqüência $(1 \mathrm{~Hz})$ e deformação $\left(10^{-4} \mathrm{rad}\right)$, por 2 horas.

As pastas foram processadas em um misturador de bancada (IKA, Labortechnik, RW20) com uma hélice naval, por dois minutos em velocidade de rotação de 300 rpm e por mais 2 minutos em 600 rpm. Em seguida, as pastas foram dispersas em um dispersor de alta energia de cisalhamento (IKA, T25 Basic), sob rotação de 9500 rpm, por cinco minutos. 
Os equipamentos utilizados para o processamento das pastas são apresentados na Figura $20^{[70]}$.
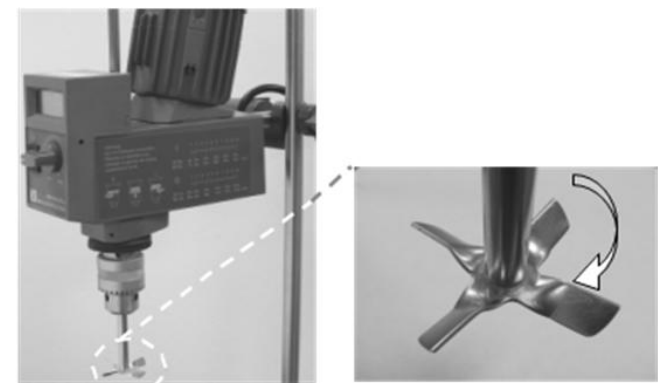

(a)
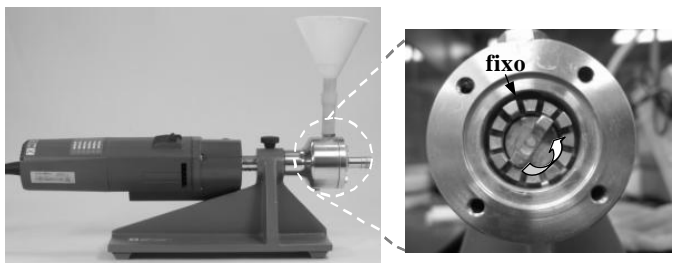

(b)

Figura 20 - Equipamentos utilizados no processamento das pastas. Em (a) ilustra-se o misturador de bancada, com baixa energia de cisalhamento e em (b) o dispersor de alta energia de cisalhamento.

O tipo de ensaio reológico realizado depende do tipo de avaliação do comportamento do material. Por exemplo, quando se pretende avaliar materiais à base de cimento durante o manuseio e aplicação, o mais indicado é um ensaio de escoamento com diferentes taxas de cisalhamento. No entanto, para casos em que se pretende acompanhar a cinética de hidratação, a consolidação da estrutura e a influência de aditivos ou adições, são indicados os ensaios dinâmicos, pois, além de não afetarem a estrutura em processo de consolidação, simulam o material no molde ou já aplicado ${ }^{[71]}$. 


\subsection{Princípios das técnicas de caracterização}

\subsubsection{Picnometria de gás He}

A picnometria a gás permite a determinação do volume verdadeiro de um sólido, mesmo poroso. Este valor é obtido através da variação da pressão de gás numa câmara de volume conhecido.

O equipamento utilizado neste trabalho é ilustrado na Figura 21a, e na Figura 21b, são apresentados os porta-amostras utilizados. Um dos parâmetros deste ensaio para a caracterização da densidade do sólido é o tamanho do porta-amostra.

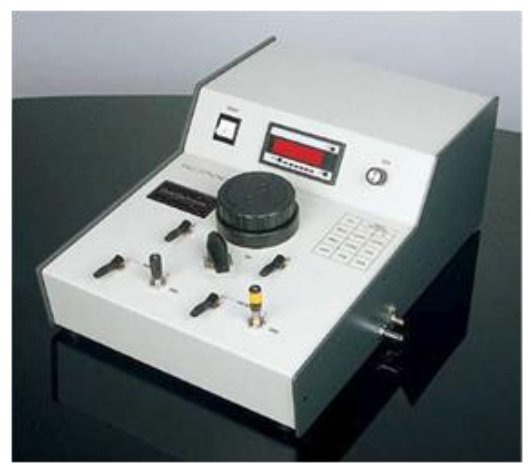

(a)

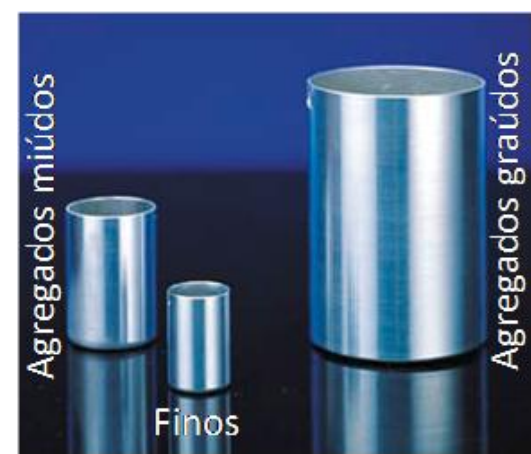

(b)

Figura 21 - Picnômetro de gás Hélio, Quantachrome MVP 5DC. Em (a) é apresentado o equipamento e em (b) as opções de porta-amostras.

O equipamento apresenta duas câmaras de volume conhecido (por calibração prévia): a câmara onde se coloca a amostra e a câmara de expansão (referência), ligadas por uma válvula (válvula de expansão).

O ensaio consiste em colocar uma amostra com massa conhecida na câmara, inicialmente, sem comunicação com a câmara de referência. O gás He é injetado na câmara de referência e anotado o valor de pressão atingido $\left(p_{1}\right)$ e, em seguida, o 
gás é transferido para a câmara onde se encontra a amostra e a nova pressão $\left(p_{2}\right)$ é anotada.

Admitindo comportamento ideal do gás He, o volume do sólido pode ser calculado a partir da equação:

$$
p_{1}\left(V_{a}-V_{s}\right)=p_{2}\left(V_{a}-V_{s}+V_{e}\right)
$$

Onde $V_{a}$ é o volume da câmara da amostra, $V_{\mathrm{e}}$ é o volume da câmara de expansão e $V_{\mathrm{s}}$ o volume do sólido.

\subsubsection{Granulometria (Laser)}

O método utilizado para estas análises foi o de espalhamento de luz laser, utilizando um granulômetro a laser com intervalo de 0,05 a $555 \mu \mathrm{m}$. O princípio baseia-se em um feixe laser que passa por uma célula óptica, onde circula a amostra em meio aquoso (ou não-aquoso), a luz é espalhada pelas partículas e o restante não espalhado incide em um sistema de lentes focais. Um detector de estado sólido formado por um conjunto de 31 anéis fotossensíveis concêntricos, reúne a luz espalhada ao longo de um intervalo de ângulos sólidos de espalhamento. Uma relação é feita entre o diâmetro médio das partículas com os ângulos. Ângulos baixos estão associados a tamanhos de partículas maiores, e ângulos altos associam-se a tamanhos de partículas menores.

\subsection{3 Área de superfície específica (BET)}

Os métodos convencionais para a avaliação da área superficial utilizam adsorção de um gás em baixa temperatura (na maioria das vezes nitrogênio líquido). Um dos tratamentos matemáticos mais comuns é o de BET (referente às isotermas estudadas por Brunauer-Emmett-Teller $\left.{ }^{[72]}\right)$, que incorporou o conceito de adsorção 
de multicamadas. Geralmente, as isotermas podem ser "decompostas" em três regiões características. A primeira delas ocorre nos baixos valores de pressão relativa, e dizem respeito à adsorção das moléculas de $N_{2}$ nas regiões favoravelmente energéticas da superfície do pó. É nesta região onde ocorre a formação da monocamada que reside a informação sobre a área de superfície específica do pó e onde é feito o tratamento de BET para a sua determinação. A segunda região ocorre para valores intermediários de pressão relativa e é referente

à sobreposição de camadas de gás sobre a superfície do pó. A terceira e última região da isoterma ocorre para altos valores de pressão relativa e é característica do fenômeno de condensação do volume gasoso.

\subsubsection{Difração de Raios-X}

A difração de raios $X$ pelos cristais resulta de um processo em que os raios $X$ são dispersos pelos elétrons dos átomos sem mudança de comprimento de onda (dispersão coerente ou de Bragg).

As medidas são realizadas incidindo-se os raios $X$ segundo ângulos $\theta$ sobre a amostra, sendo ele, então, difratado e captado pelo detector.

Rotaciona-se a amostra e o detector (entre $\theta$ e 2 2 ), de forma a analisar em determinados ângulos a ocorrência de interferências construtivas, seguindo a Lei de Bragg de acordo com a equação $10^{[73]}$.

$$
\lambda=2 \cdot \mathrm{d} \cdot \operatorname{sen} \theta
$$

sendo,

$\lambda=$ comprimento de onda dos raios $\mathrm{X}$;

d = distância interplanar entre os planos cristalográficos;

$\theta=$ ângulo de incidência dos raios $X$ sobre a amostra. 
Cada interferência construtiva surge no gráfico como um máximo de interferência (pico), vindo a ser determinado, com os valores de $2 \theta$ desses máximos, as distâncias interplanares da amostra para vários planos (considerando um comprimento de onda conhecido).

A caracterização de minerais ou fases pode ser efetuada com o auxílio da difração de raios $\mathrm{X}$. O fato de os cristais funcionarem como redes de difração para os raios $\mathrm{X}$, à semelhança das redes de difração comuns para a radiação UV e VIS, faz com que eles possam ser identificados pela mencionada radiação. As substâncias amorfas com carência de periodicidade nos arranjos atômicos (iônicos ou moleculares) já não podem ser caracterizadas ou então, em casos especiais, o são com grande dificuldade.

Os espaçamentos interplanares (valores de d) constituem características físicas de um mineral, a exemplo da densidade, do índice de refração, dos ângulos de extinção etc., de sorte que a identificação de um mineral, ou mesmo de um membro de uma série isomórfica, pode ser feita para um conjunto de espaços interplanares $^{[73]}$.

\subsubsection{Mobilidade eletrocinética dinâmica}

Ao se aplicar um campo elétrico alternado em uma dispersão coloidal de partículas, estas se movimentam de forma oscilatória proporcionalmente à carga elétrica de sua superfície. O movimento oscilatório destas partículas resulta na transferência de momento para o líquido, gerando uma onda acústica conhecida como efeito ESA (Electrokinetics Sonic Amplitude) ${ }^{[74]}$ ou amplitude sônica eletrocinética. 
Medidas eletroacústicas ou eletrocinéticas têm grande vantagem, pois podem ser feitas com o sistema sob agitação, uma vez que o movimento das partículas não interfere na medida eletroacústicas a alta frequência. Além da medida que possibilita o cálculo de mobilidade eletroforética dinâmica pode-se também realizar várias medidas simultâneas como pH, condutividade iônica e temperatura da dispersão durante a introdução de aditivos ou mudança do $\mathrm{pH}$.

A relação entre a mobilidade eletrocinética dinâmica $\mu_{d}$ e o sinal acústico medido na suspensão é dada pela seguinte equação ${ }^{[75]}$ :

$$
\mu_{\mathrm{d}}=\frac{E S A}{\phi \Delta \rho c_{1}}
$$

onde ESA é a amplitude sônica eletrocinética medida pelo equipamento, $\phi$ é a fração volumétrica de sólidos dispersos no solvente, $\Delta \rho$ é a diferença de densidade entre a partícula e o solvente e $c_{1}$ é a velocidade do som no solvente.

O potencial zeta $(\zeta)$ é definido como o potencial elétrico no plano de cisalhamento quando a partícula está em movimento sob ação de um campo elétrico. Este movimento se dá devido à carga elétrica superficial que possuem as partículas.

Para se calcular o potencial zeta, deve-se levar em consideração algumas propriedades do solvente que tem dependência da temperatura como: viscosidade $(\eta)$ e permissividade dielétrica $(\varepsilon)$. O modelo proposto por $\mathrm{O}^{\prime}$ Bryen $^{[76]}$ leva em consideração todos estes fatores e pode ser entendido a partir das seguintes equações:

$$
\zeta=\frac{\mu_{\mathrm{d}} \cdot \eta}{\varepsilon} \cdot G(\alpha)^{-1}
$$

onde $\mathrm{G}(\alpha)^{-1}$ é o fator inercial das partículas. 
O fator inercial $G(\alpha)^{-1}$ pode ser calculado a partir da equação 13:

$$
G(\alpha)^{-1}=\sqrt{\left(1+\frac{2 \cdot A^{3} \cdot B}{D}\right)^{2}+\left(\frac{2 \cdot A^{2} \cdot B \cdot(1+A)^{2}}{D}\right)}
$$

Os termos A, B e D genericamente ilustrados na equação acima podem ser descritos matematicamente da seguinte maneira:

$$
\begin{gathered}
A=\sqrt{\frac{2 \cdot \pi \cdot f \cdot r^{2} \cdot \rho}{\eta}} \\
B=\left(3+2 \cdot \frac{\Delta \rho}{\rho}\right) \\
D=9 \cdot\left(2 \cdot A^{2}+2 \cdot A+1\right)
\end{gathered}
$$

onde fé a freqüência de alternância do campo elétrico, $r$ é o raio das partículas e $\rho$ é a densidade absoluta do material particulado e n é a viscosidade do meio líquido.

\subsubsection{Calorimetria de condução}

A calorimetria de condução isotérmica é uma das formas mais simples e diretas de acompanhar a cinética das reações de hidratação, através da medida da taxa de liberação de calor. O resultado do ensaio em forma de calor liberado fornece informações importantes referentes às reações químicas que ocorrem durante a hidratação do cimento, e proporciona a quantificação dos efeitos causados pela adição de aditivos e adições minerais ${ }^{[77]}$.

As curvas de taxa de calor liberado em função do tempo de hidratação permitem obter as seguintes variáveis: período de indução; taxa de liberação de calor durante o período de aceleração, interpretada pela inclinação da curva de calorimetria, e o pico máximo de calor. A inclinação da curva de aceleração (tg $\alpha)$ é 
calculada a partir de uma regressão linear do segmento específico da curva de fluxo de calor em função do tempo em horas, conforme a Figura 22.

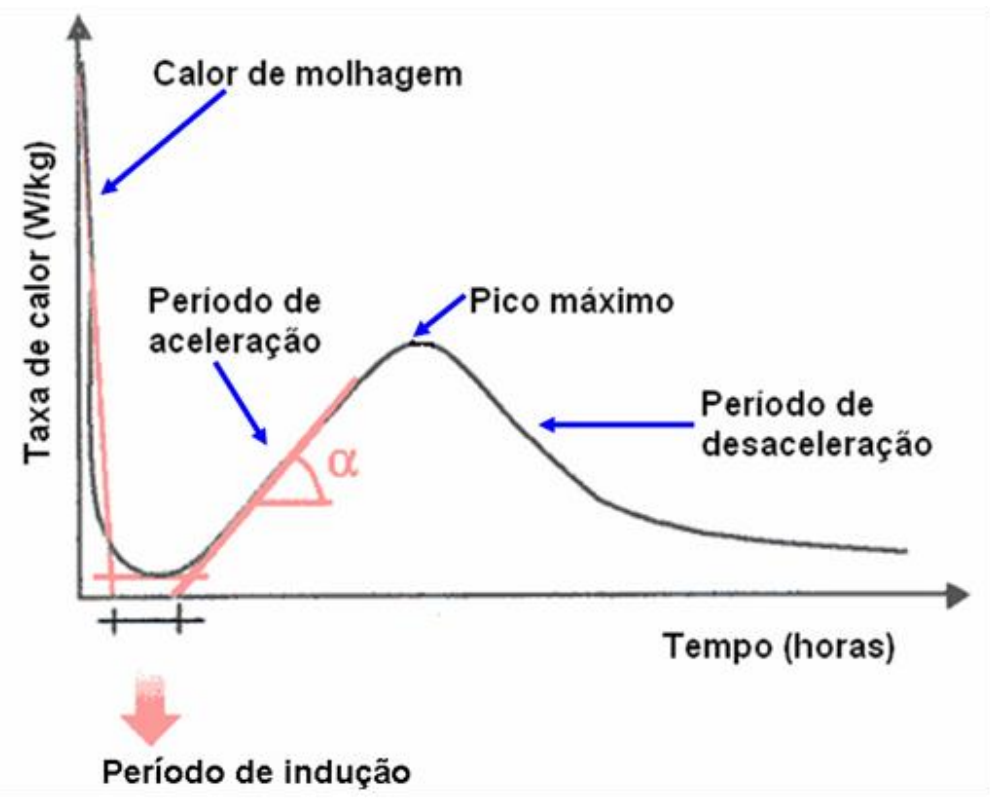

Figura 22 - Representação esquemática de curva de calor de hidratação e critérios para determinação das variáveis ${ }^{[71,78]}$.

Conforme mostrado na Figura 22, observam-se quatro períodos de liberação de calor. O período de indução é calculado a partir das intersecções do trecho horizontal com a reta traçada no período de pré-indução (calor de molhagem) e a reta obtida por extrapolação da linha de regressão do período de aceleração. Quanto mais reativa é a espécie química maior será o valor do coeficiente de inclinação da curva de aceleração $(\alpha)$. O período de desaceleração foi estabelecido como o tempo total transcorrido a partir do pico máximo de taxa de liberação de calor $^{[71,78]}$. Este período termina quando os grãos de cimento se hidratarem por completo ou quando não existir mais água para ocorrer reações de hidratação. 


\subsubsection{Reometria}

\subsubsection{Ensaio de fluxo}

O ensaio de fluxo é denominado ensaio de cisalhamento estacionário, e mede a tensão a uma dada taxa de cisalhamento (ou vice-versa). Com a variação da taxa ou da tensão de cisalhamento, a curva de escoamento pode ser traçada e, através desta ou de equações de estado reológico, podem ser determinadas as propriedades reológicas - viscosidade e tensão de escoamento. Os dados obtidos podem ser apresentados por curvas de tensão versus taxa de cisalhamento ou viscosidade versus taxa de cisalhamento. Através das curvas é possível verificar o comportamento reológico da pasta cimentícia.

O ensaio de fluxo simula o comportamento do material durante o seu manuseio e aplicação e, basicamente, consiste em aplicar uma tensão ou deformação e medir a resistência do material a este esforço aplicado ${ }^{[78]}$.

Na Figura 23, são apresentadas as diferentes geometrias utilizadas neste tipo de ensaio, podendo ser citadas algumas utilizadas para materiais cimentícios, como: as placas paralelas, os cilindros concêntricos e outros formatos. 


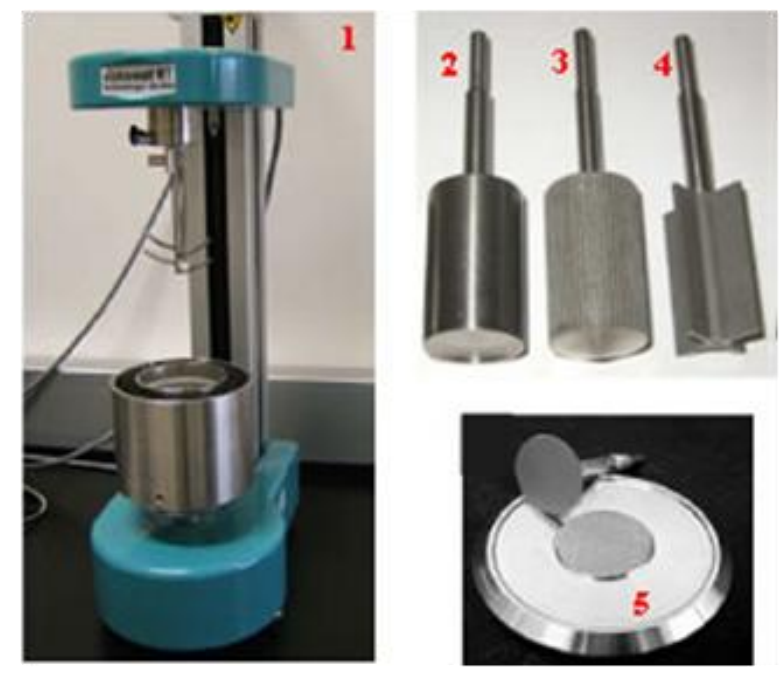

Figura 23 - Tipos de geometria utilizados para ensaios reológico de pastas de cimento e argamassas, 1-“espinha de peixe"; 2 - cilindro concêntrico liso, 3 cilindro concêntrico ranhurado, 4 - cilindro concêntrico aletado (vane) e 5 placas paralelas ranhuradas ${ }^{[78]}$.

\subsubsection{Ensaio oscilatório}

O ensaio oscilatório é um exemplo de ensaio dinâmico, cujo mecanismo possibilita a análise em baixa deformação ou tensão, não causando a ruptura da estrutura em formação. Este tipo de ensaio tem sido amplamente utilizado para avaliar as propriedades de pastas de cimento desde a mistura até o início de pega do cimento ${ }^{[79-83]}$.

A técnica consiste em aplicar uma deformação ou tensão senoidal sobre a amostra. A deformação é modelada conforme a Equação 17. A resposta obtida em função desta solicitação é a tensão ( $\tau)$, obtida através da Equação 18:

$$
\begin{array}{r}
\gamma=\gamma_{0} \times \operatorname{sen} \omega t \\
\tau=\tau_{0} \times \operatorname{sen}(\omega t+\delta)
\end{array}
$$

onde $\omega$ é a frequência angular, t é o tempo, $\gamma_{0}$ é a amplitude de deformação e $\delta$ é o ângulo de defasagem entre a tensão e a deformação. 
Os comportamentos limites para os materiais são: sólido Hookeano, onde a tensão está em fase com a deformação $\left(\delta=0^{\circ}\right)$, e fluido Newtoniano, no qual a tensão está totalmente defasada em relação à deformação $\left(\delta=90^{\circ}\right)$. A maioria dos materiais existentes não apresenta comportamento de sólidos ou líquidos ideais e, sim, uma combinação dos mesmos, denominado de viscoelasticidade, sendo $0^{\circ}<\delta$ $<90^{\circ}$.

Das Equações 17 e 18, o módulo G*, denominado módulo de cisalhamento complexo, pode ser calculado relacionando a tensão pela deformação, conforme a Equação 19:

$$
G^{*}=\frac{\tau_{0}}{\gamma_{0}}
$$

Este módulo, por ser um número complexo, pode ser divido em duas componentes (real e imaginária). A componente real, elástica, denominada de módulo de armazenamento (G'), e a componente imaginária, viscosa ou módulo de perda (G"), representadas nas Equações 20 e 21, respectivamente ${ }^{[71,78,84]}$.

$$
\begin{aligned}
& G^{\prime}=G^{*} \cos \delta \\
& G^{\prime \prime}=G^{*} \operatorname{sen} \delta
\end{aligned}
$$

A partir dos valores obtidos é possível analisar o comportamento do material. O material terá um comportamento de um sólido viscoelástico quando sua componente elástica (G') for maior que a componente viscosa (G”) e, um comportamento de líquido viscoelástico quando esta relação for contrária. Em materiais cimentícios o valor de G' está diretamente ligado ao fenômeno de consolidação, e pode ser determinado a partir de ensaios com controle de deformação e freqüência ${ }^{[71]}$. 
Para avaliar a viscoelasticidade de suspensões é preciso garantir que as medidas reológicas sejam realizadas na região viscoelástica linear, na qual o módulo elástico independe da deformação aplicada. Esta região delimita a deformação crítica que se pode aplicar no material garantindo que sua estrutura não seja alterada $^{[80-82]}$. 


\section{Resultados e Discussões}

\subsection{Caracterização do cimento}

Para realização do trabalho foi utilizado cimento Portland composto com escória de alto-forno (CP II-E) já que este é um cimento comumente empregado em formulações de argamassas e concreto. As propriedades físicas deste insumo são descritas na Tabela 6 e a distribuição granulométrica ilustrada na Figura 24.

Tabela 6 - Propriedades físicas do cimento CPII - E.

\begin{tabular}{c|c|c}
\hline Propriedades Físicas & Valor & Método de ensaio \\
\hline Área Superficial Específica $\left(\mathrm{m}^{2} / \mathrm{g}\right)$ & 0,83 & $\mathrm{BET}$ \\
Densidade real $\left(\mathrm{g} / \mathrm{cm}^{3}\right)$ & 3,01 & Picnometria de gás He \\
Área Superficial Volumétrica $\left(\mathrm{m}^{2} / \mathrm{cm}^{3}\right)$ & 2,50 & - \\
$\mathrm{D}_{10}(\mu \mathrm{m})$ & 1,95 & Granulometria a laser \\
$\mathrm{D}_{50}(\mu \mathrm{m})$ & 11 & Granulometria a laser \\
$\mathrm{D}_{90}(\mu \mathrm{m})$ & 35 & Granulometria a laser \\
\hline
\end{tabular}

Os valores encontrados tanto da densidade quanto da área superficial específica são bem similares aos encontrados na literatura ${ }^{[71]}$. A área específica volumétrica foi obtida através do produto entre densidade real e área de superfície específica. Para a distribuição granulométrica foi obtido os valores de $D_{10}, D_{50}$ e $D_{90}$ que representam diâmetros de partículas em que, respectivamente, $10 \%, 50 \%$ e $90 \%$ do total das partículas são menores do que os valores indicados na Tabela 6 . 


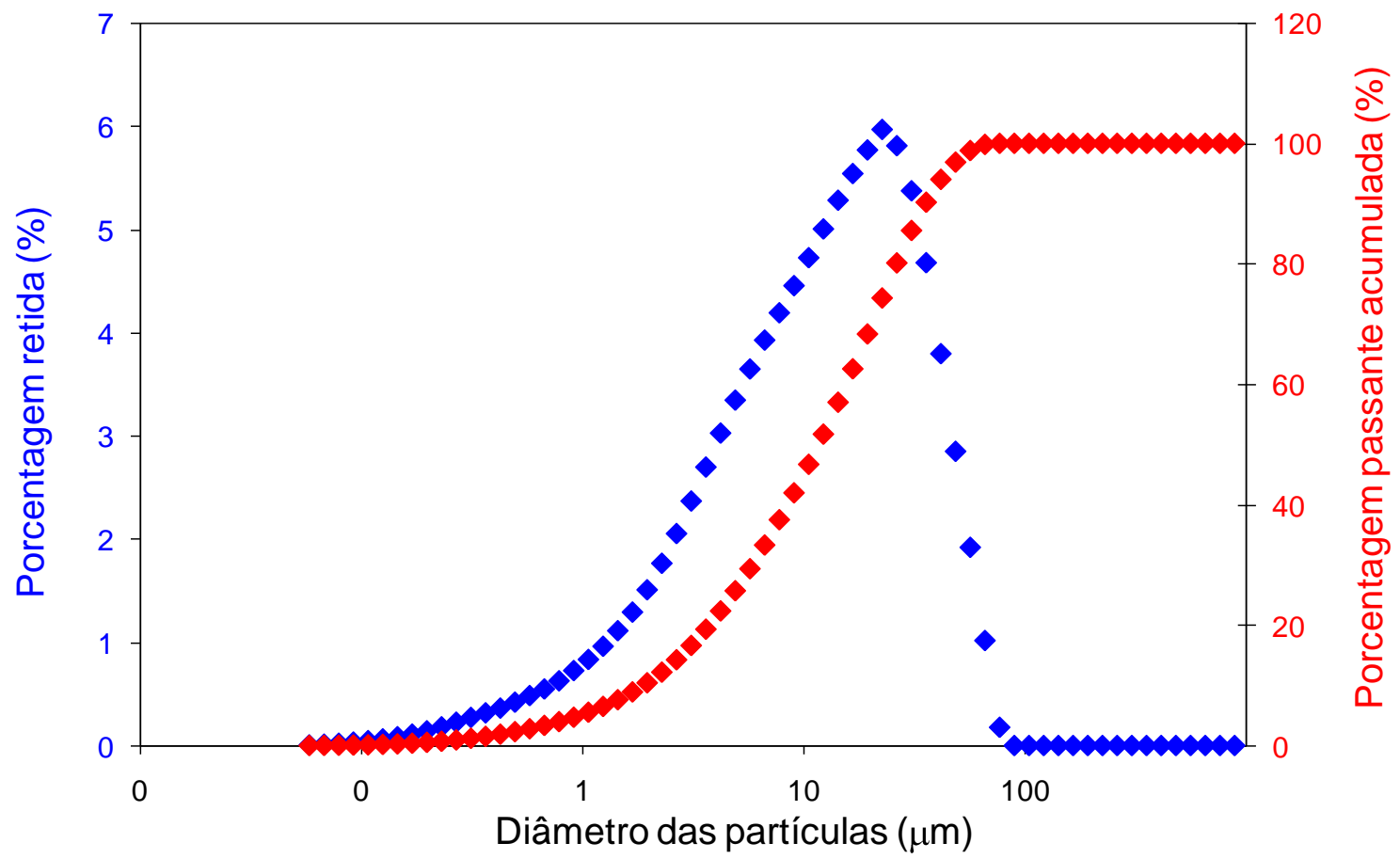

Figura 24 - Distribuição granulométrica do cimento CPII - E.

A Figura 24 ilustra o perfil de distribuição e de freqüência de diâmetro do material, evidenciando parâmetros significativos para a reologia da suspensão cimentícia. Vale ressaltar, que a quantidade de água utilizada na confecção das suspensões está diretamente relacionada com a distribuição granulométrica e forma das partículas.

O difratograma do cimento CP II-E é apresentado na Figura 25 e a Tabela 7 sumariza os compostos identificados por DRX. 


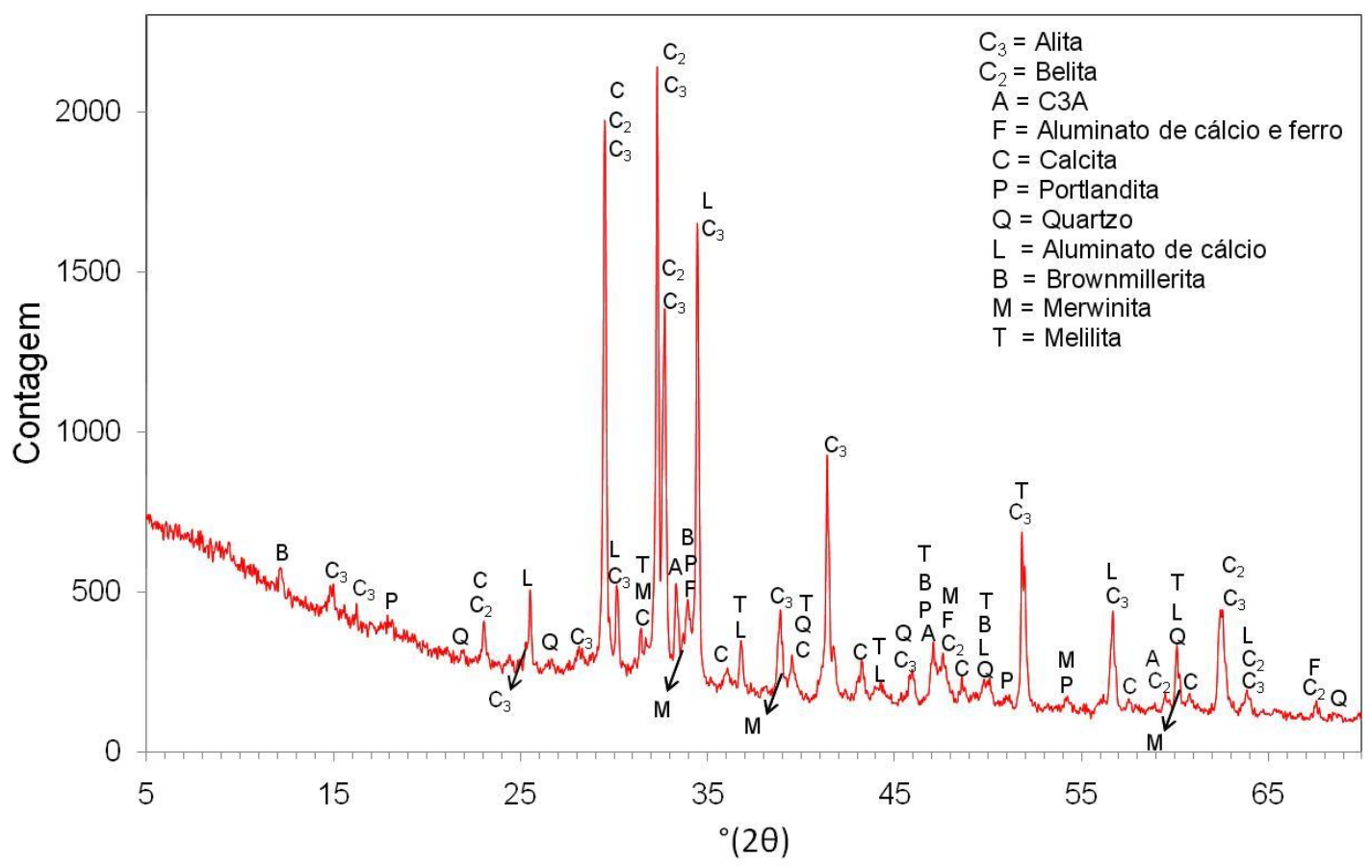

Figura 25 - Difratograma do cimento CP II-E.

Tabela 7 - Compostos identificados no cimento CP II-E, por DRX.

\begin{tabular}{|c|c|c|c|}
\hline Nome do composto químico & $\begin{array}{l}\text { Fórmula } \\
\text { química }\end{array}$ & Mineral & $\begin{array}{c}\text { Referência: } \\
\text { Ficha ICDD } \\
\text { JCPDS }\end{array}$ \\
\hline $\mathrm{C}_{3} \mathrm{~S}$ - silicato tricálcico & $\mathrm{Ca}_{3} \cdot \mathrm{SiO}_{5}$ & Alita & $42-0551$ \\
\hline $\mathrm{C}_{2} \mathrm{~S}$ - silicato dicálcico & $\mathrm{Ca}_{2} \cdot \mathrm{SiO}_{4}$ & Belita & $24-0034$ \\
\hline $\mathrm{C}_{3} \mathrm{~A}$ - aluminato tricálcico & $\mathrm{Ca}_{3} \mathrm{Al}_{2} \mathrm{O}_{6}$ & - & $33-0251$ \\
\hline Ferro aluminato de cálcio & $\mathrm{Ca}_{12} \cdot \mathrm{Al}_{9} \cdot \mathrm{Fe}_{4} \mathrm{O}_{32}$ & - & $42-1469$ \\
\hline Carbonato de cálcio & $\mathrm{CaCO}_{3}$ & Calcita & $24-0027$ \\
\hline Hidróxido de cálcio & $\mathrm{Ca}(\mathrm{OH})_{2}$ & Portlandita & 01-1079 \\
\hline Óxido de silício & $\mathrm{SiO}_{2}$ & Quartzo & 03-0419 \\
\hline Aluminato de cálcio & $\mathrm{Ca}_{3} \mathrm{Al}_{10} \mathrm{O}_{18}$ & - & $01-0572$ \\
\hline $\mathrm{C}_{4} \mathrm{AF}$ - ferro aluminato tetracálcico & $\begin{array}{c}4 \mathrm{CaO} \cdot \mathrm{Al}_{2} \mathrm{O}_{3} \\
\mathrm{Fe}_{2} \mathrm{O}_{3}\end{array}$ & Brownmillerite & $30-0226$ \\
\hline Silicato de cálcio e magnésio & $\mathrm{Ca}_{3} \mathrm{MgO}_{8} \mathrm{Si}_{2}$ & Merwinite & $04-0728$ \\
\hline Silicato de cálcio alumínio e magnésio & $\mathrm{Ca}_{8} \mathrm{Al}_{6} \mathrm{MgSi}_{5} \mathrm{O}_{28}$ & Melilite & 04-0689 \\
\hline
\end{tabular}


Como pode ser observado na Figura 25, existe uma predominância das fases $\mathrm{C}_{3} \mathrm{~S}$ e $\mathrm{C}_{2} \mathrm{~S}$, e traços da fase $\mathrm{C}_{3} \mathrm{~A}$, confirmando as fases, as quais a literatura reporta $\left(\mathrm{C}_{3} \mathrm{~S}\right.$ e $\left.\mathrm{C}_{3} \mathrm{~A}\right)$.

\subsection{Mobilidade eletrocinética dinâmica}

As análises de mobilidade eletrocinética tiveram como objetivo comparar os efeitos causados por interações entre o policarboxilato éter e as partículas de cimento em suspensão aquosa em função do tempo. Os modelos que relacionam o

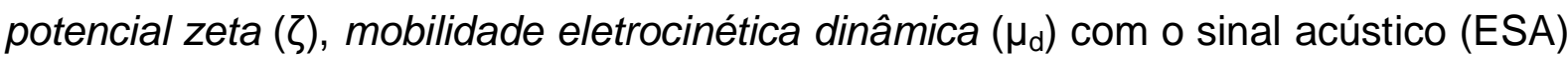
podem ser encontradas no item 4.3.5.

As medidas de potencial zeta das suspensões em função do tempo, para diferentes teores de aditivo podem ser observadas na Figura 26.

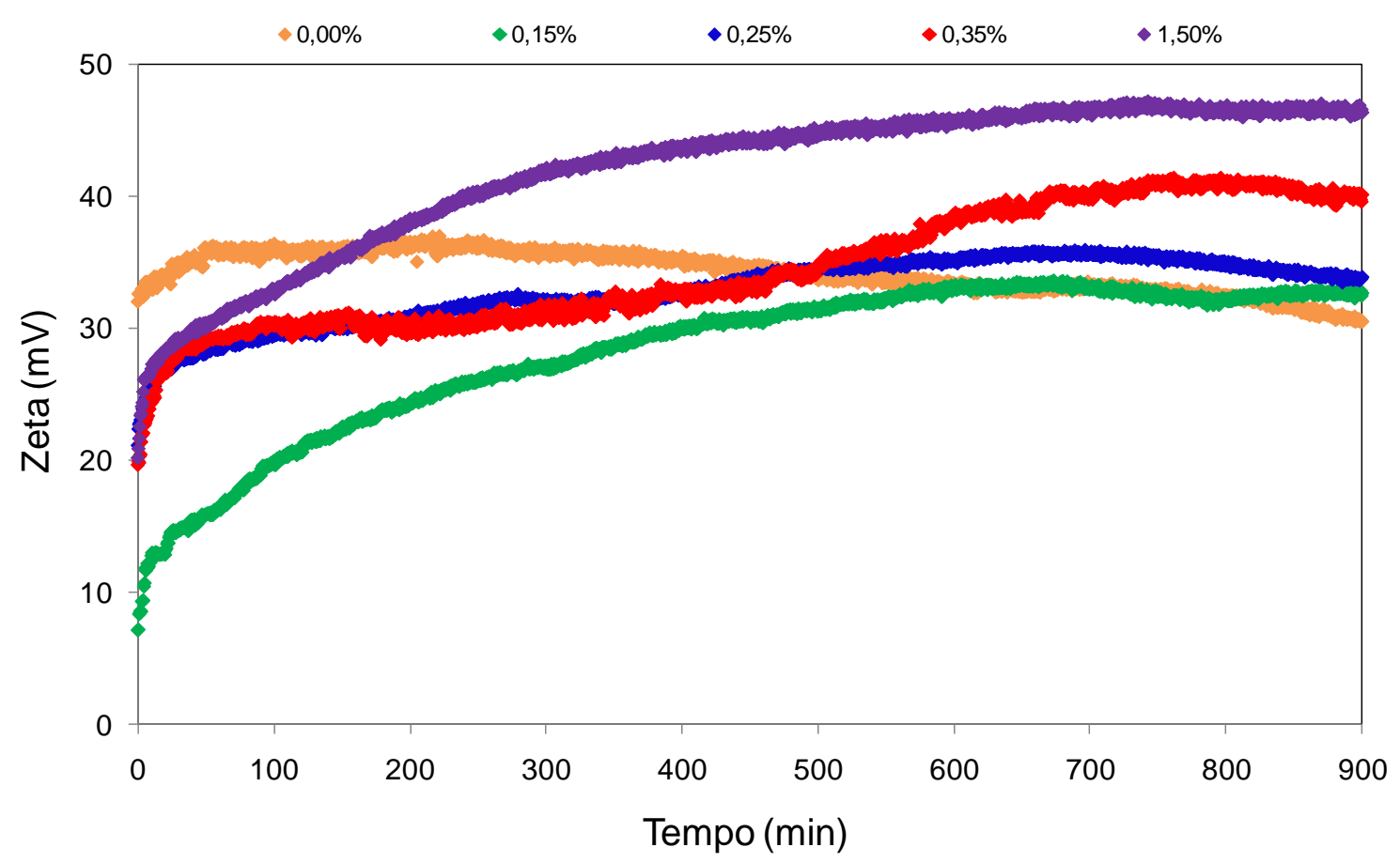

Figura 26 - Curvas de Potencial zeta em função do tempo variando-se o teor de aditivo. 
O potencial zeta inicial do cimento sem aditivos é elevado e tem valor positivo. Isto é provavelmente decorrente da dissolução dos produtos de cálcio, como o do sulfato de cálcio, e a adsorção do íon $\mathrm{Ca}^{2+}$ preferencial na superfície das partículas de cimento. Uma diminuição significativa do potencial zeta inicial ocorre nos primeiros minutos após a introdução do aditivo. Comparando com cimento sem aditivo pode-se supor que a adsorção de moléculas com grupos ionizáveis negativos sobre as partículas do cimento, que se apresentam prioritariamente positivas, reduz a mobilidade eletroforética simultaneamente por dois mecanismos principais: diminuição da carga elétrica de superfície (positiva) por adsorção de macromoléculas (negativas) e aumento do raio hidrodinâmico da partícula. Estes fenômenos proporcionam uma diminuição na distribuição de carga superficial da partícula simultaneamente ao aumento do tamanho e peso da mesma, como resultado, tem-se a diminuição do potencial zeta. Esta variação de potencial está diretamente relacionada aos efeitos originados pelo mecanismo eletrostático e não pode ser considerado como única contribuição para a fluidez do sistema do ponto de vista reológico. A diminuição do potencial elétrico da superfície poderia ser considerada como prejudicial à fluidez da dispersão de cimento, contudo o que pode ser afirmado é que a introdução do polímero modifica a superfície do mesmo e que a mudança detectada na fluidez, que será mostrada a seguir no texto, pode estar relacionada a efeitos espaciais (ou estéricos) das moléculas poliméricas adsorvidas. Não se pode deixar de considerar que a parte ionizável da molécula do aditivo é apenas parte da molécula que apresenta elevado peso molecular e que deve ser determinante para efeitos espaciais de estabilização da dispersão.

Com o passar do tempo, contudo, ocorre o aumento do potencial zeta do sistema (Figura 26), sendo que os valores finais são superiores ao do cimento sem 
aditivo. Neste caso pode-se considerar que o cálcio solúvel representa um papel fundamental. Em primeiro lugar deve ocorrer a adsorção do cálcio nas partículas do cimento que foi impedida pela presença das moléculas poliméricas. Como o potencial zeta após 900 min e para todos os teores de aditivo é superior ao do cimento sem aditivo acredita-se que o cálcio também possa interagir com as terminações derivadas de ácidos orgânicos formando um quelato com o aditivo. Como cada carboxila tem apenas uma carga negativa, a formação do quelato levaria à inversão da carga elétrica da molécula aumentando ainda mais o potencial zeta total.

No entanto, a eficiência da estabilização dependerá também da força iônica do meio que influenciará o grau de dissociação das cadeias poliméricas, o recobrimento total da superfície das partículas e do peso molecular das cadeias poliméricas e concentração de íons em sua extensão ${ }^{[1,2]}$.

$\mathrm{Na}$ Figura 27, pode ser observado que o pico de condutividade ocorre em tempos maiores com o aumento do teor de aditivo. Esta variação pode ser ocasionada pela interferência das moléculas poliméricas na solubilização ou pela redução de íons em solução. 


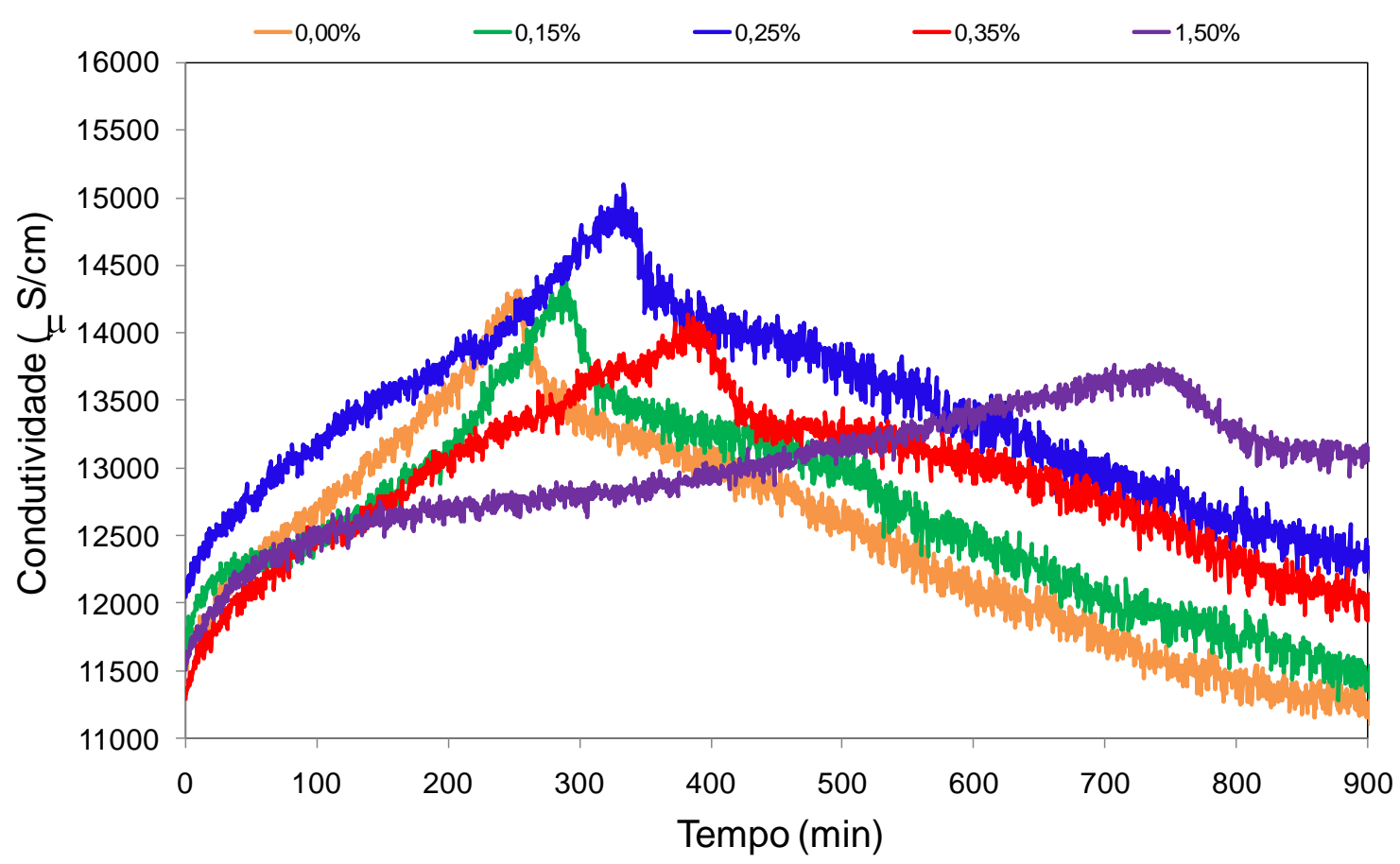

Figura 27 - Curvas de condutividade iônica em função do tempo para dispersões de cimento CPII - E com diferentes teores de aditivo.

Os picos de condutividade estão relacionados com o início das reações de hidratação, ou seja, a dissolução e precipitação dos constituintes do cimento. A dissolução dos sulfatos alcalinos que liberam íons, como é o caso do sulfato de cálcio que dissolve até a saturação liberando íons $\mathrm{Ca}^{2+}$ é um dos fenômenos que promovem o aumento da condutividade. Com o passar do tempo a mesma diminui devido à precipitação de hidratos resultante da solução supersaturada.

O estado de estabilização da suspensão pode ser avaliado através da medida de potencial zeta, sendo que os valores inicial e final indicam a variação do potencial durante o ensaio. A variação de potencial zeta e da condutividade em função dos teores de aditivo é mostrada nas Figuras 28 e 29. 


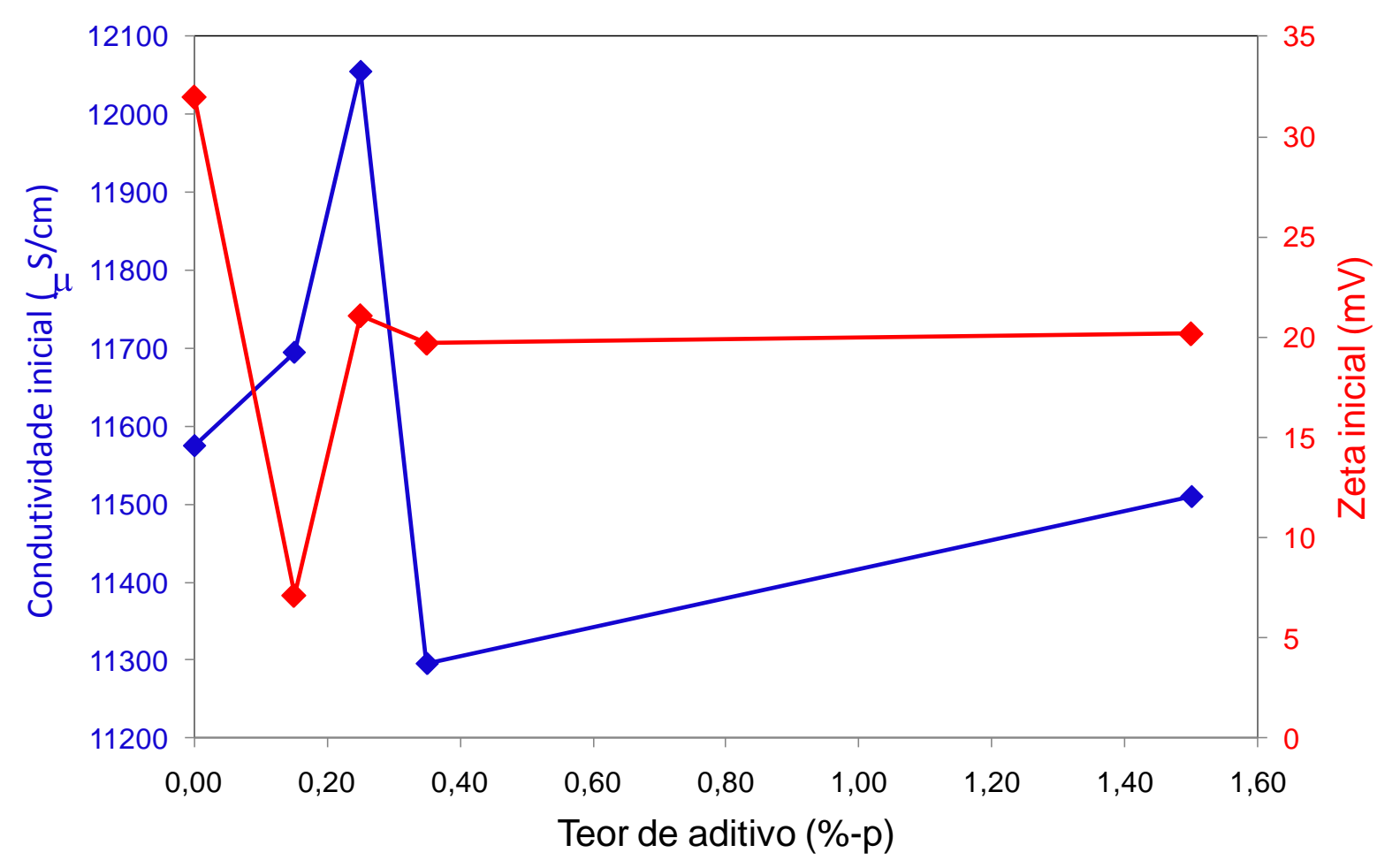

Figura 28 - Comparação entre os valores iniciais de condutividade iônica e potencial zeta, para teores de 0,0 - 0,15 - 0,25 - 0,35 e 1,50\%-p

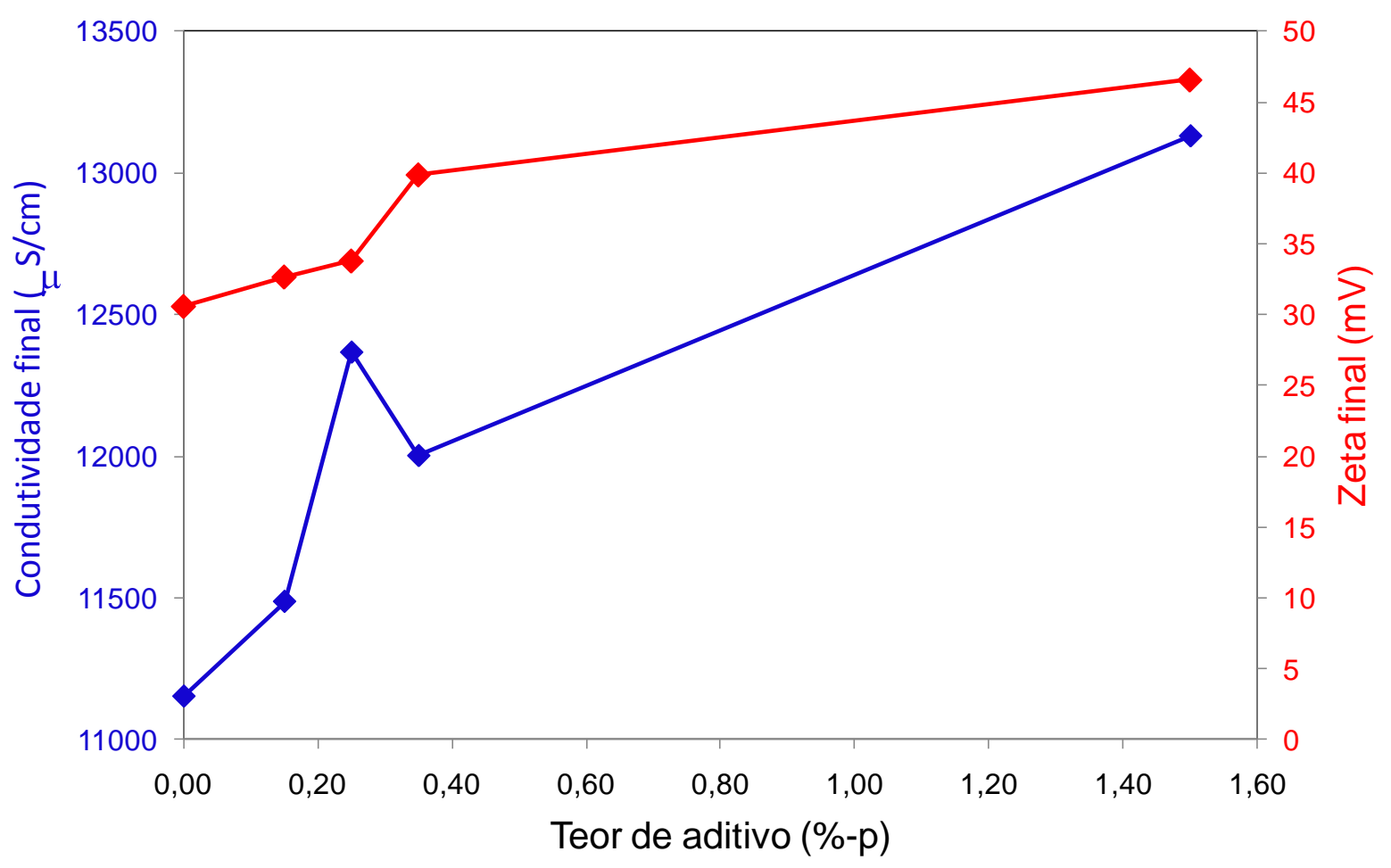

Figura 29 - Comparação entre os valores finais de condutividade iônica e potencial zeta, para teores de 0,0 - 0,15 - 0,25 - 0,35 e 1,50\%-p 


\subsection{Avaliação da interação dos íons da suspensão cimentícia com o policarboxilato.}

Com o intuito de ilustrar a interação que dos íons $\mathrm{Ca}^{2+}$ da suspensão cimentícia e o dispersante, foram realizadas medidas de condutividade e $\mathrm{pH}$ de uma solução policarboxilato/água ( 2 \% v/v e 20 \% v/v), em função da adição de diferentes teores de uma solução $0,1 \mathrm{~mol} / \mathrm{L}$ de $\mathrm{Ca}\left(\mathrm{NO}_{3}\right)_{2}$. Como ilustrado nas Figuras 30 e 31 .

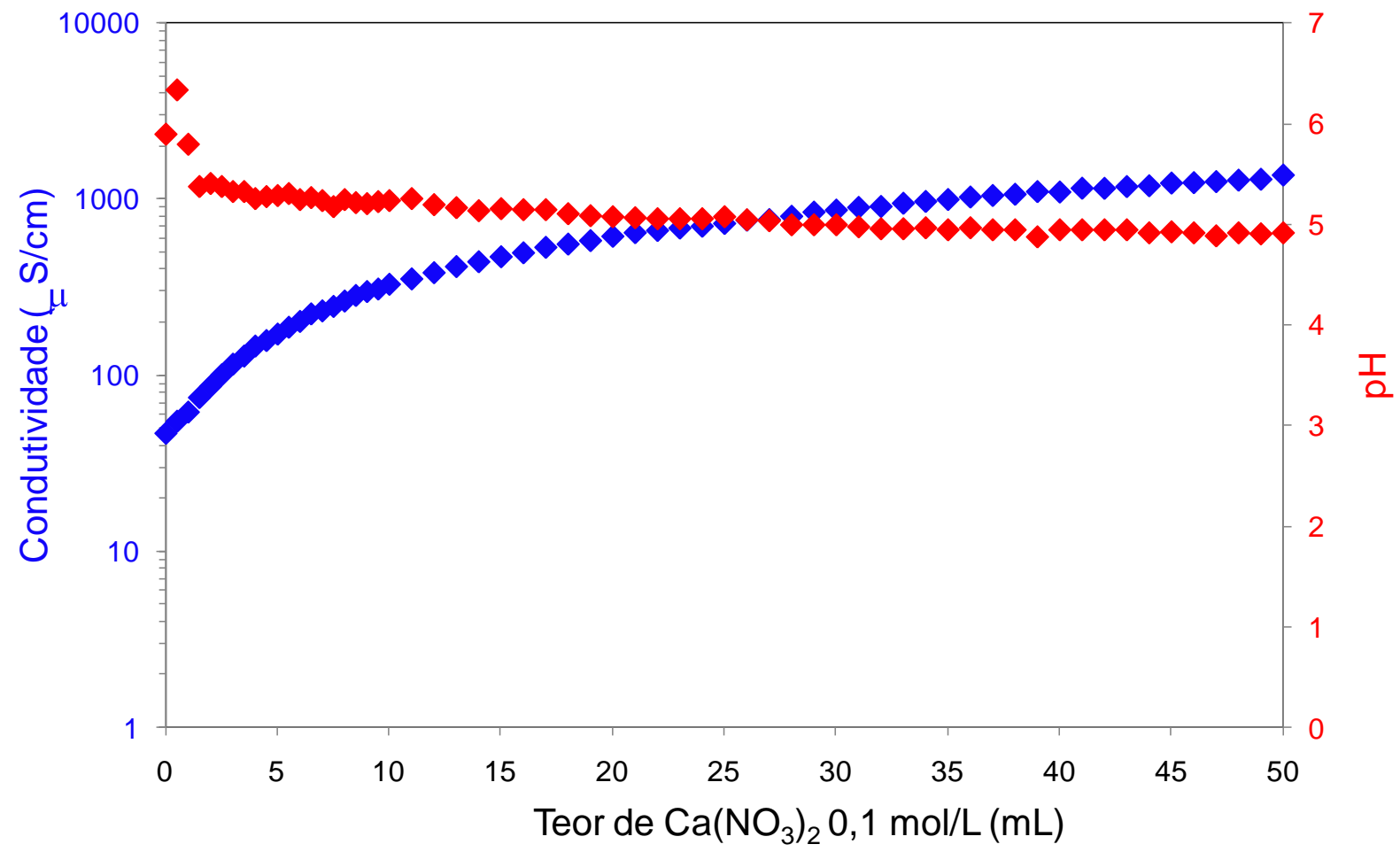

Figura 30 - Curvas de condutividade e pH em função do teor de $\mathrm{Ca}\left(\mathrm{NO}_{3}\right)_{2}$, (solução $2 \%$ v/v).

Na Figura 30, é verificado o aumento da condutividade em função do teor de $\mathrm{Ca}\left(\mathrm{NO}_{3}\right)_{2}$, este comportamento pode ser justificado pelo aumento dos íons cálcio em solução. A variação do $\mathrm{pH}$, pode estar relacionada com possíveis reações dos íons $\mathrm{Ca}^{2+}$ em solução com os grupos ionizáveis presentes nas cadeias poliméricas do dispersante. Este comportamento pode ser observado melhor na Figura 31. 


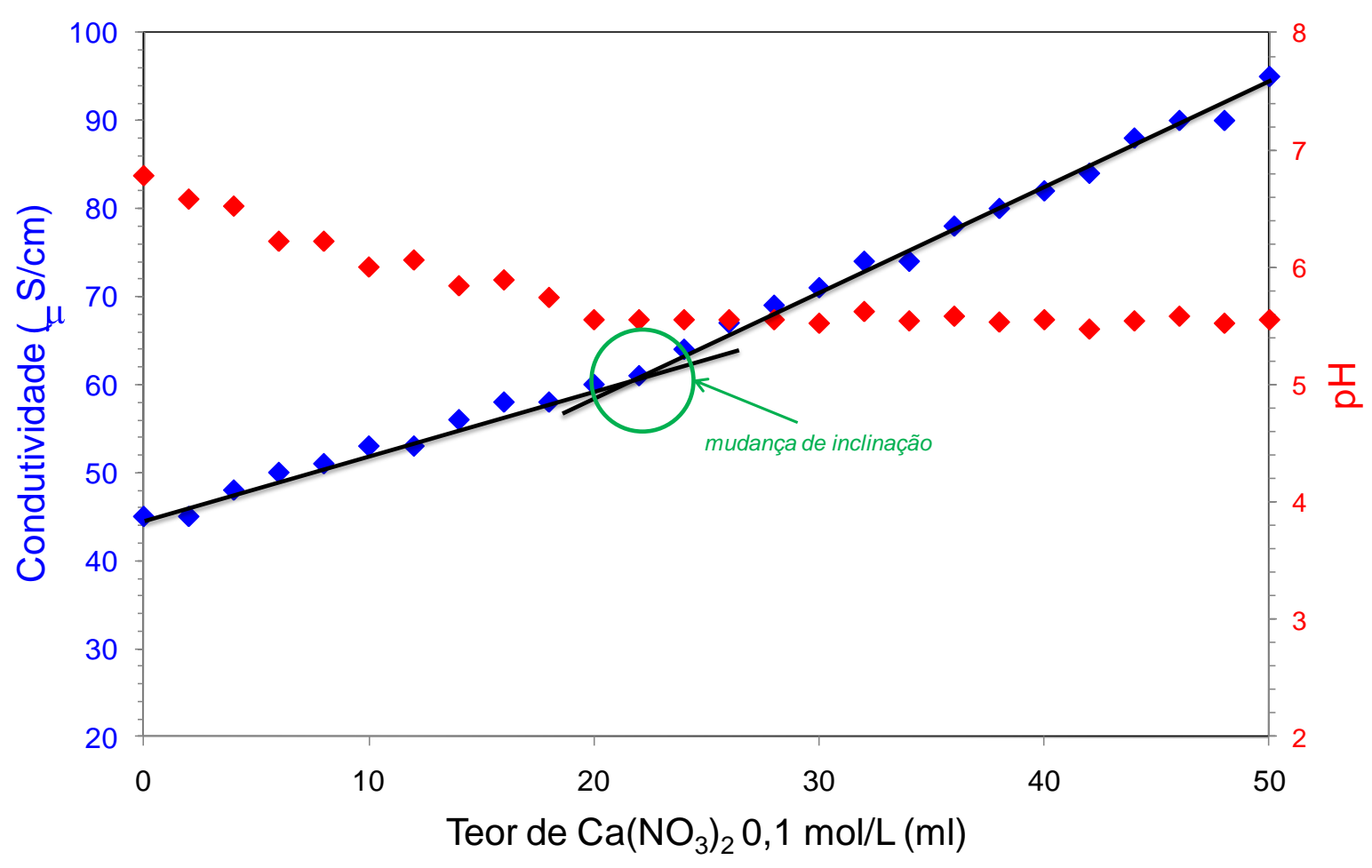

Figura 31- Curvas de condutividade e pH em função do teor de nitrato de cálcio - $\mathrm{Ca}\left(\mathrm{NO}_{3}\right)_{2 \cdot}$ (solução $20 \% \mathrm{v} / \mathrm{v}$ )

Para a solução $(20 \% \mathrm{v} / \mathrm{v})$ de aditivo/água, onde a concentração das moléculas de policarboxilato éter é maior, verifica-se o aumento da condutividade, porém um aumento bem menor. Esta diminuição pode estar relacionada à quantidade de moléculas do dispersante na suspensão, pois as mesmas podem interagir com os íons $\mathrm{Ca}^{2+}$ de forma mais intensa devido à baixa concentração destes íons. No entanto, em um determinado instante em que os íons cálcio "sobram" na solução, ou seja, quando há $\mathrm{Ca}^{2+}$ sem influência do polímero, a inclinação da curva de condutividade sofre um aumento, possibilitando um aumento mais rápido da condutividade. Deste modo, é evidente que o policarboxilato éter interage com os íons $\mathrm{Ca}^{2+}$, reduzindo a sua concentração na solução. 
Vale a pena ressaltar, que estes resultados são ilustrativos e parte inicial de um futuro estudo para o entendimento dos mecanismos de ação do dispersante a base de policarboxilatos em partículas de cimento, para suspensões concentradas.

\subsection{Calorimetria de condução}

Neste trabalho o teor do aditivo foi variado em valores percentuais em relação à massa do cimento, de 0,0 a 1,5\%.

As curvas de fluxo de calor liberado e calor acumulado são mostradas na Figura 32. Pode-se observar que a adição de policarboxilato éter na pasta não alterou o perfil típico da curva de evolução de calor de hidratação do cimento. No entanto, verifica-se a alteração na taxa de reação, e mudanças nos períodos de indução, aceleração das reações e de desaceleração.

Dois fenômenos são responsáveis pela variação no período de indução. O primeiro consiste na atuação dos grupos ionizáveis das moléculas poliméricas nas cargas de superfície das partículas, diminuindo a concentração do íon $\mathrm{Ca}^{2+}$ em solução, tornando a precipitação dos hidratos mais lenta. O segundo é baseado na dificuldade imposta ao processo de dissolução do cimento anidro, por meio da formação de camadas adsorvidas sobre a superfície das partículas de cimento dificultando a aproximação das moléculas de água ${ }^{[85]}$.

Vale a pena ressaltar, que a presença do policarboxilato, altera somente as velocidades das reações químicas que ocorrem durante a hidratação do cimento. Portanto todas as reações químicas que ocorrem sem o aditivo, estão ocorrendo também com a presença de policarboxilato. No entanto ocorrem em tempos distintos, conforme ilustrado a partir da alteração no período de indução (Figura 32a), onde pode-se citar por exemplo: para a pasta pura o tempo de indução foi de 1 
hora e 10 minutos, para as pastas aditivadas com 0,25, 0,55 e 1,5 os tempos foram respectivamente de 4,00, 9,25 e 14,66 h.
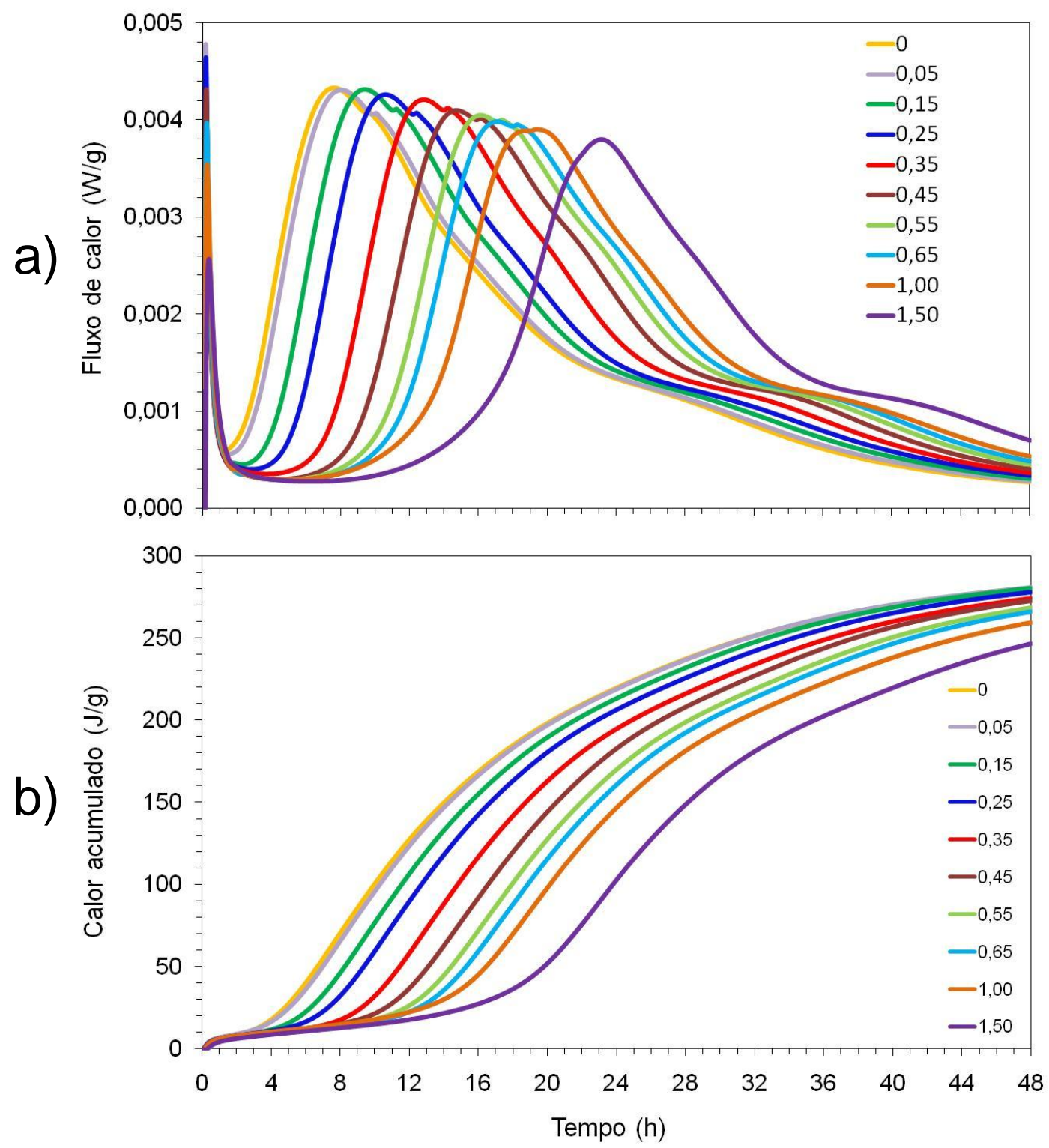

Figura 32 - Curvas de fluxo de calor (a) e calor acumulado (b) em função do tempo para pastas sem aditivo e com adição de diferentes teores de aditivo.

Após o período de indução, inicia-se o período onde as reações de hidratação são aceleradas e a liberação de calor passa a aumentar. Da mesma forma que no período anterior, o teor de policarboxilato influenciou na taxa de reação e esta interferência pode ser visualizada a partir da alteração na inclinação das curvas de fluxo de calor. 
$\mathrm{Na}$ Figura 32b, observa-se que após 48 horas de ensaio o calor total acumulado sofreu influência direta do teor de aditivo utilizado. Quanto maior o teor de policarboxilato, menor foi o calor acumulado. No entanto, as reações ainda estão ocorrendo e com maiores tempos, os calores acumulados das pastas aditivas podem atingir níveis semelhantes aos da pasta pura.

A maior variação de calor acumulado ocorreu no intervalo de aproximadamente $16 \mathrm{~h}$. Os resultados mostram que a diminuição do calor acumulado foi mais significativo para menores teores de aditivo, sendo que a partir de $1 \%$ de aditivo a variação torna-se menor chegando a valores bem próximos para o teor de 1,5\% independente do tempo de ensaio, como mostrado na Figura 33.

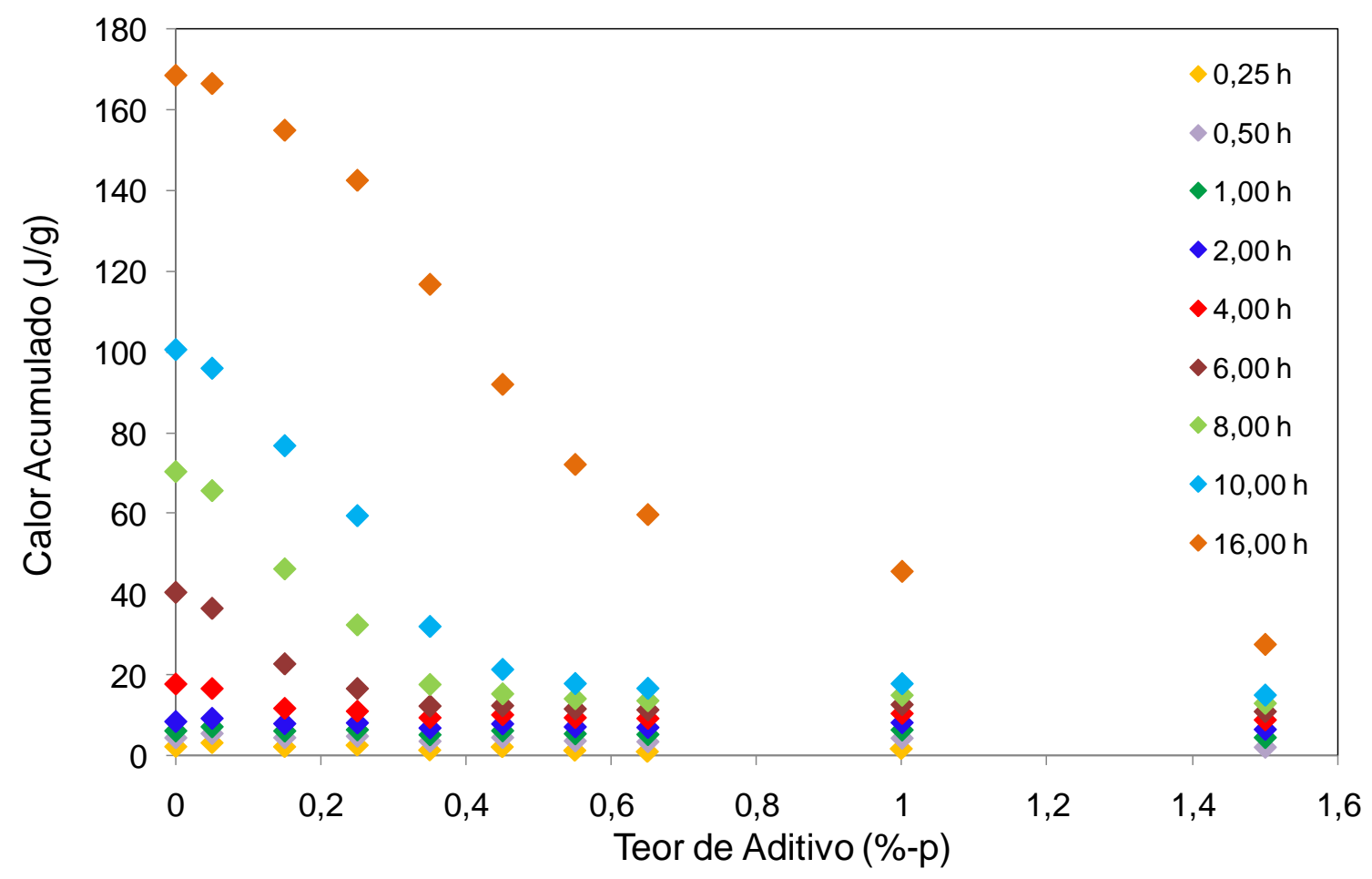

Figura 33 - Variação do calor acumulado em função do teor de aditivo, para um intervalo de 16 horas.

Após $48 \mathrm{~h}$ de ensaio, o calor total liberado nas reações de hidratação apresentou uma tendência inversamente proporcional ao teor de policarboxilato éter, conforme ilustrado na Figura 34. 


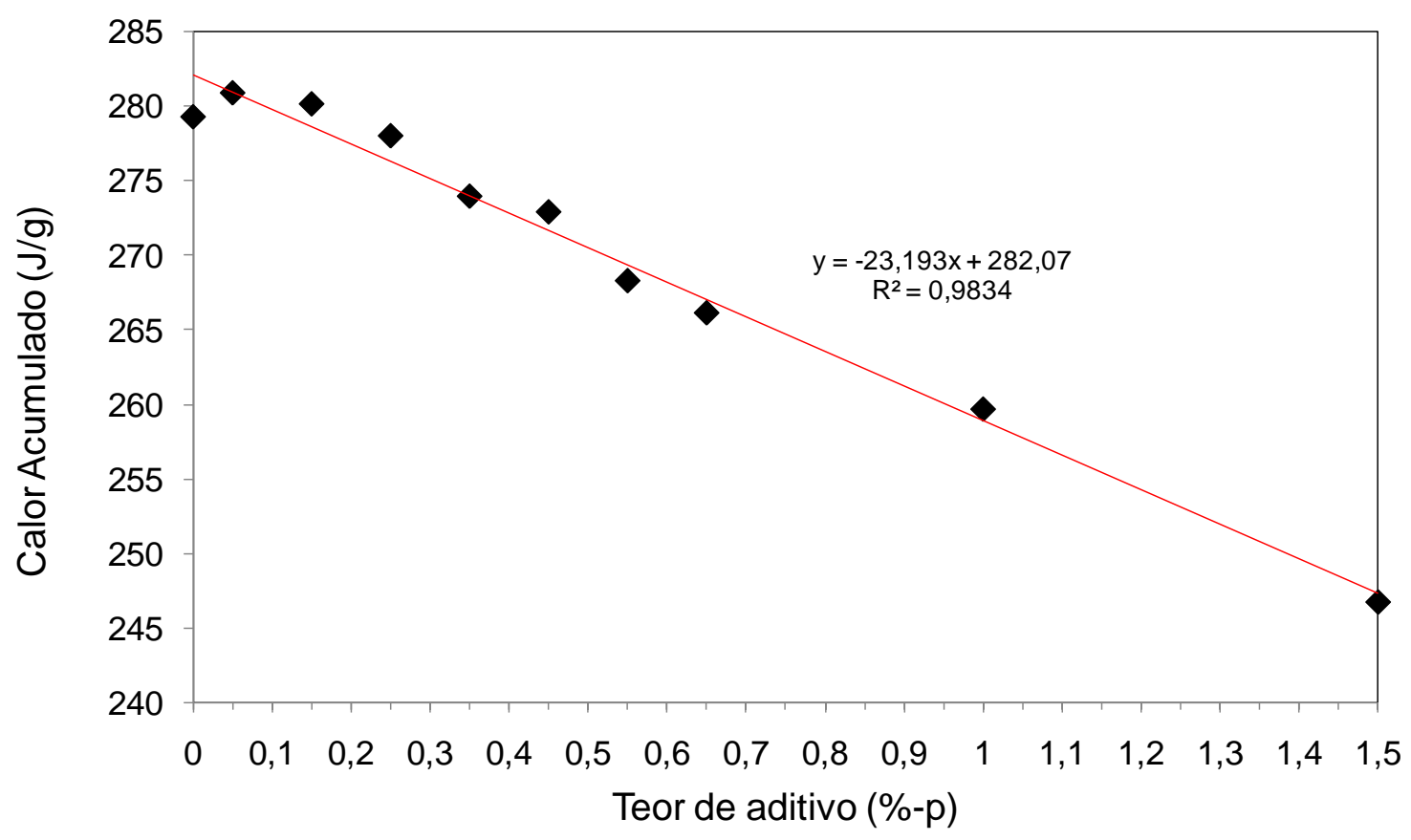

Figura 34 - Calor total liberado após 48 h de ensaio em função do teor de aditivo.

Com base no gráfico da Figura 32a, pode-se determinar os tempos de início e fim de pega a partir de um método gráfico das tangentes. Este método consiste em retas que tangenciam a curva no máximo e mínimo de calor liberado, sendo estas interceptadas por uma reta sobreposta à curva no período de aceleração da reação de hidratação. Os pontos de intersecções das tangentes determinam os valores de início e final de pega, conforme ilustrado na Figura 35, onde as retas vermelhas indicam o início de pega e as verdes o fim de pega das pastas sem aditivo e com $1,5 \%$ de policarboxilato éter. 


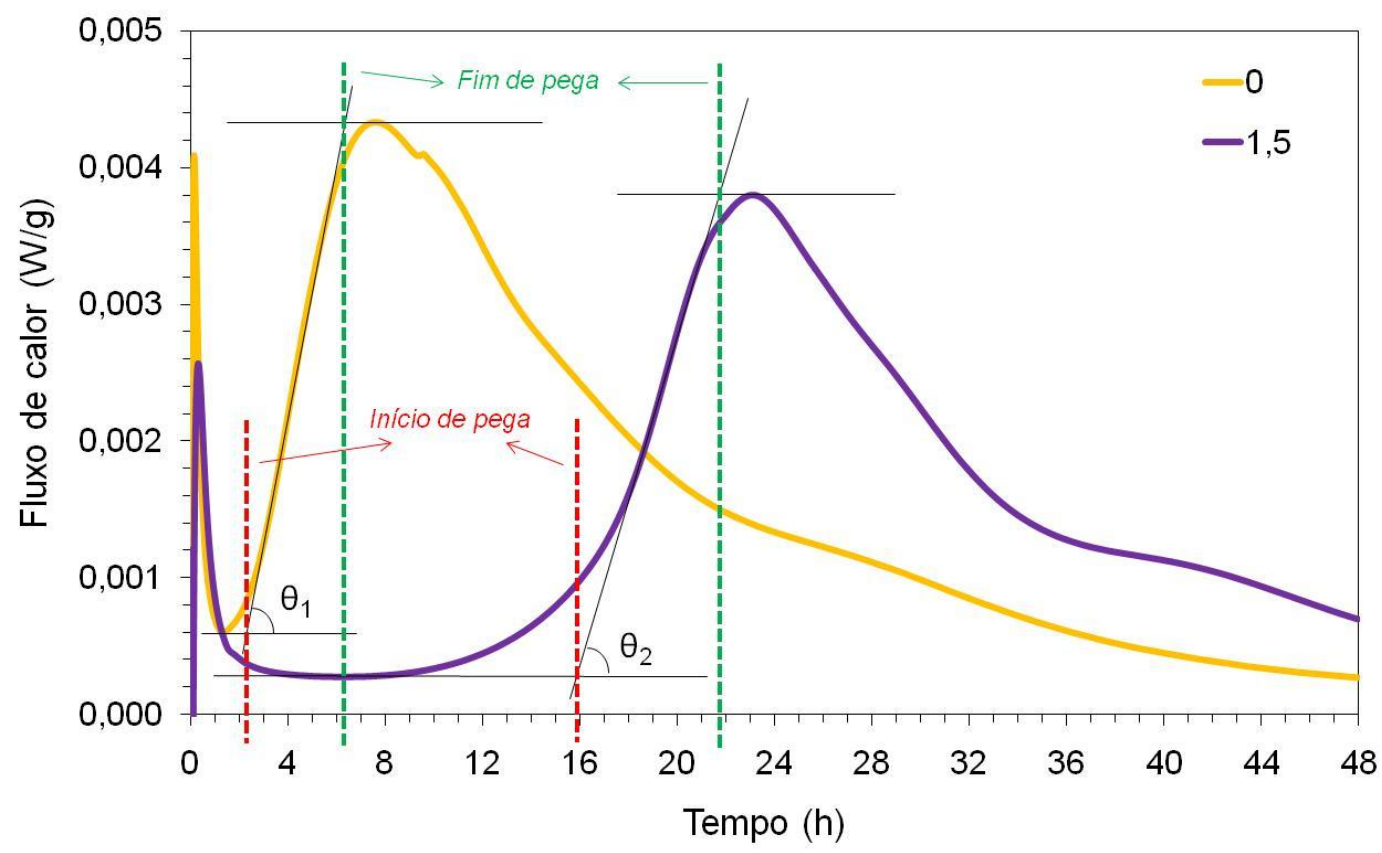

Figura 35 - llustração do método gráfico, com base nas tangentes no máximo e mínimo de calor liberado na hidratação do cimento.

Assim, os tempos de início e fim de pega são ilustrados na Tabela 8, e os resultados comprovam o retardo nas reações de hidratação do cimento em função do aumento do teor do aditivo.

O início de pega para a pasta de referência foi de 2 horas e 20 minutos e para a pasta com menor teor de aditivo $(0,05 \%)$ foi de 2 horas e 34 minutos, chegando a atingir 15 horas e 30 minutos na pasta com 1,5\% de policarboxilato. 
Tabela 8 - Tempos de início e final de pega em função do teor de aditivo.

\begin{tabular}{c|c|c|c}
\hline Teor de aditivo (\%-p) & Início de pega (h) & Final de pega (h) & $\begin{array}{c}\text { Diferença entre } \\
\text { os tempos de } \\
\text { pega (h) }\end{array}$ \\
\hline 0 & 2,33 & 6,11 & 3,78 \\
0,05 & 2,57 & 6,50 & 3,93 \\
0,15 & 3,75 & 7,84 & 4,09 \\
0,25 & 4,80 & 9,24 & 4,44 \\
0,35 & 6,90 & 11,44 & 4,54 \\
0,45 & 8,55 & 13,39 & 4,84 \\
0,55 & 9,89 & 14,78 & 4,89 \\
0,65 & 10,71 & 15,78 & 5,07 \\
1,00 & 12,22 & 17,56 & 5,34 \\
1,50 & 15,50 & 21,70 & 6,20 \\
\hline
\end{tabular}

As possíveis causas para o retardo do tempo de início e final de pega são:

- adsorção dos polímeros na superfície das partículas de cimento, atuando como uma barreira física (efeito estérico) ao acesso da água e à dissolução das fases;

- possível interação química dos grupos ionizáveis do polímero com o cimento (efeito eletrostático).

Estes efeitos influenciam diretamente na taxa de reação, como observado na Figura 35, a inclinação das curvas representadas por $\theta_{1}$ e $\theta_{2}$ são diferentes, mostrando que a reação ocorre com taxa menor se a pasta tiver maior teor de aditivo. Essa diferença entre as taxas de reação de hidratação resulta em 
consideráveis diferenças entre os tempos de início e fim de pega, conforme ilustrado na Figura 36.

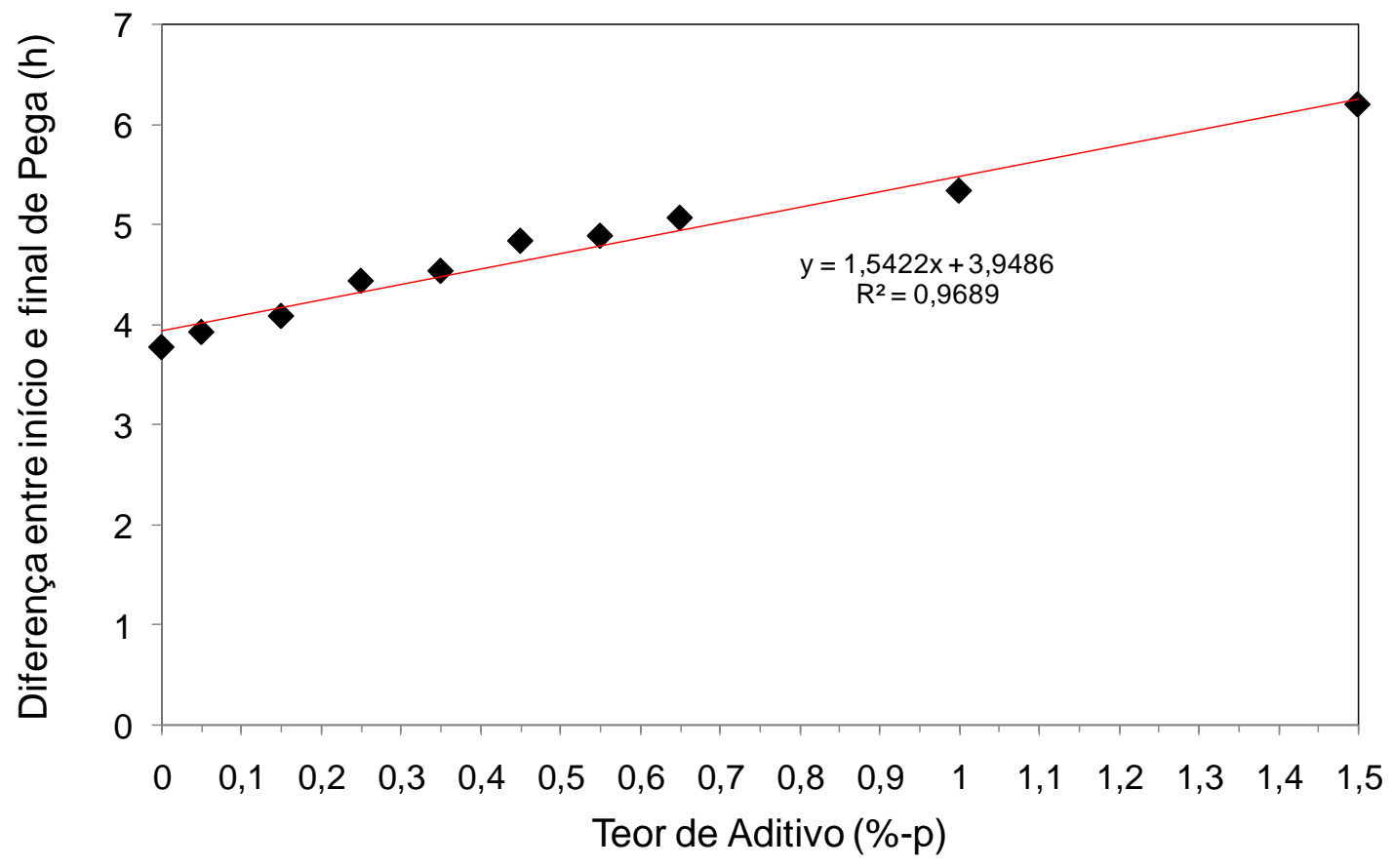

Figura 36 - Tempo entre o início e o fim de pega.

A quantificação do calor liberado durante a hidratação indica a taxa em que o material está reagindo, acelerando ou retardando as reações, em função de uma variável, que neste caso foi o teor de aditivo. No entanto, não indica o impacto nas características dos materiais sob solicitação de fluxo ou oscilação. Para isso, foram realizados ensaios de reometria rotacional e oscilatória com intuito de quantificar esses efeitos, estando os resultados apresentados na seqüência. 


\subsection{Reometria}

\subsubsection{Ensaio de fluxo}

A partir dos ensaios de fluxo contínuo, foram determinados os resultados de tensão de cisalhamento e viscosidade em função da variação do teor de aditivo, conforme ilustrado nas Figuras 37 e 38.

a)
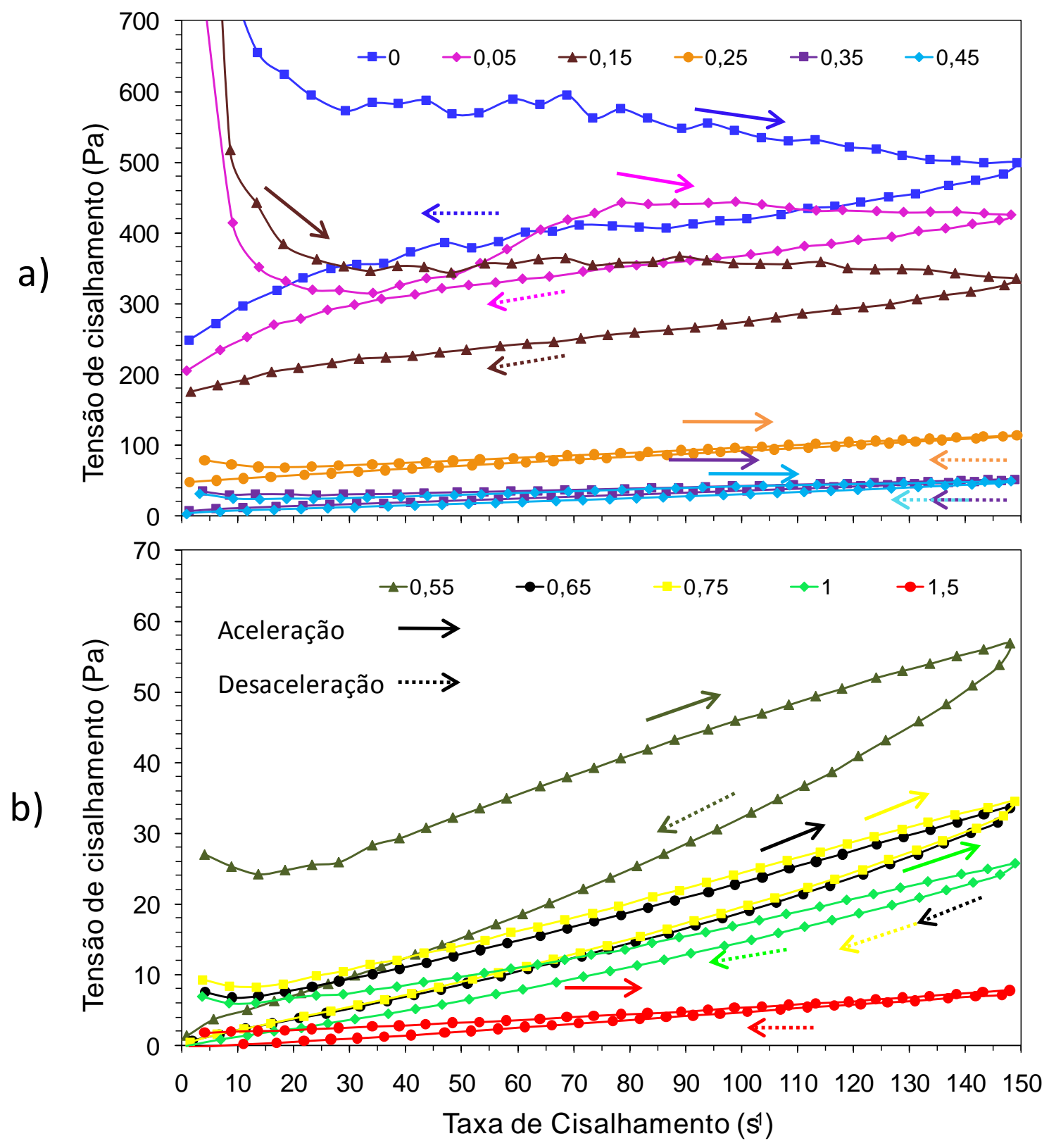

Figura 37 - Variação da tensão de cisalhamento (a) para teores de 0 a $0,45 \% p$ e (b) para teores de 0,55 a $1,5 \%$ p. 
a)
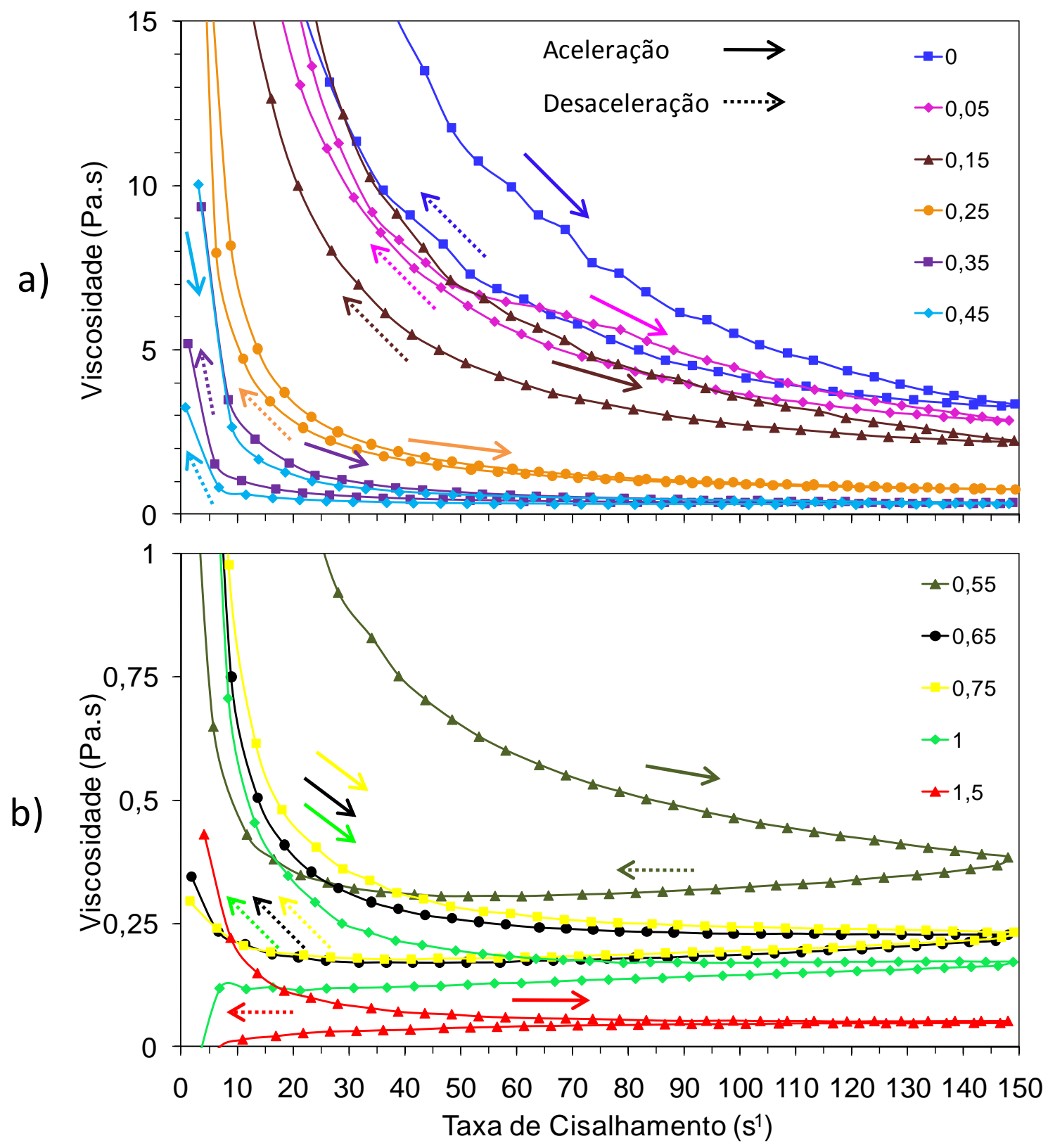

Figura 38 - Variação da viscosidade (a) para teores de 0 a 0,45 \%p e (b) para teores de 0,55 a $1,5 \%$ p.

Com o aumento do teor de aditivo na pasta, tanto a viscosidade quanto a tensão de cisalhamento diminuíram. Este efeito deve ser resultado da desaglomeração das partículas de cimento. Como foi demonstrado nos resultados de potencial zeta, existe uma diminuição inicial do potencial zeta o que deveria aumentar a viscosidade. Contudo, dois mecanismos de estabilização de dispersões podem ocorrer simultaneamente: eletrostático e estérico. A modificação do potencial 
zeta com a introdução do aditivo com relação ao cimento sem aditivo indica que há uma interação das moléculas do aditivo com a superfície do cimento. Como as moléculas têm uma elevada massa molecular e grande volume pode-se supor que quando ocorre a adsorção das moléculas do aditivo há uma diminuição inicial do caráter eletrostático de estabilização, mas que o efeito estérico deve estar agindo desde o momento inicial da introdução do aditivo e assim reduzindo a viscosidade. Com o passar do tempo de interação observou-se também o aumento do potencial zeta do sistema o que leva a um aumento da estabilidade da dispersão cimentícia devido à ação de dois fenômenos de estabilização simultâneos.

Com base nos resultados apresentados na Figura 38, pôde-se quantificar a viscosidade aparente, obtida na máxima taxa de cisalhamento $\left(150 \mathrm{~s}^{-1}\right)$ e a tensão de escoamento a partir da modelagem matemática proposta por Herschel-Bulkley (equação 4).

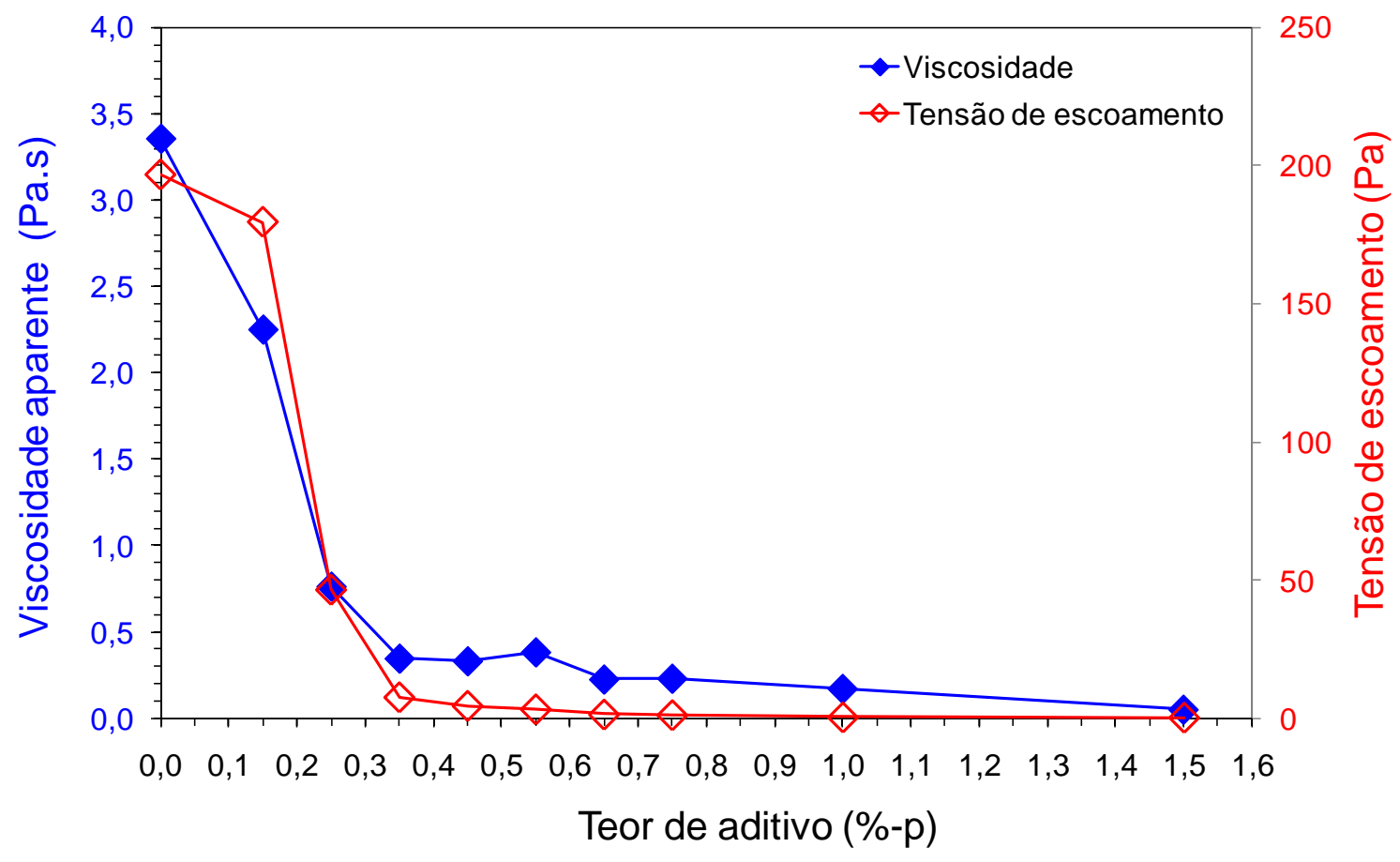

Figura 39 - Curvas de viscosidade na taxa de cisalhamento $\left(150 \mathrm{~s}^{-1}\right)$ e de tensão de escoamento para diversos teores de aditivo. 
O aumento do teor de dispersante ocasionou uma queda na viscosidade aparente, mas a partir do teor de 0,35\% a diferença não se alterou de forma considerável. Da mesma maneira que para a viscosidade, o aumento do teor de aditivo foi responsável pela redução da tensão de escoamento, conforme ilustra a Figura 39.

A partir das curvas de tensão de cisalhamento (Figura 37 a e b) é possível observar que a parte ascendente e a parte descendente não coincidem, resultando na formação de uma área de histerese. Este comportamento indica que o misturador não foi capaz de fornecer energia suficiente para quebrar os aglomerados presentes na mistura. Além disto, a não coincidência das curvas de aceleração e desaceleração, e a não inversão das mesmas evidencia o comportamento tixotrópico das suspensões em estudo.

A Tabela 9 apresenta os valores das áreas de histerese obtidas através da diferença entre as áreas das curvas de aceleração e desaceleração. Verifica-se uma acentuada diminuição das áreas de histerese com o aumento do teor de aditivo evidenciando a influência do aditivo na quebra dos aglomerados e, conseqüentemente sobre a eficiência de mistura do material. 
Tabela 9 - Área de histerese das curvas de cisalhamento das suspensões cimentícias.

\begin{tabular}{c|c|c}
\hline $\begin{array}{c}\text { Teor de aditivo } \\
(\%-p)\end{array}$ & $\begin{array}{c}\text { Área de histerese das } \\
\text { curvas de viscosidade } \\
\left(\text { Pa.s }^{-1}\right)\end{array}$ & $\begin{array}{c}\text { Área de histerese das } \\
\text { curvas de tensão de } \\
\left.\text { cisalhamento (Pa.s } \mathbf{s}^{-1}\right)\end{array}$ \\
\hline 0 & 711,06 & 25168,60 \\
0,05 & 535,65 & 10151,84 \\
0,15 & 1214,46 & 18606,92 \\
0,25 & 60,15 & 1192,71 \\
0,35 & 48,79 & 1467,52 \\
0,45 & 62,14 & 1793,10 \\
0,55 & 62,76 & 2174,41 \\
0,65 & 16,50 & 643,87 \\
0,75 & 21,77 & 764,79 \\
1,00 & 16,32 & 501,61 \\
1,50 & 4,98 & 151,99 \\
\hline
\end{tabular}

A redução da viscosidade aparente e da tensão de escoamento ocorreu conforme esperado. Porém, não foi observada a inversão no valor da viscosidade aparente e nem da tensão de escoamento em função do aumento do teor de aditivo, fato que pode ser observado em literatura para outros tipos de dispersantes.

A dosagem excessiva de dispersante altera de maneira considerável a viscosidade (Figura 40). Para teores maiores que 1,0\%, já ocorre a variação do perfil da curva, podendo atingir perfis totalmente contrários ao usual, como mostrado na Figura 40 a e b. Neste caso, as pastas apresentam viscosidades aparentes muito semelhantes, mas, os perfis reológicos das curvas de viscosidade em função da 
taxa de cisalhamento são diferentes, provavelmente devido à formação de emaranhados poliméricos que altera a reologia da pasta, devido ao excesso de aditivo.
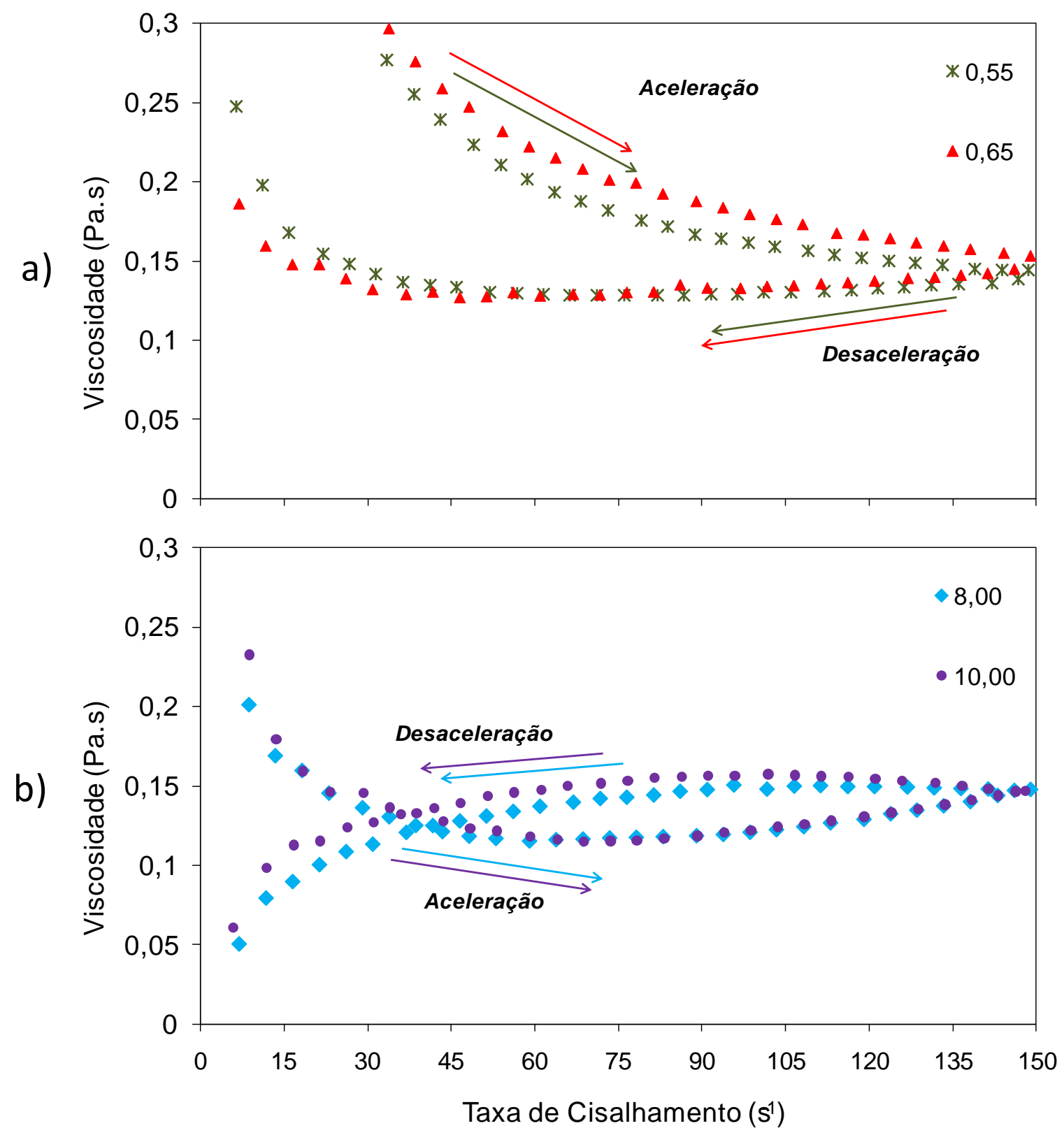

Figura 40 - Variação do perfil das curvas de viscosidade em função da taxa de cisalhamento; a) para teores normais e b) para altos teores de aditivo.

Por isso, a otimização do teor de aditivo, além de ser fundamental para adequar as propriedades das pastas durante o fluxo, é importante também durante a 
consolidação, pois conforme observado anteriormente, as reações de hidratação são afetadas pela alteração do teor de polímero na composição.

\subsubsection{Ensaio oscilatório}

Os resultados dos ensaios oscilatórios são apresentados em forma de G' e G" respectivamente a componente elástica e componente viscosa e que indicam o estado de consolidação da suspensão em função do tempo.

A evolução de G' e G” pode ser observada nos gráficos abaixo, onde se tem a variação da componente elástica e da componente viscosa em função do teor de aditivo. Inicialmente, verifica-se um alto valor de G' e G” para a pasta sem aditivo, já para as pastas aditivadas percebe-se uma significativa diminuição de ambos os módulos. Este efeito é devido as forças de aglomeração que inicialmente dominam o sistema, porém após a adição do aditivo temos as forças eletroestéricas agindo sobre as forças de aglomeração. Esta interação das forças afetará as curvas de G' e G”, sendo que a alteração na evolução dos módulos e até mesmo na estabilidade da consolidação dependerá do teor de aditivo utilizado na pasta. Como ilustrado na Figura 41. 


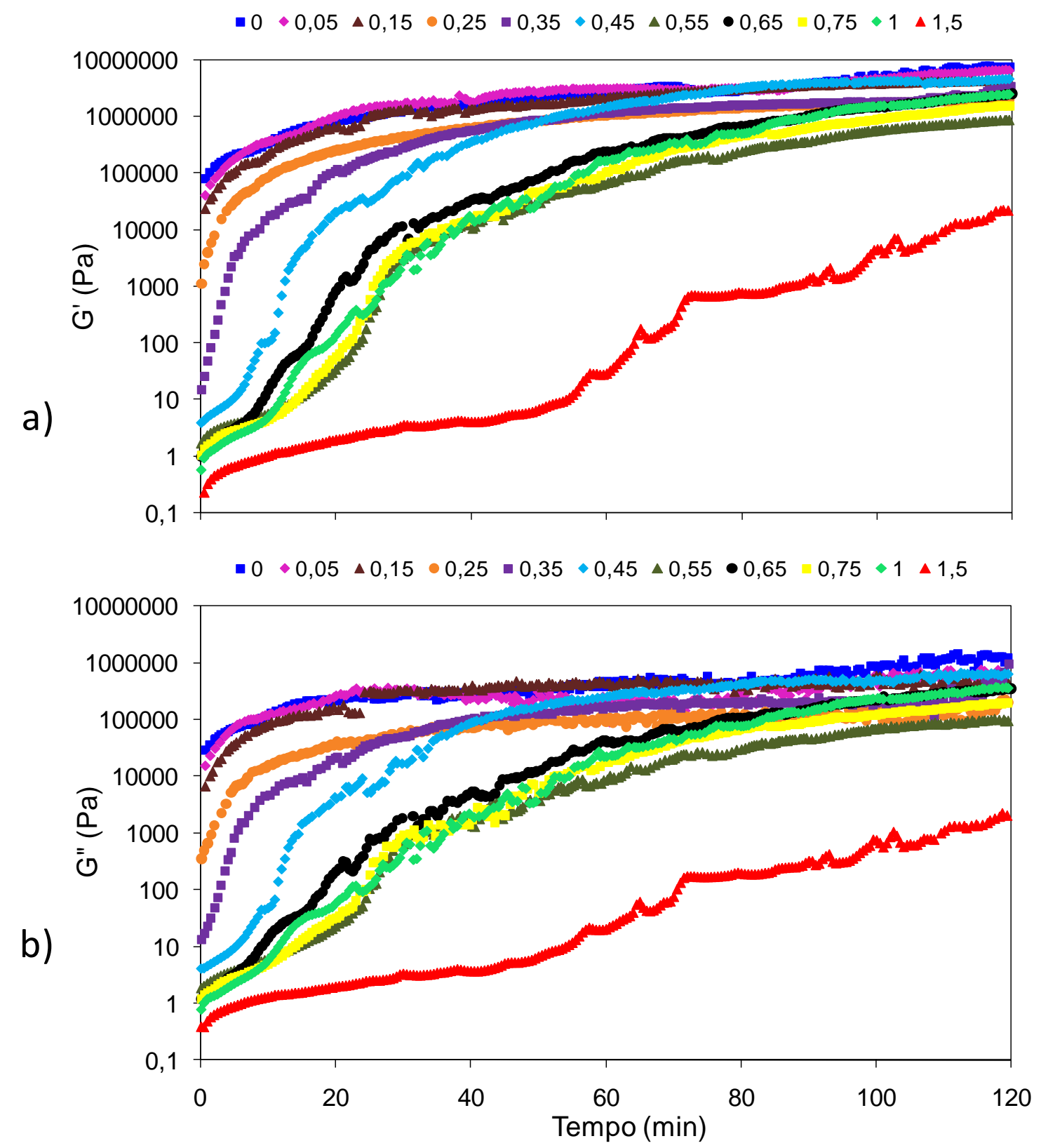

Figura 41 - Curvas de G' (a) e curvas de G” (b) em função do tempo, para diversos teores de aditivo.

A presença do aditivo retarda o tempo de consolidação, já que altera as reações de hidratação e depende da taxa de adsorção sobre as partículas de cimento, como também do teor adicionado nas pastas.

O excesso de aditivo pode gerar problemas na consolidação dos materiais cimentícios, como por exemplo: a diminuição da resistência pós-cura devido ao 
excesso de material polimérico na estrutura do material. Portanto, deve-se considerar a otimização do teor de aditivo como um dos pontos mais importantes para o processamento das pastas cimentícias aditivadas.

Como ilustrado na Figura 41, para um teor de 0,25\%-p, existe um tempo de "eficiência" do dispersante, onde a pasta permanece dispersa por, pelo menos 5 minutos. A partir deste tempo, há uma rápida aglomeração das partículas na pasta cimentícia, devido às reações de hidratação do cimento. Aumentando-se mais o teor do aditivo, é possível observar uma significativa diminuição nos níveis de G' e aumento no período em que as suspensões permanecem desaglomeradas, ocasionando o retardo da consolidação.

A partir do teor de 0,35\%-p foi observado valores semelhantes de viscosidade nos ensaios de fluxo, mas durante o ensaio oscilatório os valores foram muito diferentes, salientando o maior efeito do aditivo durante a consolidação das pastas cimentícias.

A partir dos valores de G' e G”, verifica-se que o teor mais adequado para as pastas estudadas com o uso do cimento CP II-E foi de $0,35 \%$, isto visando a razão custo/benefício e a eficiência do aditivo. Com este teor tem-se uma pasta com baixa viscosidade, baixa tensão de escoamento e um tempo considerável de eficiência no tempo de retardo da consolidação, que resulta em aproximadamente $7 \mathrm{~h}$ conforme Tabela 8 (página 80), para o início de pega da pasta em questão.

O uso de altas doses de policarboxilato éter pode alterar o comportamento viscoelástico da amostra como mostrado na Figura 42. 


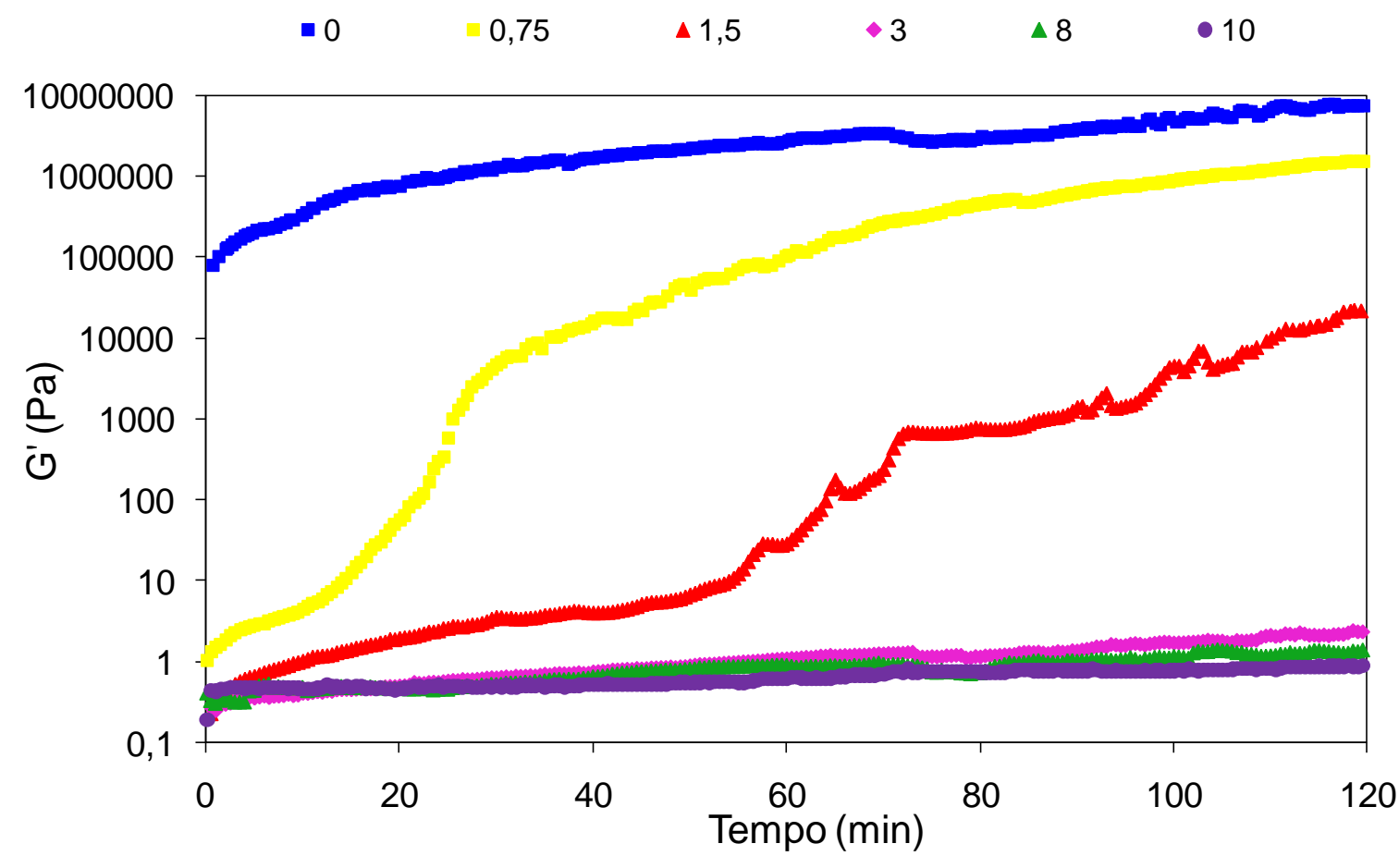

Figura 42 - Curvas de G' em função do tempo, para altos teores de aditivo.

Verifica-se uma acentuada diminuição do valor de G' para teores maiores que 0,75\%, sendo ainda observado que mesmo após 120 minutos a consolidação da pasta cimentícia possui valores muito baixos para teores acima de $3 \%$ de aditivo. Este efeito deixa claro que a hidratação do cimento desenvolve-se de acordo com a quantidade de aditivo, ou seja, o excesso de polímero na suspensão evita a dissolução dos constituintes do cimento e prejudica a formação das fases no sistema, tornando a consolidação lenta e inviável para o processamento de materiais cimentícios.

O ensaio oscilatório ilustra as características das pastas durante a consolidação onde, durante o processo estão ocorrendo reações de hidratação do cimento.

A relação entre calor acumulado e G' pode ser observada na Figura 43, evidencia a diminuição da taxa de reação de hidratação com o aumento do teor de 
policarboxilato éter, pois a liberação do calor aumenta conforme as reações acontecem, ou seja, quando G' aumenta. Portanto, o aditivo conseguiu por um determinado período retardar as reações da pasta, mas passado este intervalo temse a consolidação da mesma, resultando no aumento do calor liberado pelas reações de hidratação.

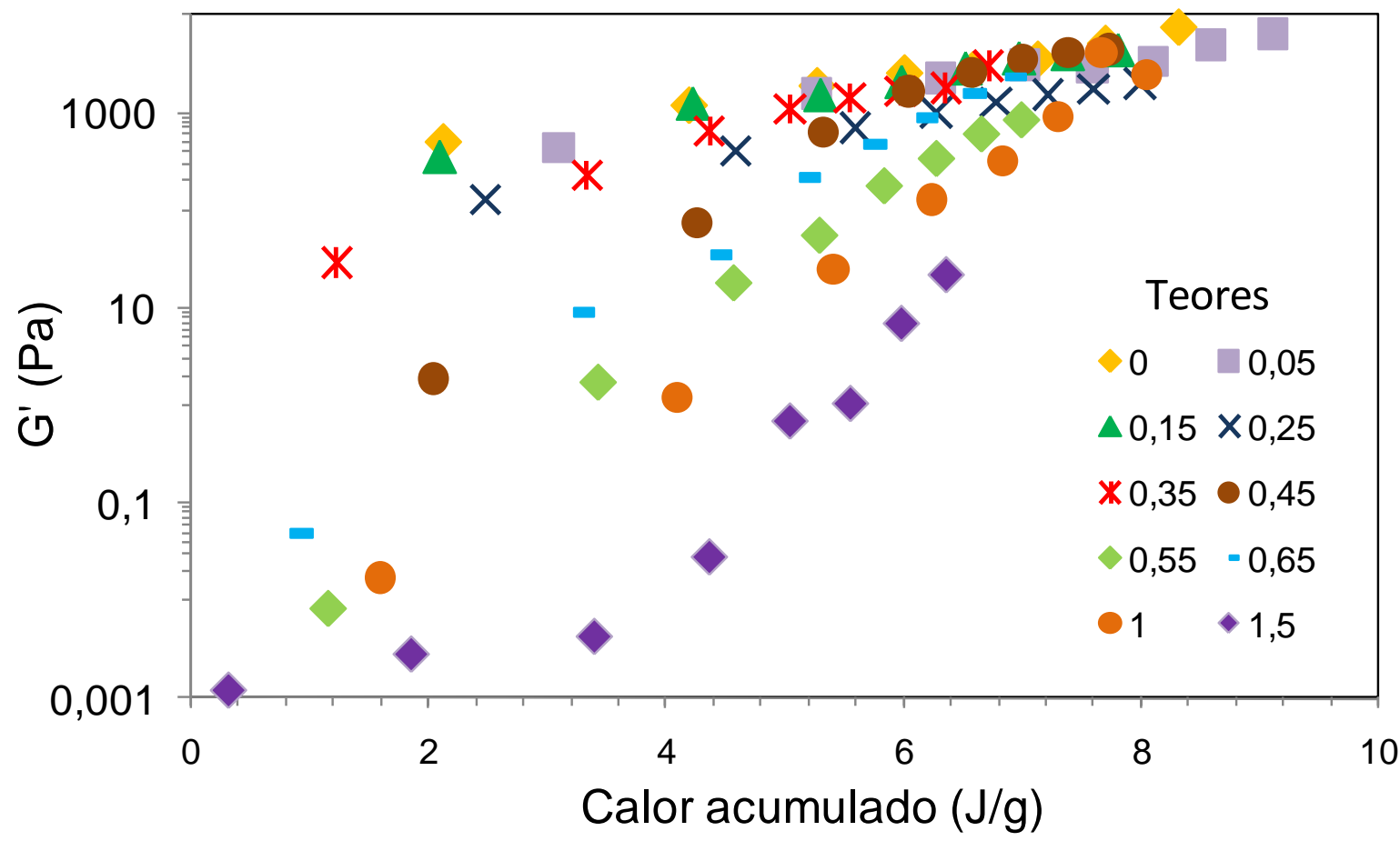

Figura 43 - Curvas de G' em função do calor acumulado para suspensões sem aditivo e com diferentes teores de policarboxilato éter.

Para a pasta sem aditivo, tem-se uma rápida variação (Figura 43) nos valores de G' pois as reações de hidratação não sofrem influencia do aditivo e a mesma inicialmente já apresenta altos valores de G'. No entanto as pastas aditivadas por terem suas reações retardadas devido ao mecanismo eletroestérico originado pela adsorção do aditivo nas partículas do cimento, apresentam uma variação menor quanto maior for o teor de policarboxilato éter. Mas, com o passar do tempo e a evolução da consolidação, todas as pastas poderão alcançar valores finais de G' semelhantes. 


\section{Conclusões}

Utilizando uma metodologia inovadora composta de diferentes tipos de ensaios, foi possível avaliar a influência do aditivo Glenium 51 na consolidação das pastas de cimento, sendo verificado que o fenômeno de consolidação de materiais cimentícios é influenciado tanto pelos fenômenos químicos de hidratação do cimento, como também pelos fenômenos físicos, que estão diretamente ligados à aglomeração das partículas de cimento em meio aquoso.

A diminuição do potencial de superfície foi determinada através de medidas de potencial zeta por ESA. Os resultados confirmam de forma clara a interação dos grupos funcionais da macromolécula com as cargas de superfície das partículas do cimento. Sendo, observada uma diminuição do potencial zeta nos primeiros instantes após a mistura, este efeito é decorrente da estabilização estérica originada pela adsorção de uma camada polimérica na superfície das partículas, evitando a aproximação das mesmas. Com o passar do tempo, as reações de hidratação vão acontecendo e a estabilização da suspensão passa a ser controlada pelos mecanismos eletroestérico originado pelos grupos funcionais contidos nas cadeias laterais do polímero.

A interação dos grupos funcionais do aditivo com os íons cálcio em solução foi confirmada com as medidas de condutividade em função do teor de nitrato de cálcio. Onde se verifica uma mudança na inclinação da curva de condutividade, no instante em que, possivelmente a concentração de íons cálcios passa a ser maior que as cargas negativas do polímero. Este aumento, junto com a diminuição da influência das cargas do polímero resultou no aumento da condutividade. 
A presença do aditivo promoveu alterações nas propriedades reológicas das suspensões, sendo que o aumento do teor gerou a queda tanto na viscosidade quanto na tensão de escoamento. Estes efeitos são maiores quanto maior for o aumento do teor de aditivo.

Mesmo elevando o teor de aditivo para valores de $10 \%$, não foi observado uma inversão dos valores de viscosidade em função da variação do teor do policarboxilato, conforme ocorre para vários tipos de aditivos.

A velocidade de reação de hidratação do cimento também foi afetada pela presença do aditivo. Quanto maior o teor, maior foi o tempo de início de pega. O retardo das reações de hidratação está diretamente relacionado com o estado de dispersão das partículas, que por meio do mecanismo eletroestérico mantém as partículas de cimento afastadas e com potencial de dissociação e precipitação de hidratos reduzidos. Além disso, quanto maior o teor de aditivo, maiores foram as diferenças entre o início e o final de pega, ilustrados pela alteração na inclinação das curvas no ensaio de calorimetria. Lembrando que, as reações tanto para a pasta sem aditivo, quanto para as pastas aditivadas as reações ocorrem normalmente, no entanto para as pastas aditivadas a taxa de reação é bem menor, resultando em um maior período de aceleração, ou seja, a reação alcança o final de pega em tempo muito acima do normal.

Os resultados dos ensaios de fluxo realizados neste trabalho mostram uma significativa redução da viscosidade em função do aumento dos teores de aditivo. Já os resultados dos ensaios oscilatórios mostraram que o Glenium 51 foi responsável pela redução das componentes elástica e viscosa (G' e G”). Desta forma, pode-se afirmar que o controle inicial do comportamento reológico das pastas é dependente do teor de policarboxilato,sendo de grande importância a otimização destes teores, 
pois o excesso dos mesmos podem ocasionar mudanças no comportamento viscoelástico da pasta. Resultando em situações inviáveis de aplicação.

A partir dos resultados, verifica-se que o teor mais adequado para as pastas estudadas com o uso do cimento CP II-E foi de 0,35 \%, isto visando a razão custo/benefício e a eficiência do aditivo. Com este teor tem-se uma pasta com baixa viscosidade, baixa tensão de escoamento e um tempo considerável de eficiência no tempo de retardo da consolidação, que resulta em aproximadamente $7 \mathrm{~h}$ conforme Tabela 8 (página 80), para o início de pega da pasta em questão.

Por fim, é possível afirmar que o presente trabalho possibilitou uma melhor elucidação dos fenômenos envolvidos na consolidação de pastas cimentícias, além de um melhor entendimento do mecanismo de interação dos aditivos policarboxilatos, sobre o comportamento reológico de suspensões cimentícias, promovendo subsídios que visam auxiliar na definição dos parâmetros de formulação de materiais à base de cimento. 


\section{Referências}

1. Ortega, F.S., Pandolfelli, V. C., Rodrigues, J. A., Souza, D. P. F.;, Artigo Revisão: Aspectos da Reologia e da Estabilidade de Suspensões Cerâmicas Parte II: Mecanismos de Estabilidade Eletrostática e Estérica. Cerâmica, 1997. 43: p. 77-83.

2. Ortega, F.S., Pandolfelli, V. C., Rodrigues, J. A., Souza, D. P. F.;, Artigo Revisão: Aspectos da Reologia e da Estabilidade de Suspensões Cerâmicas Parte III: Mecanismo de Estabilização Eletroestérica de suspensões com Alumina. Cerâmica, 1997. 43: p. 113-119.

3. Oliveira, I.R., Studart, A. R., Pileggi, R. G., Pandolfelli, V. C., Dispersão e Empacotamento de Partículas: princípios básicos e aplicações em processamento cerâmico. 2000, São Paulo: Fazendo Arte Editorial. 224.

4. Ramachandran, V.S., et al., Superplasticizing Admixtures, in Handbook of Thermal Analysis of Construction Materials. 2002, William Andrew Publishing: Norwich, NY. p. 261-292.

5. Gouvêa, D., Murad, B. B. S., Influência das características ácido-básicas da superfície dos óxidos na estabilidade de suspensões cerâmicas de Al2O3 ou SnO2 com dispersantes comerciais. Cerâmica, 2001. 47, no 301.

6. Andersen, P.J., The effect of superplasticizers and air-entraining agents on the zeta potential of cement particles. Cement and Concrete Research, 1986. 16: p. 931-940.

7. Mikanovic, N., Simard, M-A., Jolicoeur, C. C., Interaction between poly-napthalene sulfonatetype superplasticizers and cements during initial hydration., in Proceedings of the Sixth CANMET/ACI International Conference on Superplasticizers and Others Chemical Admixtures in Concrete, ACI SP-195, Edited by V. M. Malhotra. 2000: Nice - France. p. 561583.

8. Andersen, P.J., Roy, D. M., Gaidis, J. M., The effect of superplasticizer molecular weight on its adsorption and dispersion of cement. Cement and Concrete Research, 1986. 16: p. 980-986.

9. Diamond, S., Struble, L. J., Interaction between naphthalene sulfonate and silica fume in Portland cement pastes. In: Materials Research Society Fall Meeting. 1987, Boston. 19p.

10. Massazza, F., Costa, V. B., Effect of superplasticizer on the CA hydration., in In: 7th International Conference on Chemistry of Cement. 1980: Paris. p. 529-534.

11. Aïtcin, P.-C., Sarkar, S. L., Retardation effect of superplasticizer on different cement fractions. Cement and Concrete Research, 1987. 17: p. 995-999.

12. Rixom, M.R., Mailvaganam, N. P., Chemical admixtures for concrete, ed. T. Edition. 1999, New York. 437p.

13. Aitcin, P.-C., Concreto de Alto Desempenho. Tradução: Geraldo G. Serra. 2000, São Paulo: Ed. Pini. 667p.

14. Taylor, H.F.W., Cement Chemistry. 1990, London. 475.

15. Mehta, P.K., Monteiro, P. J. M., CONCRETO Microestrutura, Propriedades e Materiais. 3으. ed. 2008. 674.

16. Lea, F.M., Hewlett, P. C, Lea's Chemistry of Cement and Concrete. 4 ed. 1998. 1053.

17. ASSOCIAÇÃO BRASILEIRA DE NORMAS TÉCNICAS. NBR 5732: Cimento Portland comum. 1991.

18. Kihara, Y., et al., Aptidão à Clinquerização de Farinhas de Cimento: fator de controle e qualidade do cimento. São Paulo: ABCP, 1983. (ET-48).

19. Moir, G.K., Glasser, F.P., Mineralizer, Modifiers and Activators in the Clinkering process. In: INTERNATIONAL CONGRESS ON THE CHEMISTRY OF CEMENT, 9. Delhi. 1992. 1.

20. Wolter, A., Influence of the kiln system on the clinker properties, Zement-Kalk, Wiesbaden. 1985. 38(12): p. 327 - 329.

21. Maringolo, W., Clínquer co-processado: produto de tecnologia integrada para sustentabilidade e competitividade da indústria de cimento., in Instituto de Geociências/USP. 2001, Universidade de São Paulo: São Paulo. p. 162.

22. Odler, I., Special Inorganic Cements. 3 ed. 2000. 395. 
23. Munhoz, F.A.d.C., Efeito de Adições Ativas na Mitigação das Reações Álcali-Sílica e ÁlcaliSilicato. 2007, Escola Politécnica da Universidade de São Paulo: São Paulo.

24. Kihara, Y., Centurioune, S. L., O Cimento Portland. In: Isaias, G. C. CONCRETO: Ensino, Pesquisa e realizações. Vol. 1. 2005, São Paulo: IBRACON. 295-332.

25. Yahia, A., M. Tanimura, and Y. Shimoyama, Rheological properties of highly flowable mortar containing limestone filler-effect of powder content and $W / C$ ratio. Cement and Concrete Research, 2005. 35(3): p. 532-539.

26. Brunauer, S., and Copeland, L. E., The Chemistry of Concrete. 1964.

27. Jawed, I., Skalny, J., Young, J. F., Hydratation of Portland Cement. In: Barnes, P. (Ed.). Structure and performance of cement. 1983. p. 237 - 318.

28. Odler, I.A.-M., S., Possibilities of quantitative determination of the Aft-(ettringite) and AFm(monosulphate) phases in hydrated cement pastes. Cement and Concrete Research, 1984. 14: p. 133-141.

29. Odler, I., Hydration, setting and hardening of Portland cement. In: HEWLETT, P. C. (Ed.). Lea's Chemistry of cement and concrete. 4. ed. 1998.

30. Young, J.F., A review of the mechanisms of set-retardation in portland cement pastes containing organic admixtures. Cement and Concrete Research, 1972. 2: p. 415-433.

31. Stein, H.N., Rheological Behavior of Suspensions; , in Encyclopedia of fluid mechanics: slurry flow techology, N.P. Cheremisinoff, Editor. 1986, Gulf Publishing: Houston. p. 3-47.

32. Banfill, P.F.G., The Rheology if Fresh Mortar: a review. Simpósio Brasileiro de Tecnologia das Argamassas, 2005: p. 73-82.

33. Pileggi, R.G., Ferramentas para o Estudo e Desenvolvimento de Concretos Refratários, in Engenharia de Materiais. 2001, Universidade Federal de São Carlos: São Carlos.

34. Darby, R., Hydrodynamics of Slurries and suspensions, in Encyclopedia of fluid mechanics, N.P. Cheremisinoff, Editor. 1986, Gulf Publishing: Houston. p. 49-91.

35. Rago, F.e.a., A Reologia da Pasta de Cimento e a Influência da Cal. I Simpósio Brasileiro de Tecnologia das Argamassas, 1995: p. 25-32.

36. Brito, S.L.M., Estudo de suspensões obtidas a partir da composição de um sistema varistor à base de ZnO para viabilizar técnicas de conformação por eletroforese (EPD), in Engenharia Metalúrgica e de Materiais. 2003, Universidade de São Paulo: São Paulo.

37. Cyr, M., Contribuition à la caractérisation des fines minérales et à la compréhension de leur rôle joué dans le comportement rhéologique des matrices cimentaires, in Engenharia Civil. 1999, L'INSA de Toulouse et L'Université de Sherbrooke: Toulouse. p. 273.

38. Van Vlack, L.H., Princípios de Ciência e Tecnologia dos Materiais, ed. 4. 1994, Rio de Janeiro: Editora Campus. 567p.

39. Callister, W.D., Materials Science and Engineering: An Interactive. 2000, New York. p.524.

40. Yang, M., Neubauer, C. M.; Jennings, H. M., Interparticle Potential and Sedimentation Behavior of Cement Suspensions. Advanced Cement Based Materials, 1997. v.5: p. 1-7.

41. Derjaguin, B.V., Landau, L.;, Theory of Stability of Highly charged Lyophobic sols and Adhesion of Highly charged Particles in Solutions of Eletrolytes. Acta Physicochim, 1941. 14: p. 633-652.

42. Verwey, E.J.W., Overbeek, J. T. G.;, Theory of the Stability of Lyophobic Colloids. 1948, Amsterdan: Elsevier Publishing Company Inc. p.203.

43. Gregory, J., Approximate expressions for retarded van der waals interaction. Journal of Colloid and Interface Science, 1981. 83(1): p. 138-145.

44. McCartney, L.N., Levine, S.;, An Improvement on Derjaguin's Expression at Small Potentials for the Double Layer Interaction Energy of Two Spherical Colloidal Particles. Journal of Colloid and Interface Science, 1969. 30: p. 345-354.

45. Hunter, R.J., Introduction to Modern Colloid Science. Vol. 1. 1994, New York: Oxford Science Publications.

46. Hover, K.C., Concrete Mixture Proportioning with Water-reducing Admixtures to Enhance Durability: a quantitative model. Cement and Concrete Composites, 1998. 20: p. 113-119. 
47. Ramachandran, V.S., Concrete Admixtures Handbook - Properties, Science, and Technology. 1995, New Jersey: Noyes Publications. 1153p.

48. Rixom, M.R., The Economic Aspects of Admixture Use. Cement and Concrete Composites, 1998. 20: p. 141-147.

49. Malhotra, V.M., Innovative applications of superplasticizers in concrete - A review. Proceeding of Mario Collepardi symposium on advances in concrete science and technology, 1997: p. 271-314.

50. Buekett, J., International Admixture Standards. Cement and Concrete Composites, 1998. 20: p. 137-140.

51. Uchikawa, H., S. Hanehara, and D. Sawaki, The role of steric repulsive force in the dispersion of cement particles in fresh paste prepared with organic admixture. Cement and Concrete Research, 1997. 27(1): p. 37-50.

52. Dodson, V.H., Concrete admixtures (VNR Structural Engineering Series), ed. edition. 1990, New York. 208p.

53. Dezhen, G., Dayu, X., Zhang, L., Model of mechanism for naphthalene series water-reducing agent. ACl Journal, 1982. 79: p. 378-386.

54. Ramachandran, V.S., Malhotra, V. M., Superplasticizers. In: Concrete Admixture Handbook: Properties science and technology. 1998, Canada: Noyes Publication. 1112p.

55. Neville, A.M., Propriedades do Concreto. 2 ed. 1997, São Paulo: Ed. Pini. 828p.

56. Collepardi, M., Admixtures used to enhance placing characteristics of concrete. Cement and Concrete Composites, 1998. 20: p. 103-112.

57. Yamada, K., et al., Effects of the chemical structure on the properties of polycarboxylate-type superplasticizer. Cement and Concrete Research, 2000. 30(2): p. 197-207.

58. Prince, W., Edwards-Lajnef, M. Aitcin, P-C., Interaction between ettringite and a polynaphthalene sulfonate superplasticizer in a cementitious paste. Cement and Concrete Research, 2002. 32: p. 79-85.

59. Hanehara, S. and K. Yamada, Interaction between cement and chemical admixture from the point of cement hydration, absorption behaviour of admixture, and paste rheology. Cement and Concrete Research, 1999. 29(8): p. 1159-1165.

60. Prince, W., M. Espagne, and P.C. Aïtcin, Ettringite formation: A crucial step in cement superplasticizer compatibility. Cement and Concrete Research, 2003. 33(5): p. 635-641.

61. Nakajima, Y., Goto, T., Yamada, K., Cement characteristics affecting the performance of Bnaphthalene sulfonate superplasticizer. Proceedings of the Seventh CANMET/ACI International Conference on Superplasticizers and Others Chemical Admixtures in Concrete, ACI SP-217. 2003, Berlim - Germany: Edited by V. M. Malhotra. 311-326.

62. Jolicoeur, C., Simard, M-A., Chemical admixture-cement interactions: Phenomenology and physico-chemical concepts. Cement and Concrete Composites, 1998. 20(2-3): p. 87-101.

63. Ramachandran, V.S., Adsorption and hydration behavior of tricalcium aluminate-water and tricalcium aluminate-gypsum-water systems in the presence of superplasticizers. ACl Journal, 1983. 80: p. 235-241.

64. Ramachandran V. S., M., V. M., Jolicoeur, C., Spiratos, N., Superplasticizers: properties and applications in concrete. 1998, Canada: Materials Techonoly Laboratory, CANMET. 403p.

65. Carino, N.J., Lew, H. S., Model of mechanism for naphthalene series water-reducing agent. ACl Journal, 1983. 80: p. 177-182.

66. Kim, B.-G., Jiang, S., Jolicoeur, C., Aitcin, P-C., The adsorption behavior of PNS superplasticizer and its relation to fluidity of cement paste. Cement and Concrete Research, 2000. 30: p. 887893.

67. Yoshioka, K., Tazawa, E., Kawai, K., Enohata, T., Adsorption characteristics of superplasticizers on cement component minerals. Cement and Concrete Research, 2002. 32: p. 1507-1513.

68. Uchikawa, H., Sawaki, D., Hanehara, S., Influence of kind and added timing of organic admixture on the composition, structure and property of fresh cement paste. Cement and Concrete Research, 1995. 25: p. 353-364. 
69. Nawa, T., Eguchi, H., Fukaya, Y., Effect of alkali sulfate on the rhaological behaviour of cement paste containing a superplasticizer. . Proceedings of the Third CANMET/ACI International Conference on Superplasticizers and Others Chemical Admixtures in Concrete, ACl SP-119, ed. E.b.V.M. Malhotra. 1989, Ottawa - Canada. p.405-424.

70. Romano, R.C.O., Schreurs, H., John, V. M., Pileggi, R. G, Influência da técnica de dispersão nas propriedades de sílica ativa, Aceito para publicação. Revista Cerâmica, 2008.

71. Quarcioni, V.A., Influência da Cal Hidratada nas Idades Iniciais da Hidratação do Cimento Portland - Estudo em Pasta - (Tese - Doutorado), in Engenharia de Construção Civil. 2008, Universidade de São Paulo: São Paulo. p. 172.

72. Webb, P.A., Orr, C., Analytical Methods in Fine Particle Technology. 1997, Norcross: Micromeritics Instrument Corporation.

73. Formoso, L.L.M., Trescases, J. J., Dutra, C. V., Gomes, C.B., Técnicas Analíticas Instrumentais Aplicadas à Geologia. 1984, São Paulo.

74. Hunter, R.J., Review: Recent Developments in the Eletroacoustic Characterisation of Colloidal Suspensions and Emulsions. Colloids and Surfaces A: Physicochemical an Engineering Aspects, 1998: p. 37-65.

75. Borner, A., Herbig, R., ESA Measurement for Electrophoretic Deposition of Ceramic Materials. Colloids and Surfaces A: Physicochemical an Engineering Aspects, 1999: p. 439-447.

76. Sciences, M.A., ESA-8000 System Operating Manual. 1998, Matec Applied Sciences Inc: Massachussets. p. 1-5.

77. Silva, D.A., Efeitos dos Polímeros HEC e EVA na Microestrutura de Pastas de Cimento Portland, in Departamento de Engenharia dos Materiais. 2001, Universidade Federal de Santa Catarina: Florianópolis. p. 246.

78. Betioli, A.M., Influência dos Polímeros MHEC e EVA na Hidratação e Comportamento Reológico de Pastas de Cimento Portland. 2007: Florianópolis. p. 188.

79. Papo, A., Caufin, B., A Study of the Hydration Process of Cement Pastes by Means of Oscillatory Rheological Techniques. Cement and Concrete Research, 1991. 21: p. 1111-1117.

80. Schultz, M.A., Rheological studies of fresh cement pastes., in Engenharia Cerâmica. 1991, University of Illinois at Urbana-Champaign: Illinois. p. 192.

81. Schultz, M.A., Struble, L. J., Use of oscillatory shear to study flow behavior of fresh cement paste. Cement and Concrete Research, 1993. 23: p. 273-282.

82. Nachbaur, L., Mutin, J. C., Nonat, A., Choplin, L., Dynamic mode rheology of cement pastes. In: II International Rilem Workshop on Hydration and Setting. Anais...France: Dijon, 1997: p. 271-280.

83. Nachbaur, L., Mutin, J. C., Nonat, A., Choplin, L., Dynamic mode rheology of cement and tricalcium silicate pastes from mixing to seting. Cement and Concrete Research, 2001. 31: p. 183-192.

84. Schramm, G., Reologia e Reometria, Fundamentos Teóricos e Práticos. 2006, Rio de Janeiro. p.229.

85. Garcia, J.R., Oliveira, I. R., Pandolfelli, V.C, Processo de hidratação e os mecanismos de atuação dos aditivos aceleradores e retardadores de pega do cimento de aluminato de cálcio. Cerâmica, 2007. 53: p. 42-56. 